DOE/NASA/0600-79/1

NASA CR-159775

DO NOT DESTROY

R-1575

\title{
DESIGN, FABRICATION, \\ TEST, AND EVALUATION OF A PROTOTYPE 150-FOOT LONG COMPOSITE WIND TURBINE BLADE
}

Herbert W. Gewehr

Kaman Aerospace Corporation

bo

$\Lambda$

$\Lambda$

a

b

7

co

$\cup$

1

$\mathrm{Cl}$

$<$

Z

September 1979

Prepared for

NATIONAL AERONAUTICS AND SPACE ADMINISTRATION

Lewis Research Center

Under Contract NAS3-20600

for

24 MAR 1980

MCDU NNELL DOUGIAS

U.S. DEPARTMENT OF ENERGY RESEARCH \& ENEINEERING LIGRARY Energy Technology Distributed Solar Technology Division 
NOT ICE

This report was prepared to document work sponsored by the United States Government. Neither the United States nor its agent, the United States Department of Energy. nor any Federal employees, nor any of their contractors, subcontractors or their employees, makes any warranty. express or implied, or assumes any legal liability or responsibility for the accuracy, completeness, or usefulness of any information, apparatus, product or process disclosed, or represents that its use would not infringe privately owned rights. 
DESIGN, FABRICATION,

TEST, AND EVALUATION OF A

PROTOTYPE 150-FOOT LONG

COMPOSITE WIND TURBINE BLADE

Herbert W. Gewehr

Kaman Aerospace Corporation

Bloomfield, Connecticut 06002

September 1979

Prepared for

National Aeronautics and Space Administration

Lewis Research Center

Cleveland, Ohio 44135

Under Contract NAS3-20600

for

U. S. DEPARTMENT OF ENERGY

Energy Technology

Distributed Solar Technology Division

Washington, D. C. 20545

Under Interagency Agreement EX-76-1-01-1028 
TFT processes as applied to rotor blades and spars are the subjects of patents pending by Kaman Aerospace Corporation, Bloomfield, Connecticut, and Structural Composites Industries, Inc., Azusa, California. 
TABLE OF CONTENTS

LIST OF ILLUSTRATIONS

PAGE NO.

LIST OF TABLES

iv

1.0 SUMMARY

viii

2.0 INTRODUCTION

1

3.0 CONCLUSIONS AND RECOMMENDATIONS

4.0 DESIGN AND ANALYSIS 8

4.1 Design Approach 8

4.2 Design Description 8

4.3 Performance, Loads, and Dynamics 13

4.4 Materials 29

4.5 Structural Analysis $\quad 50$

5.0 TOOLING $\quad 72$

6.0 BLADE FABRICATION 81

7.0 QUALITY ASSURANCE 95

8.0 SHIPPING AND HANDLING 102

9.0 BLADE TESTS 106

$\begin{array}{lll}10.0 & \text { BLADE COST AND PRODUCTION COST PROJECTIONS } & 120\end{array}$

11.0 REFERENCES 123

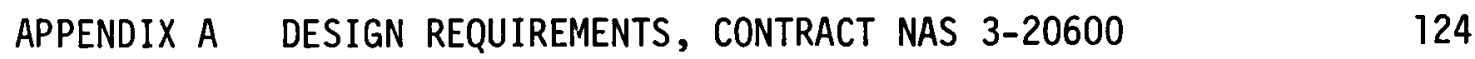




\section{LIST OF ILLUSTRATIONS}

FIGURE

NUMBER

PAGE NO.

1150 Foot Composite Wind Turbine Blade 2

2150 Foot Wind Turbine Blade Assembly Details . 3

3 Transverse Filament Tape (TFT) 4

4 Blade Weight Distribution 10

5 Blade Center of Gravity Distribution 11

6 Blade Bending Stiffness Distributions 12

7 Blade Root End Adapter Attachment Detail 14

8 Bolt Installation, Hub Adapter to Spar Connection 15

9 Blade Bending Moments, Case $1 \quad 18$

10 Blade Bending Moments, Case 2 19

11 Blade Bending Moments, Case 3220

12 Blade Bending Moments, Case 4 21

13 Blade Bending Moments, Case 6

14 Blade Bending Moments, Case 5

15 Campbell Diagram for 150 Foot Wind Turbine Blade 25

16 Mechanism for Stall Flutter 27

17 Location of Stall Flutter Boundary (Negative Damping Area) vs Blade Operating Range for Most Critical Condition

18 Classical Flutter Analysis 30

19 Aeroelastic Stability Analysis, Five Degrees-ofFreedom

20 TFT Laminate Static Characterization, $0^{\circ}$ Tensile Test, ASTM D 3039

21 TFT Laminate Static Characterization, $90^{\circ}$ Tensile Test, ASTM D 3039

22 TFT Laminate Static Characterization, $0^{\circ}$ Compression Test, ASTM D 695

23 TFT Laminate Static Characterization, $90^{\circ}$ Compression Test, ASTM D 695

24 TFT Laminate Static Characterization, Poisson's Ratio Test, ASTM E 132

25 TFT Laminate Static Characterization, Short Beam Shear Test, ASTM D 2344 


\section{LIST OF ILLUSTRATIONS (continued)}

FIGURE

NUMBER

PAGE NO.

26 TFT Laminate Static Characterization, In-plane (Rail) Shear Test, Northrop Specification

IT-58, Rev. 8

27 TFT Laminate Fatigue Characterization, Dog-bone Specimens for Krouse Tests

28 TFT Laminate Fatigue Characterization, Molded, Straight-sided Specimens for Krouse Tests

29 TFT Laminate Fatigue Characterization

30 Quarter-scale Root End Fatigue Test Specimen

31 Sub-element Tests of Afterbody Skins and Skin-to-core Bonds

32 Sub-element Tests of Skin-to-skin Bond Lines and T-clip-to-spar Bond Lines

Sub-element Test of Afterbody Panel to Spar Attachment

34 Sub-element Test of Shear Strength of Syntactic Foam

35 Blade Bending Stress Distribution for Case 1 Rated Wind Condition

Blade Bending Stress Distribution for Case 2 Gust Condition

37 Blade Bending Stress Distribution for Case 3 Feathering Condition

38 Blade Bending Stress Distribution for Case 4 Gust (to Zero) Condition

39 Blade Bending Stress Distribution for Case 5b Static Condition

40 Blade Bending Stress Distribution for Case 6 Yaw Condition

41 NASTRAN Finite Element Model for Deflection and Stiffness Analyses

42 Z-Displacements for 150 Foot Wind Turbine Blade

43 NASTRAN Buckling Model for the Spar of the 150 Foot Wind Turbine Blade

44 Buckling Mode Shapes for the Spar of the 150 Foot Wind Turbine Blade

45 Finite Element Model of Spar Root End Attachment 


\section{LIST OF ILLUSTRATIONS (continued)}

FIGURE

NUMBER

PAGE NO.

46 Bolt Hole Deflections Obtained from 2-D Root End Attachment Finite Element Analysis

47 Cyclic Radial Bearing and Tangential Stresses for Case 1 - Normal Fatigue Condition

48 Net Area Cyclic Stress Distribution for Case 1 Normal Fatigue Condition

49 Finite Element Model of Spar-to-Adapter Bolt Joints

50 Taper Requirements for Attachment Bushings Based on Bolt Deflections for the Case 2 Loading Condition

51 Internal Loads Analysis of Afterbody Panel at Blade Root for Case 5

52 Original Afterbody-to-Spar Attachment 71

53 Final Afterbody-to-Spar Attachment 71

54 Mandrel Structural Schematic 73

55 Spar Mandrel Stringer Framework Installation 74

56 Spar Mandrel Nearing Completion 75

57 Spar Mandrel Deflection, Shear and Bending Stress Distributions

58 General Arrangement - Large Spar Winding Machine 77

59 Afterbody Panel Bond Fixture 79

60 Four Stage Spar Winding Schedule 82

61 Freeing the Half-inch Spar Shell From the Mandrel 83

62 Repair of the Spar Shell Aft Web 84

63 Winding the Spar for the 150 Foot Wind Turbine Blade 85

64 Spar Winding 86

65 Afterbody Panel Layup for the 150 Foot Wind Turbine Blade 88

66 Afterbody Panel After Autoclave Cure 89

67 Machining Holes in Composite Spar for Hub Adapter Bolts 90

68 Dry-fitting Afterbody Panels to Spar 92

69 Blade Assembly Bond Fixture 93

Pneumatic Hoses Applying Pressure to Panel-to-Spar
Bond Lines 


\section{LIST OF ILLUSTRATIONS (continued)}

FIGURE

NUMBER

PAGE NO.

71 Typical Non-destructive Inspection Procedures Along Blade

72 Spar Transport From Fabrication Site to Railroad

73 Transport of Completed 150 Foot Wind Turbine Blade

74 Spar for 150 Foot Blade on Rail Cars for Crosscountry Shipment

75 . Test Set Up for Natural Frequency Tests, Flatwise and Edgewise Stiffness Tests, and Edgewise Bending Test to Design Limit Load

76 Flatwise Bending Deflections at Blade Mid-span and Tip 108

77 Edgewise Deflection at the Blade Tip

78 Blade Edgewise Bending Moment vs Radial Blade Station

79 Test Set Up for Flatwise Bending Static Test

80 Flatwise Deflection at 100\% Design Limit Bending Moment

81 Blade Flatwise Bending Moment vs Radial Blade Station

82150 Foot Blade After Failing Load Test

83 Crippling Failure of Blade Spar

84 Blade Deflection at Approximately 15,000 Pounds Tip Load, Second Buckling Test

85 Bending Moments for Simple Cantilever Buckling Test of 150. Foot Blade Section 


\section{LIST OF TABLES}

TABLE

NUMBER

PAGE NO.

1 BLADE WEIGHT AND CG

2 OPERATING CHARACTERISTICS FOR ROTATING CONDITIONS 17

3 OPERATING CHARACTERISTICS FOR NON-ROTATING CONDITIONS 24

4 MATERIALS SELECTION 32

5 SUMMARY OF SPAR STRESSES AT THE MAXIMUM CHORDAL THICKNESS LOCATION

6 SPAR QUALITY ASSURANCE 96

7 QUALITY ASSURANCE OF BLADE ASSEMBLY AND SUBASSEMBLIES 99

8 CORRECTIVE ACTION FOR DEFECTS 101

9 NON-ROTATING BLADE NATURAL FREQUENCIES 106

10 BENDING STIFFNESS DISTRIBUTIONS 110

11 ACTUAL COSTS OF THE PROTOTYPE $150 \mathrm{FT}$ BLADE 120

12 ESTIMATED COST OF 2nd AND 3rd 150 FT BLADES 121

13 ESTIMATED COSTS OF 100th AND 1000th 150 FT BLADES 122 


\subsection{SUMMARY}

This report describes the $150 \mathrm{ft}$ wind turbine blade program, carried out by Kaman Aerospace Corporation under contract to NASA Lewis Research Center, involving design, fabrication, test, and evaluation of an all-composite blade in this unprecedented size range. The primary objective of the program was to develop the engineering and fabrication technology for large wind turbine blades having the potential for low cost fabrication in production quantities. Structural Composites Industries, Inc., Azusa, California, was a subcontractor to Kaman for fabrication of the blade spar.

The blade consists of two basic elements; the spar and the afterbody, which are built separately and assembled by bonding. The blade is attached to the hub by a steel adapter bolted to the spar. A trailing edge spline provides increased in-plane stiffness for natural frequency tuning. The completed blade is shown in Figure 1, and its assembly details are shown in Figure 2.

The spar is a filament-wound monocoque structure tapering in planform, thickness and wall thickness. This configuration is well-suited to the use of transverse filament tape (TFT) (Figure 3 ), which permits rapid deposition of large quantities of spanwise-oriented glass fiber using simple production machinery. During the fabrication process, TFT was wound circumferentially around a steel mandrel, which had the appropriate planform and thickness taper. Layers of TFT were terminated at various spanwise stations to achieve desired wall thickness taper. Local reinforcement was added at the root of the spar to accommodate the hub adapter bolt connection.

The major part of the engineering effort on this project was devoted to structural design and material selection. Aerodynamic, tuning and stability analyses were 1 imited to those required to insure that the blade was a representative design for a $300 \mathrm{ft}$ diameter wind turbine generator system. Loads analyses were conducted to identify representative critical cases for structural analysis, resulting in conservative selections of an extreme gust condition for fatigue loads, and a critical hurricane wind condition for static loads.

Structural design and material selection were pursued concurrently with the manufacturing plan to insure producibility and low cost of a configuration which meets engineering design requirements. Numerous tradeoffs were made between design and manufacturing groups to achieve the low cost objective.

Laminate characterizations were performed on the TFT material via small specimen tests to define static and fatigue properties. Results indicate that TFT is a structural material suitable for wind turbine blades, and has only slightly lower mechanical properties than continuous-filament unidirectional material in the same structural orientation. The ability to deposit TFT with optimum spanwise orientation of fibers, and with any degree of planform and wall thickness taper, is a clear advantage over other forms of filament winding. 


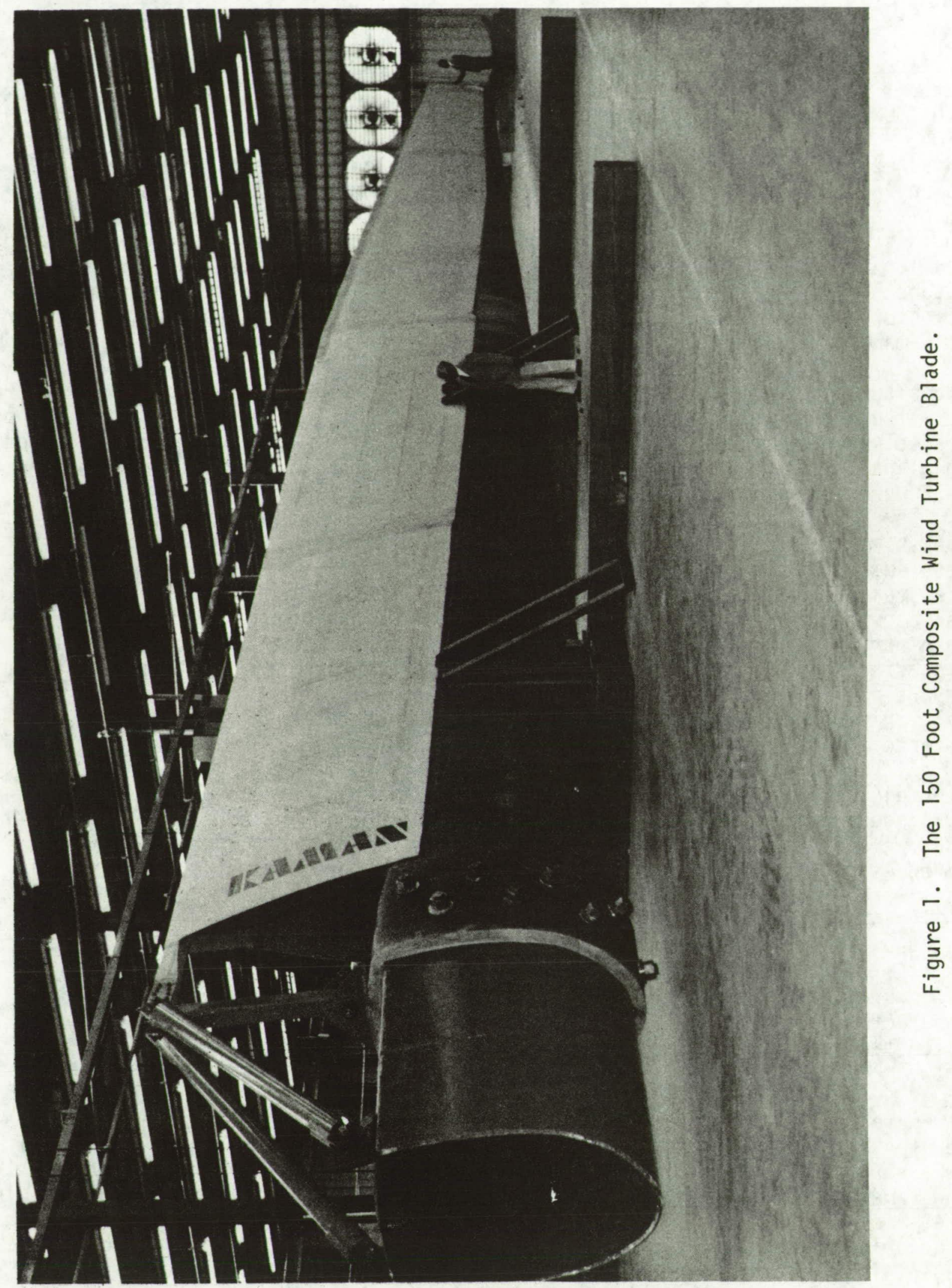



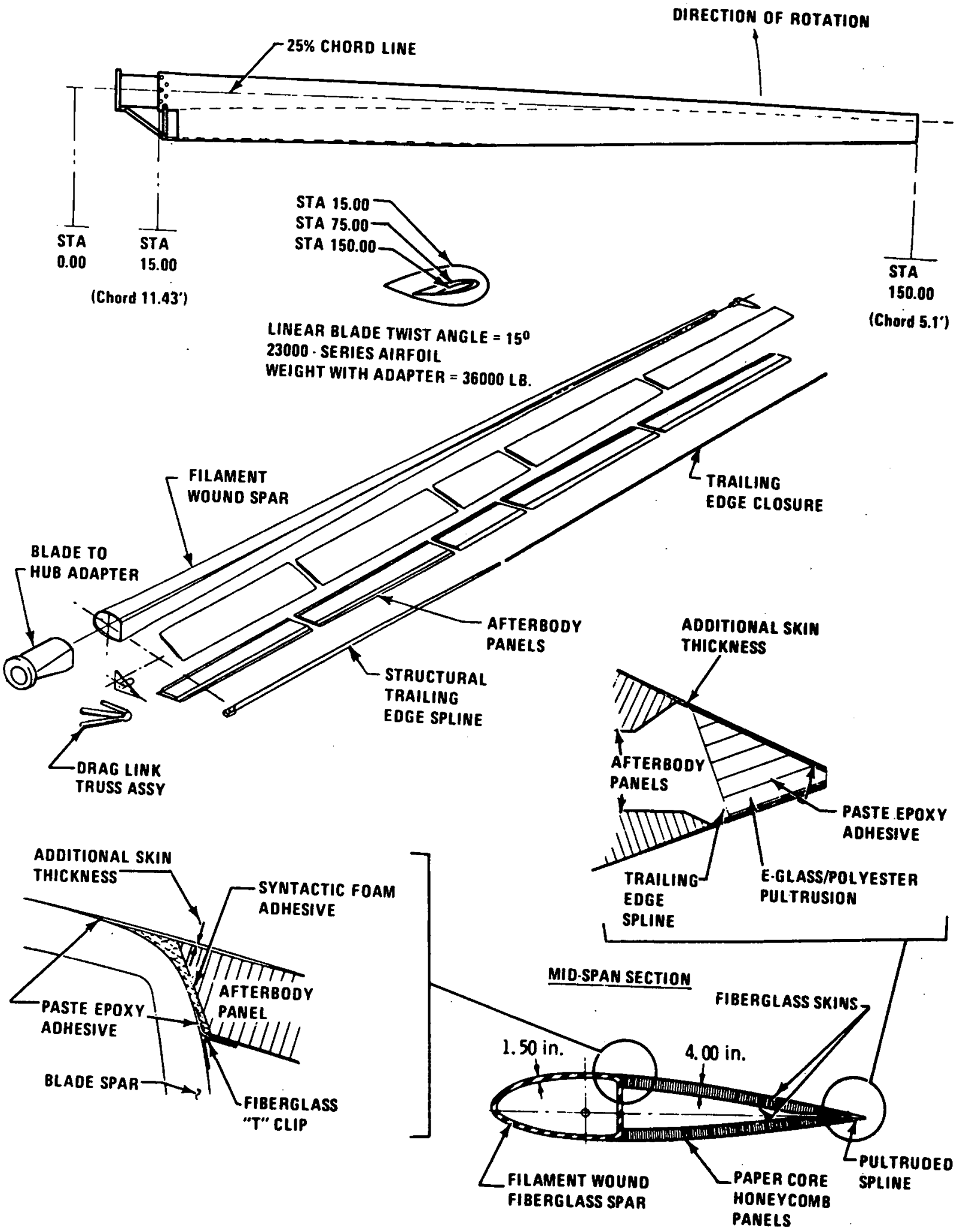

Figure 2. 150 Foot Wind Turbine Blade Assembly Details. 


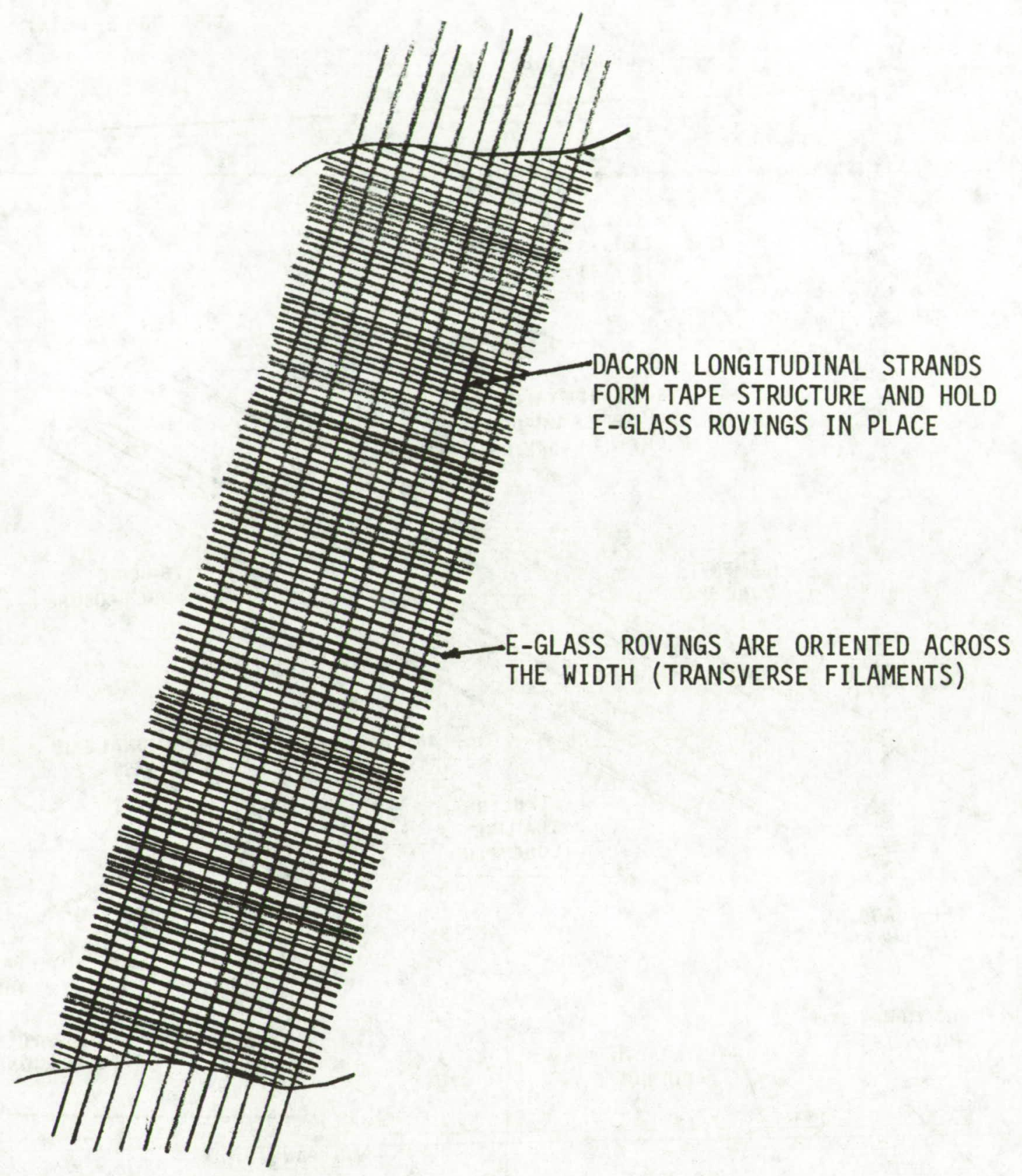

Figure 3. Transverse Filament Tape (TFT). 
scale blade tests were performed which included natural frequency tests, deflection and stiffness measurements, proof load tests, and a flatwise bending test to failure. Failure occurred by local crippling of the spar wall at 109 percent of the design load (a hurricane wind condition, $164 \mathrm{mph}$ at rotor hub height). The origin of the crippling failure was a flaw in the spar wall associated with the prototype fabrication process and soft tooling peculiar to this one-of-akind wind turbine blade. A subsequent test of the surviving outboard end of the blade (100 ft long) successfully sustained a flatwise bending moment almost 3 times the design load. This later test demonstrated that large knockdown factors from theoretical crippling strength predictions are not necessary for pure monocoque glass/epoxy structures of this type providing no serious material defects (such as the visible flaws present at the location of the crippling failure) are present.

During the course of the program, the finished spar was successfully transported by railroad from the SCI facility in California to the Kaman plant in Connecticut, demonstrating transportability of composite blades in the $150 \mathrm{ft}$ size range. This consideration had been thought to be one of the key limiting factors on blade size; thus the demonstration was significant to feasibility considerations of large, single piece rotor blades.

The actual cost of fabricating the $150 \mathrm{ft}$ wind turbine blade was $\$ 10.26$ per pound. With slightly improved tooling and the benefit of experience in fabrication, the average cost of the second and third blades of the same design are projected to be $\$ 8.10$ per pound. Further tooling improvements and experience project the cost of the 100th blade at $\$ 4.95$ per pound, and the lo00th at $\$ 4.10$.

The program was carried out over a period of 20 months. The Project Manager for NASA Lewis Research Center was Thomas P. Cahi11; the Program Manager for Kaman was Herbert W. Gewehr.

This program has successfully demonstrated:

- Design, fabrication and testing of a $150 \mathrm{ft}$ composite wind turbine blade

- A potential low cost fabrication process for wind turbine blades

- TFT as a structural material suitable for wind turbine blades

- Transportation feasibility of blades in this size range. 


\subsection{INTRODUCTION}

Various studies have shown that the cost of energy decreases with increasing rotor size in Wind Turbine systems, and that the cost of the rotor is a major contributor to initial procurement and annual operating costs (References 1 and 2). In an effort to reduce rotor cost, NASA Lewis Research Center, with Department of Energy funding, initiated a program to develop a large, low cost wind turbine blade representative of a design for a $300 \mathrm{ft}$-diameter wind turbine. This report describes the design, analysis, and test results of that program. Structural Composites Industries, Inc. (SCI), Azusa, California, fabricated the spar for the $150 \mathrm{ft}$ blade under subcontract to Kaman.

Specific goals of the program were as follows:

- Determine the feasibility of designing and fabricating large composite blades; identify problems and risk areas

- Determine the accuracy of analytical prediction methods

- Provide a base for production cost determination

- Derive quality control methods and assess their adequacy for high volume production

- Assess feasibility of transporting large wind turbine blades. 


\subsection{CONCLUSIONS AND RECOMMENDATIONS}

This program successfully demonstrated that a 150-foot long composite wind turbine blade can be designed, fabricated, and tested. No technical limitations to fabrication of blades longer than 150 feet were uncovered.

Transverse filament tape (TFT) has been shown to be capable of meeting structural design requirements for wind turbine blades. Design allowables for TFT were developed by material characterization tests during this program.

Low cost fabrication of large wind turbine blades was successfully demonstrated by the prototype 150 -foot blade, which cost just over $\$ 10$ per pound.

Transportation of large wind turbine blades was demonstrated by rail shipment of the 141-foot spar from Mira Loma, California, to Bloomfield, Connecticut, and by various local movements by truck.

Fatigue design allowables for wound composites should be based upon tests of wound tubular specimens instead of flat laminates to minimize test terminations which obscure the true fatigue performance of wound structures.

Manufacturing variability must be considered when selecting design allowables for low cost, wound composite structures. Appropriate knock-down factors should be used, particularly for buckling allowables.

Future programs involving composite wind turbine blades should include stätic and fatigue testing of full-scale or large-scale specimens for structural substantiation. 


\subsection{DESIGN AND ANALYSIS}

This section describes the blade design, loads, stability and tuning analyses, materials selection and testing, and structural analysis of the $150 \mathrm{ft}$ wind turbine blade.

\subsection{Design Approach}

Since the primary objective was successful fabrication of a large, low cost blade, the task was approached from the standpoint of selecting a commercially available low cost process and adapting the design to it. Among the several processes considered, including both metal and composite constructions, Kaman selected a composite design which employed a new application of a commercially available glass fiber material, recommended by SCI, which Kaman termed Transverse Filament Tape (TFT). TFT is a woven roving $\mathrm{E}-\mathrm{glass}$ tape having a11 of its structural fibers oriented across the tape width. Use of TFT in the manufacturing process for the spar involved winding TFT onto a mandrel, with overlap, and simultaneously overwinding a layer of continuous filament rovings for compaction. Ninety percent of the material deposited was TFT, oriented along the spanwise axis of the spar. The overwound rovings (hoops) comprised the other 10 percent of material. Patent applications have been filed for certain aspects of this TFT process.

Special emphasis was placed on matching the design to the structural properties obtainable from the process, taking into account the anticipated commercial quality of the TFT laminate. Refinement of the process to typical aerospace standards was deliberately avoided. Determination of the material properties and structural capabilities of TFT were primary considerations in the $150 \mathrm{ft}$ blade design and analysis effort.

The afterbody which completes the airfoil shape was constructed of upper and lower panels made from resin impregnated paper honeycomb core faced with fiberglass skins. The paper core was the lowest-cost material available that could meet panel stiffness requirements, and the fiberglass skins were made from commercially available glass cloth, also low cost material.

A trailing edge spline member was made from E-glass/polyester pultrusions which were bonded together and shaped to form the 60 foot trailing edge bar.

Although low cost pultrusions were used, considerable handwork was required for the shaping process; future production would utilize a molded member.

The steel root end adapter was a low cost weldment which, for this prototype program, was simply welded to the reaction beam of the test fixture. A production adapter would have a flange or other interface provisions for attachment to the hub.

\subsection{Design Description}

Figure 1 illustrates the blade configuration in which primary components are the TFT wound E-glass/epoxy spar, an E-glass/polyester trailing edge spline made from pultrusions, sandwich panels constructed of resin impregnated kraft 
paper honeycomb faced with glass cloth/epoxy skins, and a steel hub adapter. These components are joined by epoxy bonding, except for the hub adapter, which is mechanically fastened to the spar and spline. The total blade measured weight was 36,000 pounds; 23,000 pounds of composite structure and 13,000 pounds of steel adapter and hardware. A weight breakdown is given in Table 1 , which compares final weights with those predicted at the proposal stage. Spanwise weight and $\mathrm{cg}$ distributions are given in Figures 4 and 5 . These were determined analytically.

\begin{tabular}{|l|r|r|}
\hline \multicolumn{3}{|c|}{ TABLE 1. BLADE WEIGHT AND CG } \\
\hline ITEM & PREDICTED & MEASURED \\
\hline Spar & 20,764 & 19,079 \\
Afterbody Panels and Splices & 2,430 & 2,652 \\
Adapter & 10,306 & 10,306 \\
Trailing Edge Spline and Closure & 615 & 627 \\
Truss & 1,496 & 1,488 \\
Root End Hardware & 1,515 & 1,394 \\
Adhesive and Syntactic Foam & 353 & 620 \\
BLADE TOTAL WEIGHT, LB & 37,479 & 36,166 \\
Blade CG Locations & & 8.29 \\
\hline Chordwise (in aft of C/4) & 7.81 & 43.04 \\
\hline Spanwise (ft from rotor CL) & 42.87 & \\
\hline
\end{tabular}

The spar is a D-shaped monocoque shel1, tapered in planform, depth, and wall thickness to achieve desired bending stiffness, mass distribution, and aerodynamic shape. It has a 15 degree linear twist and is about six feet wide by four feet deep at the root, and two feet wide by seven inches deep at the tip. The wide spar at the root provides stiffness for edgewise tuning of natural frequency without requiring an excessively large trailing edge spline. The spar tip is narrowed to reduce outboard blade weight for flatwise tuning. Blade stiffness distributions are given in Figure 6.

Spar wall thickness is 1.5 inches from root to midspan, and tapers down to one inch at the tip. The nominal wall thickness is measured at the corners of the aft web, where laminate compaction is greatest. Thicker areas are evident where compaction is less.

Local reinforcement is provided at the inboard end of the spar for about three feet, by interleaving between courses of TFT a woven roving having a \pm 45 degree bias orientation. This produces a four inch wall thickness of more nearly isotropic properties where the steel hub adapter is bolted to the composite spar. 


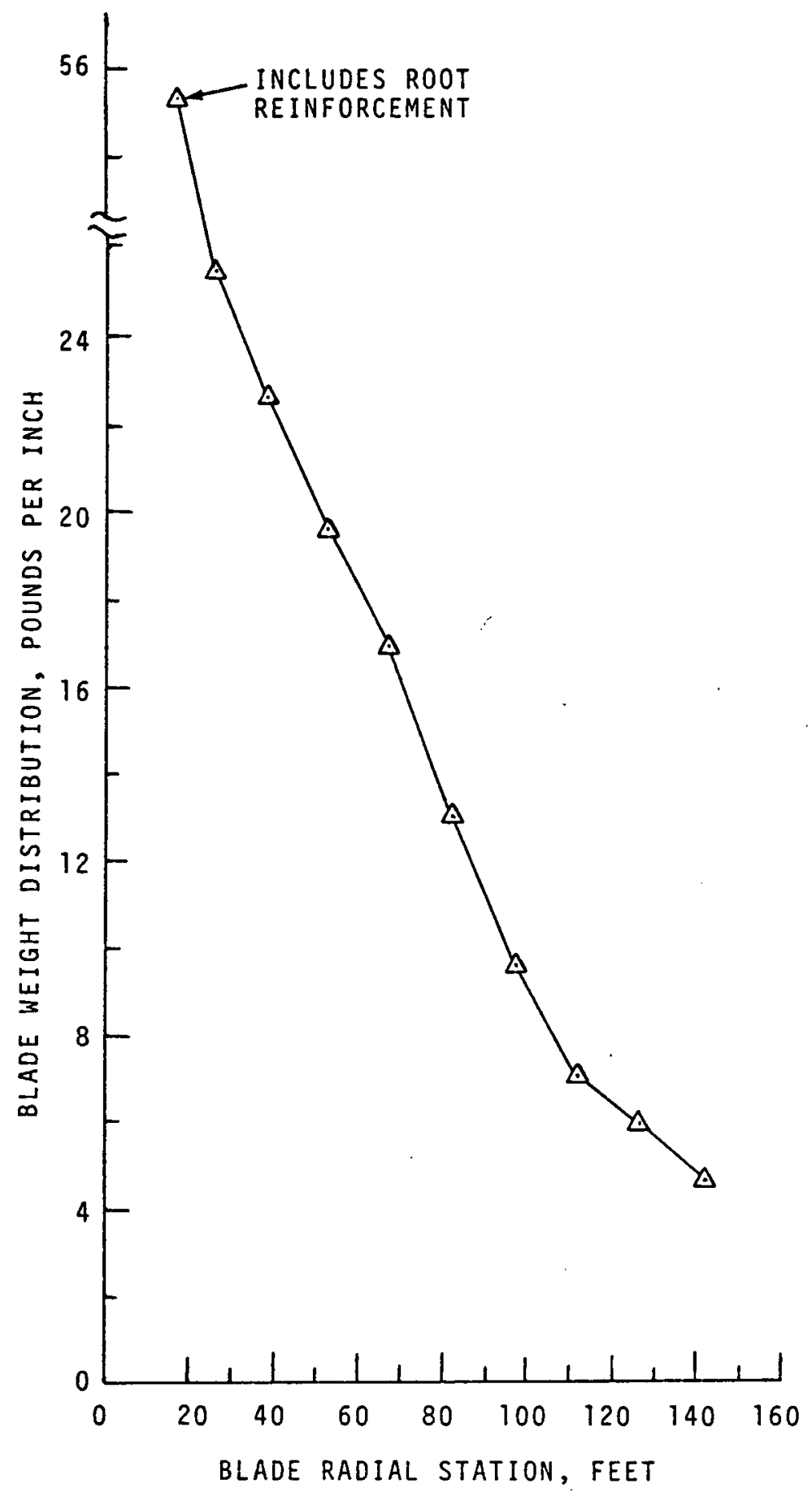

Figure 4. Blade Weight Distribution. 
FWD



Figure 5. Blade Center of Gravity Distribution. 


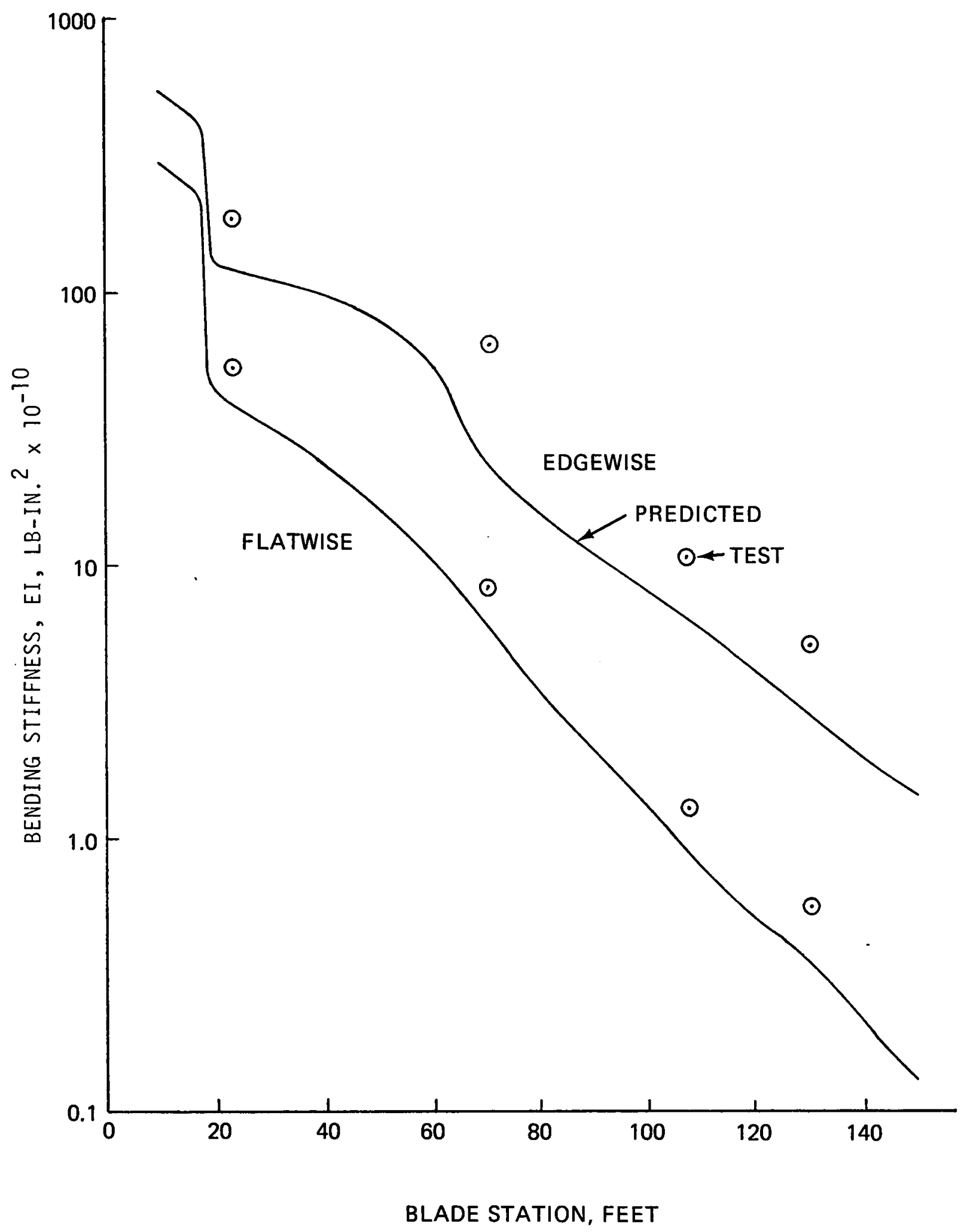

Figure 6. Blade Bending Stiffness Distributions. 
Ten afterbody panels, five upper and five lower, are honeycomb sandwich construction of kraft paper core and glass skins. The panels range in length from 15 to 30 feet, and in weight from 144 to 433 pounds. Panel thickness varies from six inches at the root to two inches at the tip. Outer skins are two plies of 1583 glass cloth and inner skins are one ply. Local reinforcement is added at panel edges for attachment to adjacent structure. The 3/8inch honeycomb cell core is phenolic resin impregnated, and weighs 2.3 pounds per cubic foot. Sizing of panel thickness was dictated by the requirement to carry afterbody airloads and to stabilize the trailing edge spline under edgewise bending loads.

The trailing edge spline was fabricated by laminating commercially available E-glass/polyester pultruded planks with epoxy adhesive, and shaping to the desired contour. Steel cheek plates were bonded and bolted to the inboard end of the spline to transmit axial loads to the root end truss. The spline diminishes in cross sectional area with span, and extends from the root to mid-span. A trailing edge closure of glass cloth extends from mid-span to the blade tip.

The composite subassemblies were joined by bonding with room-temperature curing paste epoxy adhesives. 35 psi bonding pressure was applied by pneumatic hoses retained in a steel framework. Prefabricated T-clips were fitted and bonded between the spar aft wall and the afterbody panel inner skins to improve the structural effectiveness of the panel inner skins.

Syntactic foam adhesive was injected into the cavity between the spar and the afterbody panel core to provide a shear connection between the afterbody panel and the spar.

The hub adapter was attached to the spar by 18 five-inch diameter, tapered bushings inserted into carefully machined holes in the composite. Each bushing was held in place with a three-inch diameter stud torqued to achieve 400,000 pounds preload which prevents the bushing from unseating on its loaded side. All machining cuts for each hole were made from a single setup at that hole, to achieve the alignment and squareness tolerances required for uniform load distribution in the composite. The bolt installation is illustrated in Figures 7 and 8.

\subsection{Performance, Loads, and Dynamics}

\section{Performance}

Since the primary emphasis of the program was on fabrication technology and test correlation of analytical predictions, detailed system analysis and economic optimization of rotor parameters were not warranted.

Primary aerodynamic performance parameters were preselected by NASA, including $300 \mathrm{ft}$ rotor diameter and 3 percent solidity which are representative values for efficient energy capture at an average annual wind speed of $14 \mathrm{mph}$. The rotor will provide more than $1800 \mathrm{~kW}$ rotor power output at the specified $18 \mathrm{mph}$ rated wind speed, with a readily achievable aerodynamic efficiency of 38 percent. 


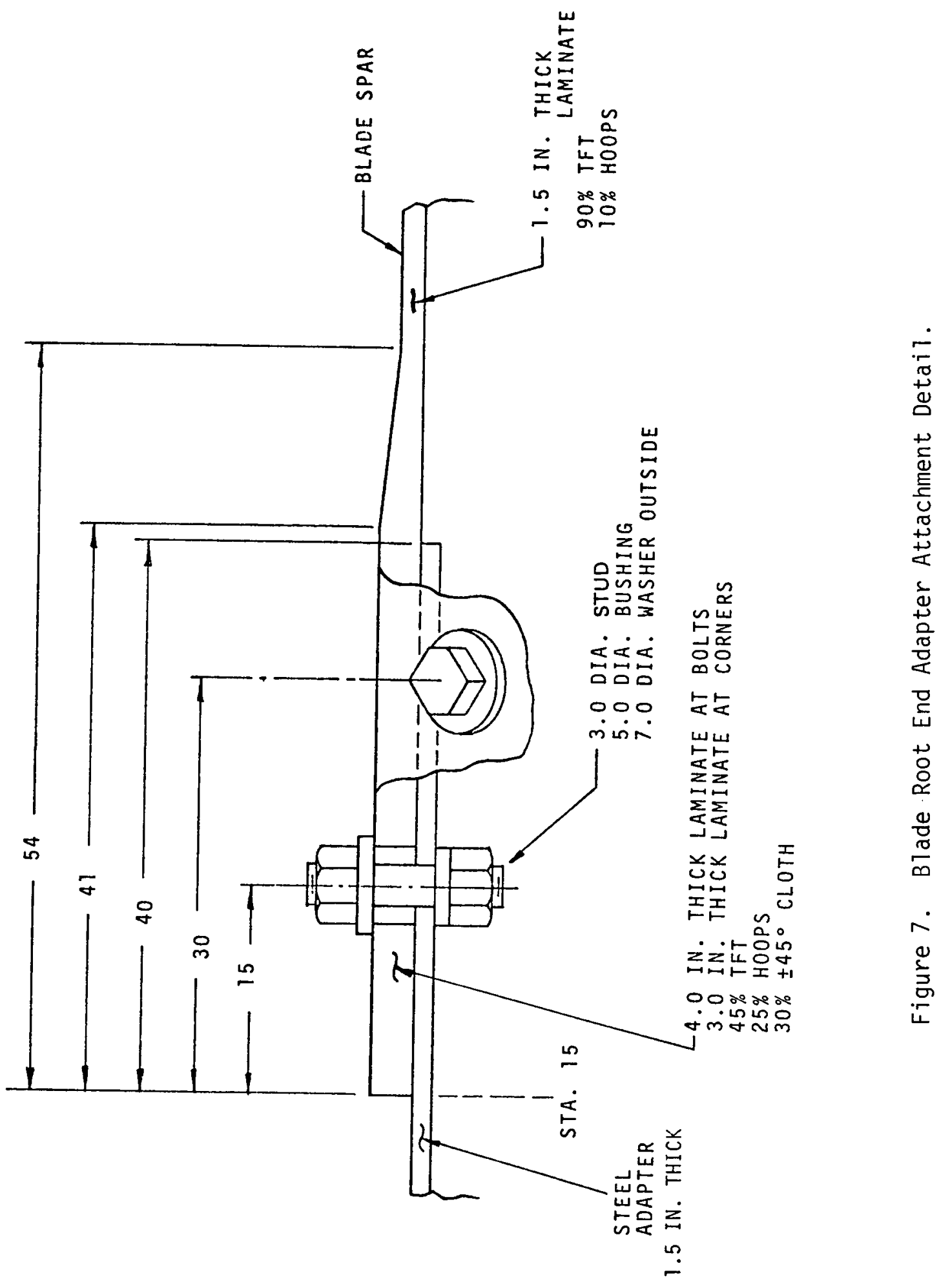




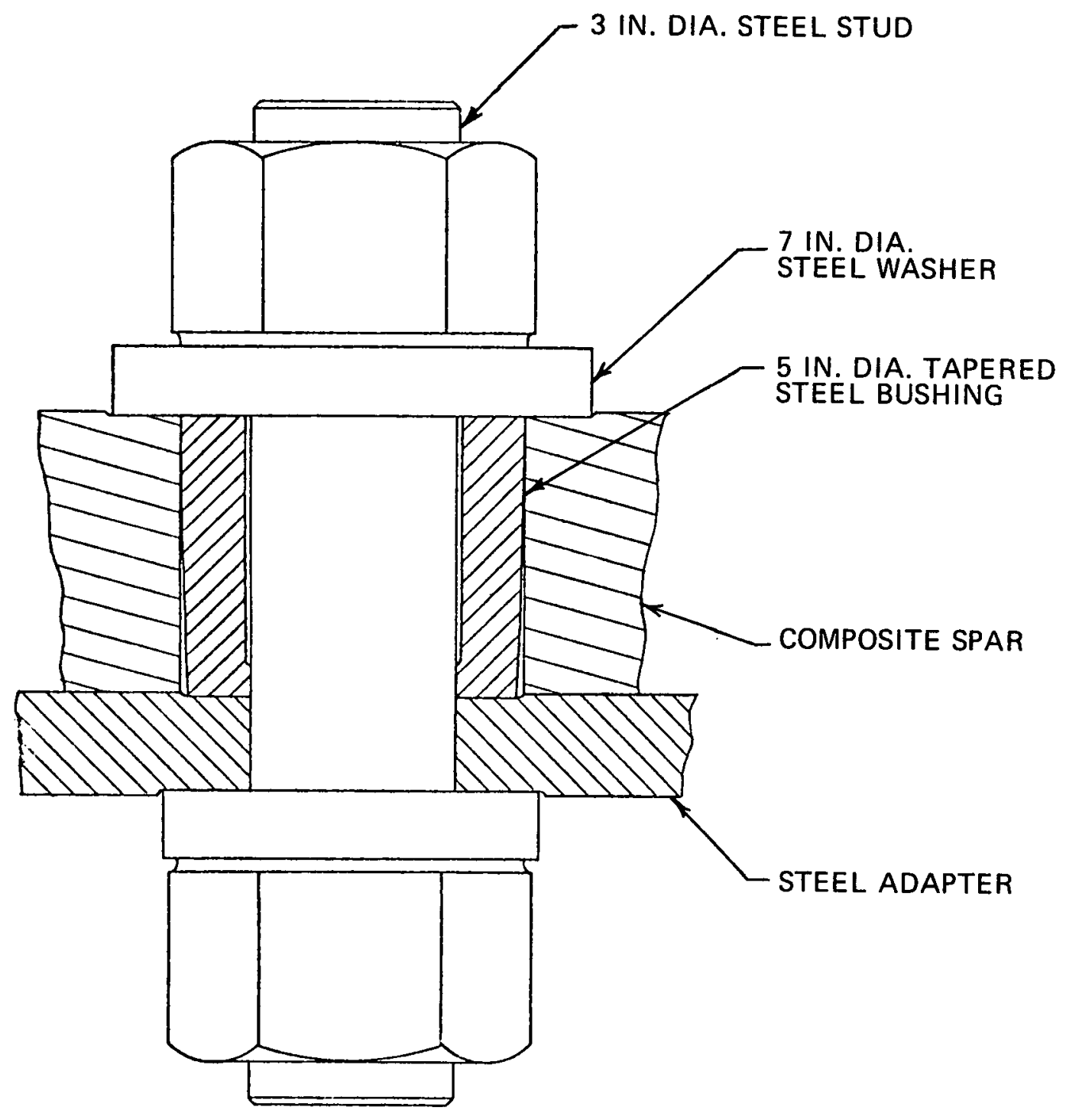

Figure 8. Bolt Installation, Hub Adapter to Spar Connection. 
Results of previous design studies were used to provide the basis of selection by Kaman of blade twist, thickness taper, planform taper, root cut-out and precone angle. The resulting parameters are listed below:

$\begin{array}{ll}\text { Rotor Radius } & 150 \mathrm{ft} . \\ \text { Root Station } & 15 \mathrm{ft} . \\ \text { Root Chord } & 11 \mathrm{ft} .5 \mathrm{in} . \\ \text { Mid-span Chord } & 10 \mathrm{ft} . \\ \text { Tip Chord } & 5 \mathrm{ft} .1 \mathrm{in} . \\ \text { Root Airfoil } & 23036 \\ \text { Mid-span Airfoi1 } & 23018 \\ \text { Tip Airfoil } & 23015 \\ \text { Blade Twist Angle } & +15^{\circ} 1 \text { inear root to tip } \\ \text { Blade Pre-cone Angle } & +10^{\circ} \\ \text { Rotor Speed } & 16 \mathrm{rpm}\end{array}$

Design Loads

Design of the $150 \mathrm{ft}$ blade was based upon a downwind, $16 \mathrm{rpm}$ rotor, and operating cases specified by NASA which provide representative critical conditions for the structure. The six cases are briefly identified as:

1. Rated power $(1800 \mathrm{~kW})$, rated wind $(18 \mathrm{mph})$

2. Increasing gust, $18 \mathrm{mph}$ to $60 \mathrm{mph}$, plus 25 percent overspeed

3. Emergency feather in 11 seconds, from $18 \mathrm{mph}$ wind speed

4. Decreasing gust, $18 \mathrm{mph}$ to zero $\mathrm{mph}$

5. Hurricane wind $(120 \mathrm{mph})$, non-rotating, blades feathered

6. Maximum yaw rate $(2 \mathrm{deg} / \mathrm{sec})$ at $50 \mathrm{mph}$ wind velocity.

Detailed descriptions are given in Appendix A.

The Kaman computer code used for loads determination included the effects of tower shadow, wind shear, and gravity. Tower shadow was represented by a trapezoidal 30 percent wind velocity reduction over a $30^{\circ}$ azimuth arc centered behind the tower. Wind shear specified by NASA is given in Appendix A. 
Operating characteristics for rotating conditions are given in Table 2, and corresponding bending moment distributions are given in Figures $9-13$.

\begin{tabular}{|c|c|c|c|c|c|c|}
\hline $\begin{array}{l}\text { CASE } \\
\text { NO. }\end{array}$ & VELOCITY & RPM & $\begin{array}{l}\text { PITCH } \\
\text { ANGLE }\end{array}$ & THRUST/BLADE & $\mathrm{kW} / \mathrm{BLADE}$ & $\begin{array}{c}\text { YAW } \\
\text { ANGLE }\end{array}$ \\
\hline $1 *$ & $18 \mathrm{mph}$ & 16 & $-5^{\circ}$ & $21,560 \mathrm{lbs}$ & 910 & 0 \\
\hline 2 & $60 \mathrm{mph}$ & 20 & $-5^{\circ}$ & 71,170 1bs & 2,320 & 0 \\
\hline 3 & $18 \mathrm{mph}$ & $(--$ & ARIABLE DL & E TO BLADE FEAT & ERING---) & 0 \\
\hline 4 & $0 \mathrm{mph}$ & 16 & $-5^{\circ}$ & $-11,5801 \mathrm{bs}$ & -74 & 0 \\
\hline 6 & $50 \mathrm{mph}$ & 16 & $-26.5^{\circ}$ & 10,770 1bs & 900 & $20^{\circ}$ \\
\hline
\end{tabular}

Analysis of the five rotating cases revealed that Case 2 produced the highest fatigue loads for the spar. Although Case 2 was projected to occur only infrequently, Kaman conservatively considered Case 2 to occur continuously for design purposes, primarily because little is known about the frequency of occurrence of fatigue-producing loads in wind turbine systems operating for a number of years. Case 2, therefore, became the design driver for 30 year life requirements. Fatigue stresses in the spar associated with Case 2 loads were maintained below the estimated endurance limit of the composite material.

Case 2 was critical for both fatigue and static loads in the trailing edge outboard of Blade Station 18. Inboard of Station 18, Case 2 is critical for fatigue, and Case 6 is critical for static loads in the trailing edge spline and its attachment to the root end truss.

Case 5 produced the highest static loads in the spar, and was selected for static strength and buckling criteria. Case 5 loads were based on the conclusion that the maximum aerodynamic force normal to the blade chord would be generated at the blade tip while the blades were feathered and parked horizontally. Although feathered, maximum force can be generated on the blade with only a +12 degree vertical angle change in wind direction from the zero lift condition; therefore, the blade was designed for the maximum force case. The critical orientation for Case 5 loads was a downward-acting force combined with gravity, which put the lower (flat) surface of the blade into compression, as indicated in Table 3. The bending moment distribution for the critical case 5 load is given in Figure 14.

Afterbody panels and their attachments to the spar and trailing edge were designed to Case 5 airloads, plus loads imposed by spar deflections. 


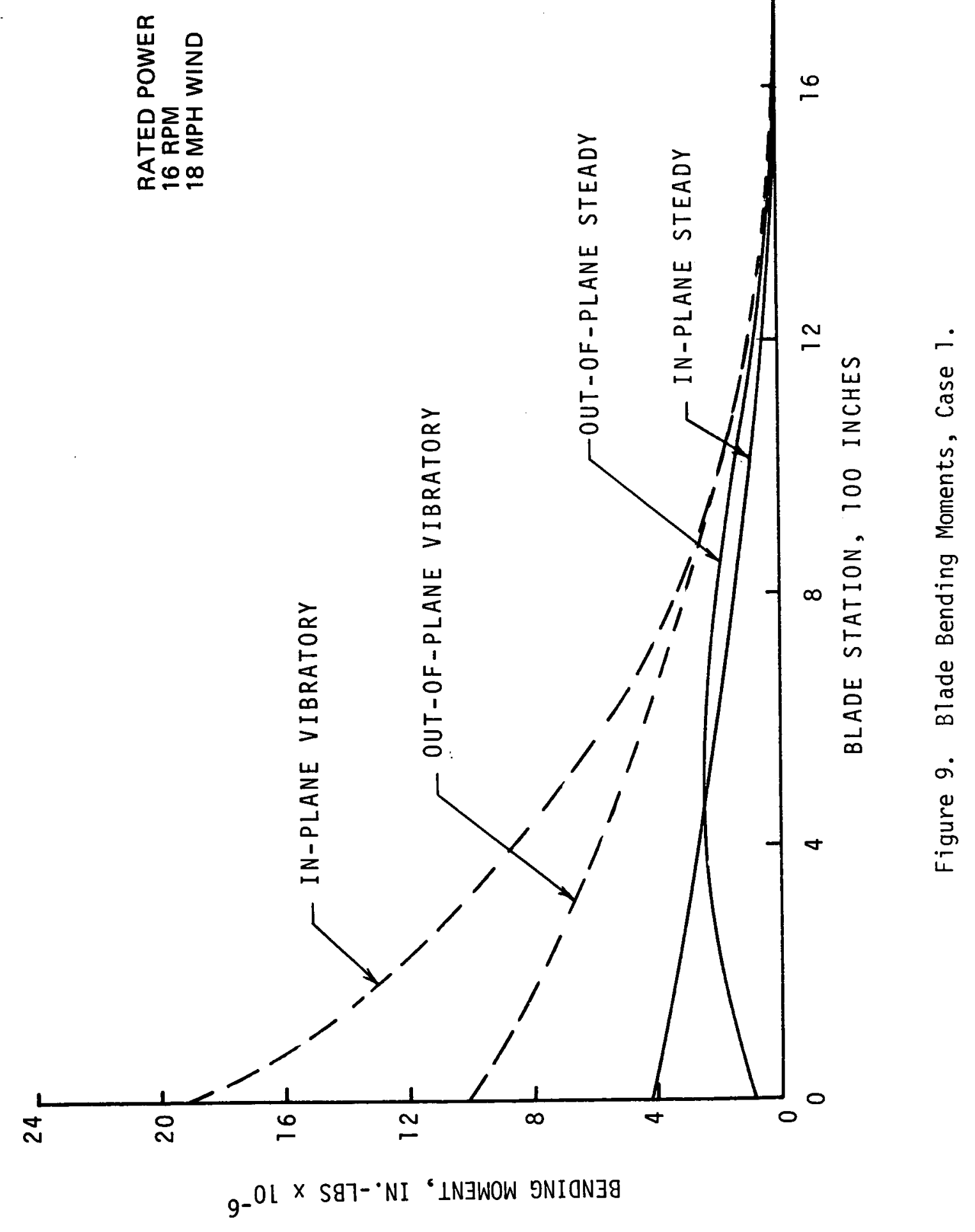




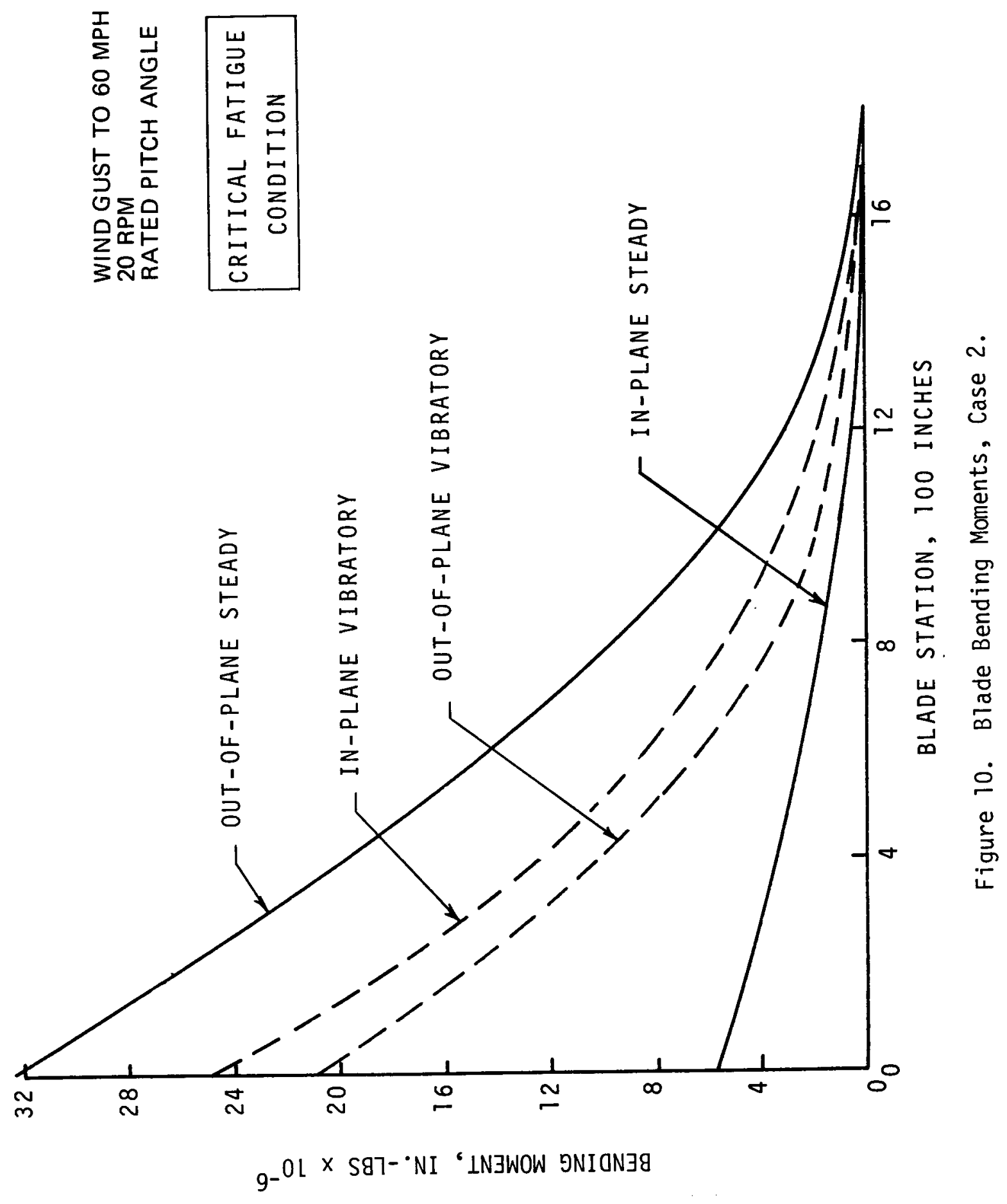




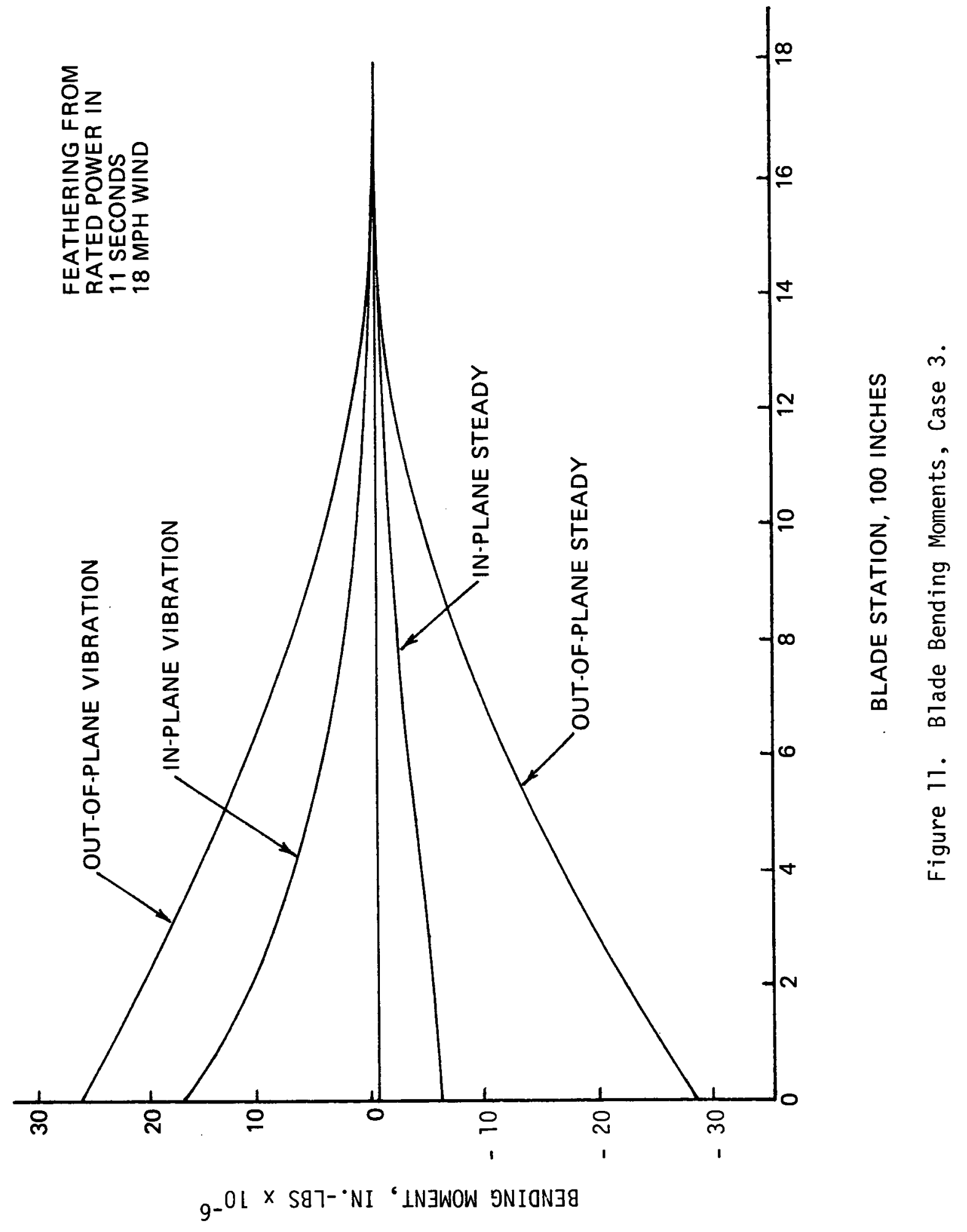




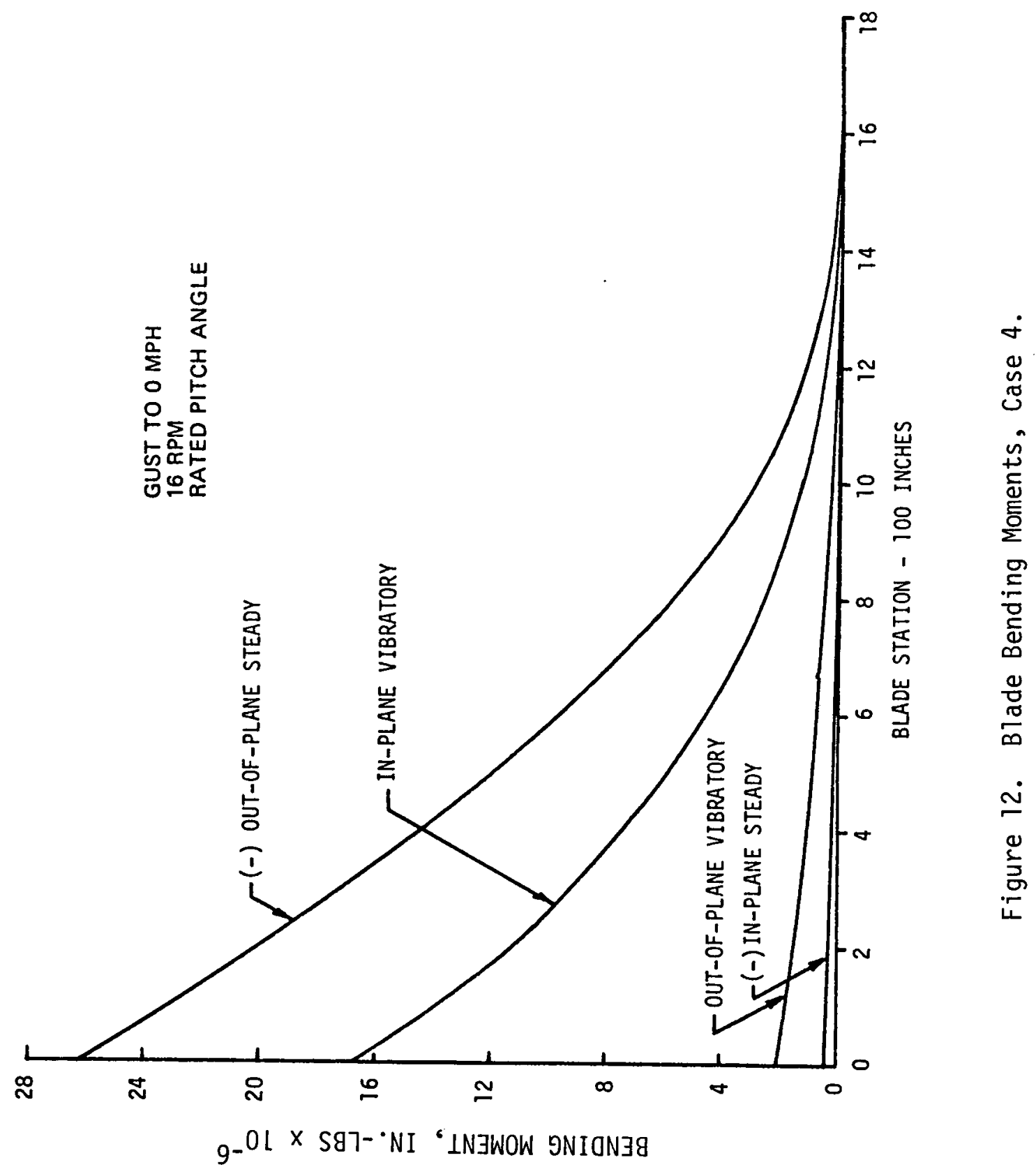




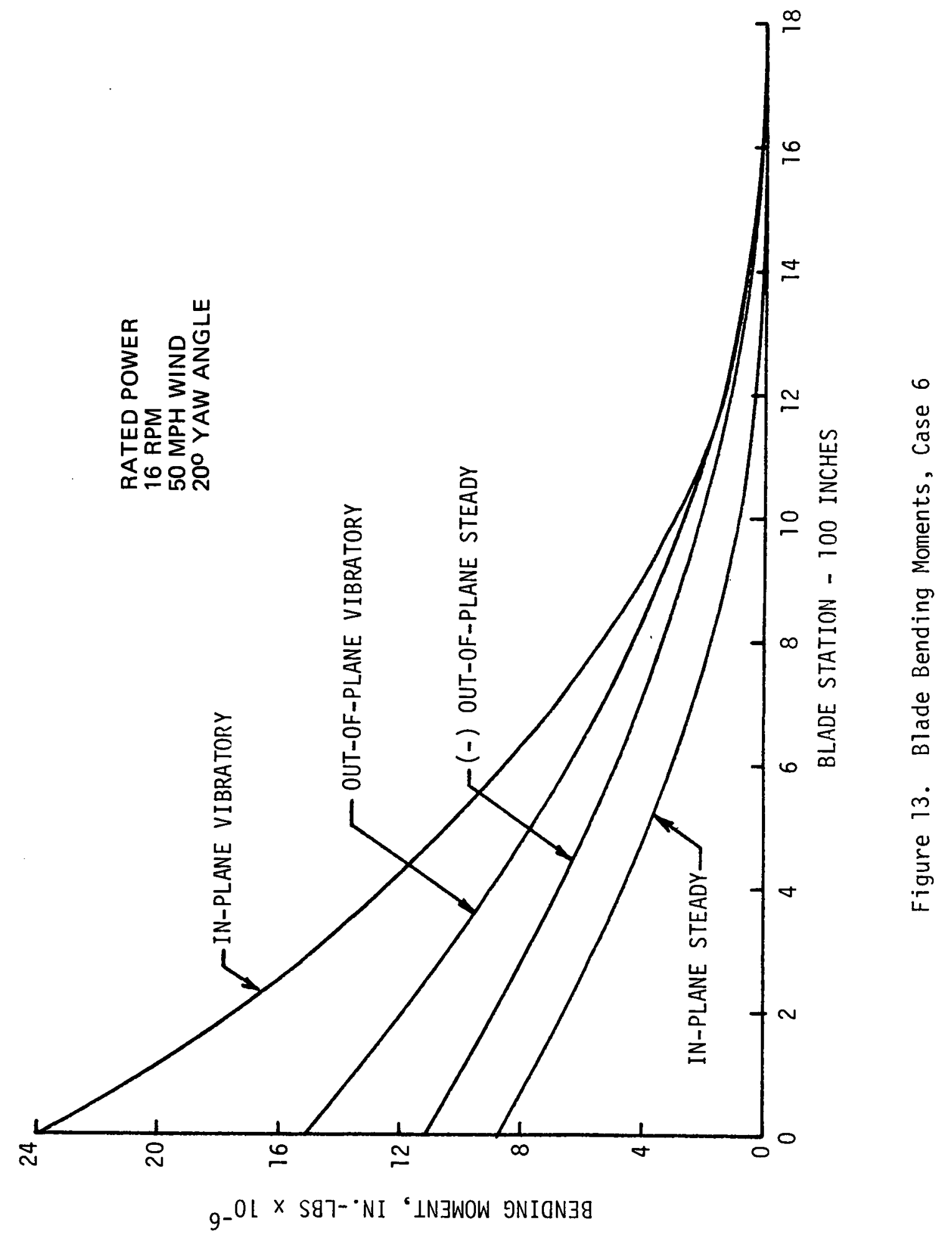




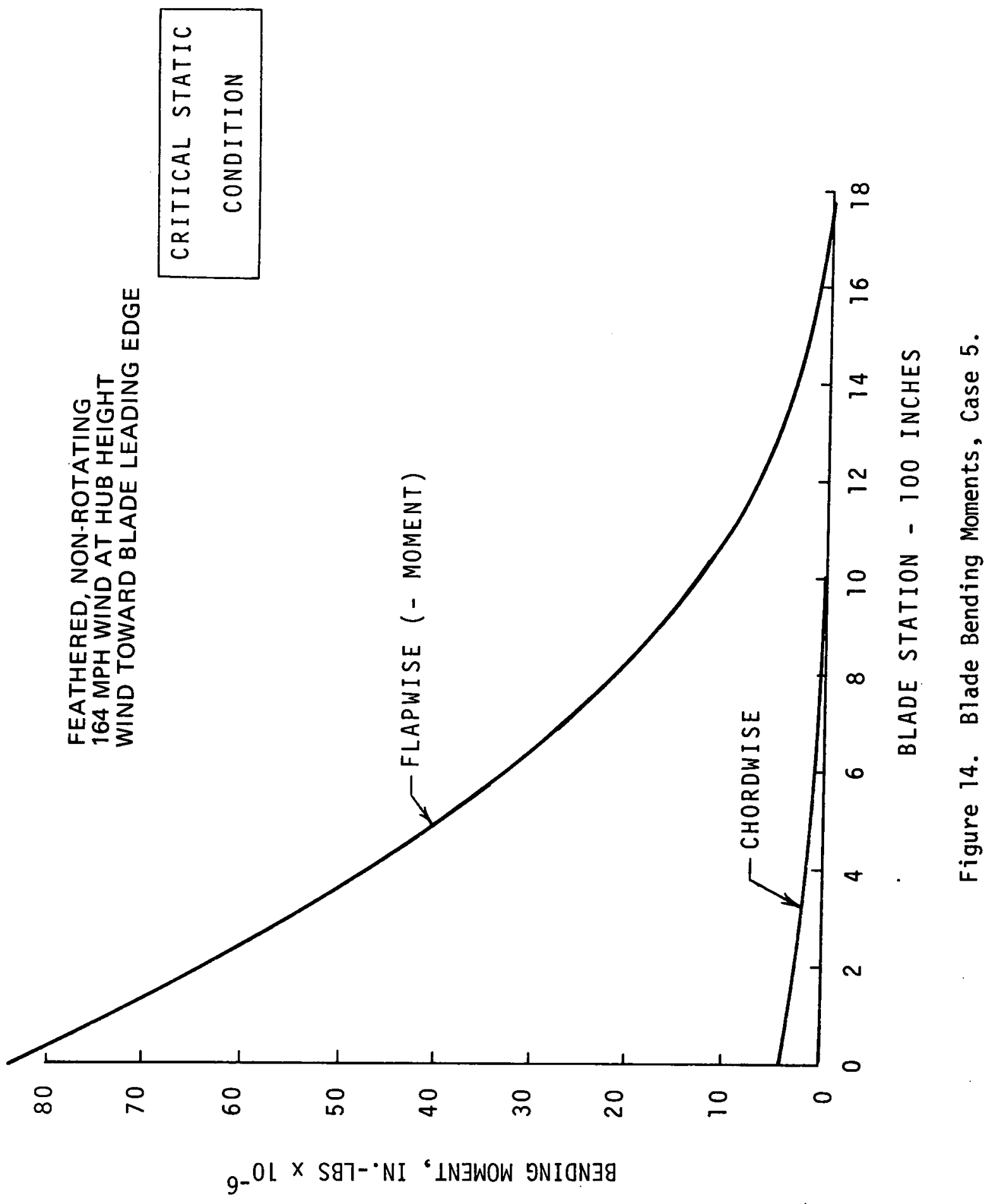




\begin{tabular}{|c|c|c|c|c|}
\hline \multicolumn{6}{|c|}{ TABLE 3. OPERATING CHARACTERISTICS FOR NON-ROTATING CONDITION } \\
(Hurricane wind: $120 \mathrm{mph}$ at 30 Feet)
\end{tabular}

Blade Tuning and Stability

Blade tuning and stability were design drivers from an overall blade configuration standpoint. The D-spar and honeycomb panel configuration was selected by Kaman over other candidate arrangements to keep the blade chordwise center of gravity in the $25-30$ percent range for stability. The spar was made narrower in the outtoard region to reduce weight for flatwise tuning, and the trailing edge spline provided stiffness for edgewise tuning.

Predicted blade natural frequencies at design rotor speed (16 rpm) are illustrated in the Campbell diagram, Figure 15, and are listed below:

$\begin{array}{lc}\text { 1st Flatwise Bending } & 2.51 / \mathrm{rev} \\ \text { 2nd Flatwise Bending } & 6.53 / \mathrm{rev} \\ \text { 1st Edgewise Bending } & 4.71 / \mathrm{rev} \\ \text { 2nd Edgewise Bending } & 13.48 / \mathrm{rev} \\ \text { 1st Torsion } & 59.4 / \mathrm{rev}\end{array}$

\section{Blade Stability}

The following blade stability investigations were performed:

Non-rotating Blade:

Static Divergence 


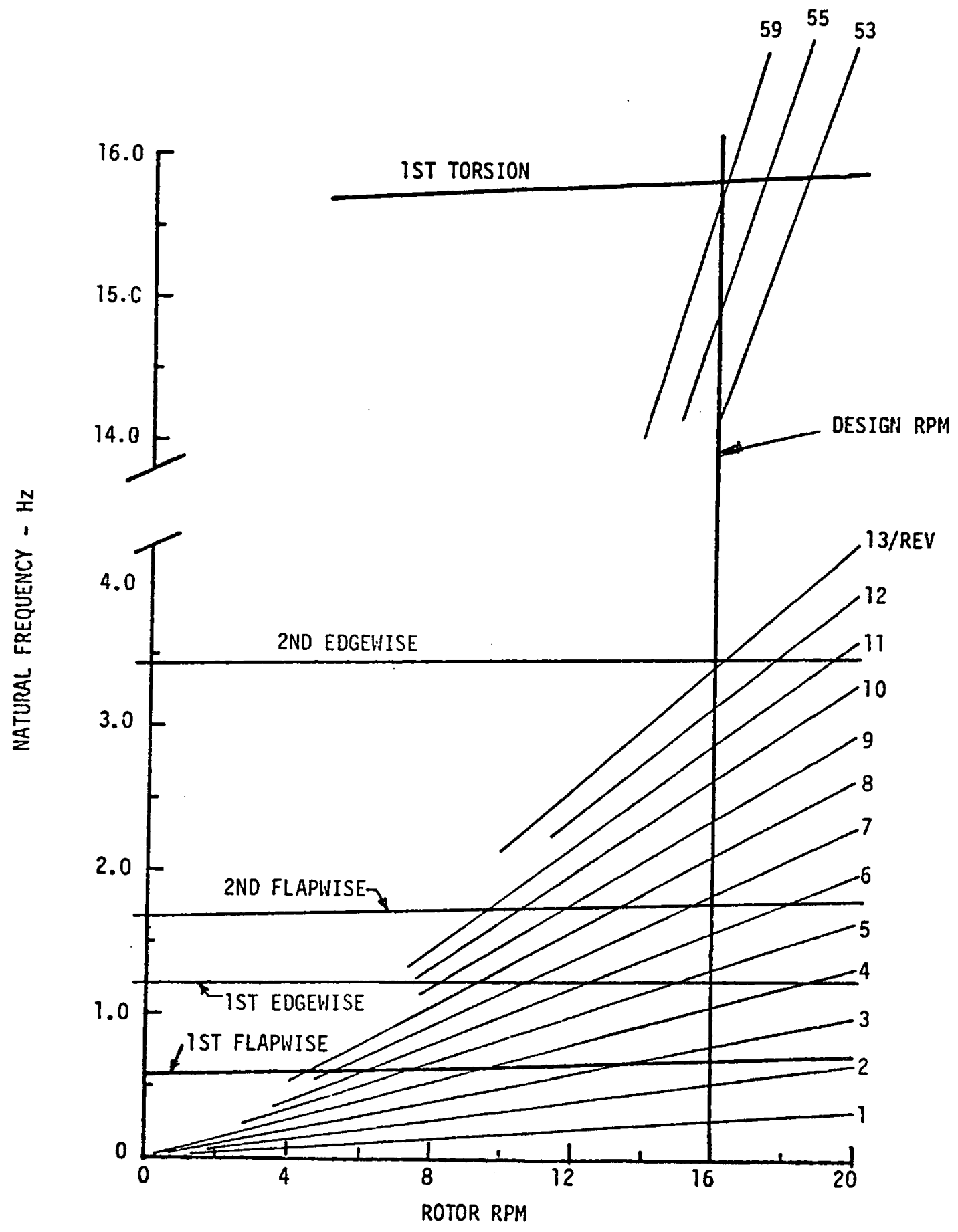

Figure 15. Campbe11 Diagram for 150 Foot Wind Turbine Blade. 
Rotating Blade:

\author{
Stal1 Flutter \\ Pitch-Flap Aeroelastic Stability \\ Pitch-Flap-Lag Aeroelastic Stability
}

The static divergence analysis was performed for the hurricane wind case with the blade parked in the horizontal position, feathered, and locked in pitch. A simplified airplane wing model was used in the analysis, in which the rate of change of aerodynamic pitching moment is equated to the torsional stiffness of the structure to derive a static divergence speed. For the case in which the wind approaches the blade leading edge, no static divergence occurs at any speed because the aerodynamic center is aft of the elastic axis and the blade is stable at all wind velocities. For the opposite case, in which the wind approaches from the trailing edge, the aerodynamic center is at $3 / 4$ chord, more than one-half chord upwind of the elastic axis. Static divergence will occur at $159 \mathrm{mph}$ wind velocity, whereupon blade twist would increase until aerodynamic moments are balanced by structural moments produced by twist. This could become a design factor for torsional stiffness and strength for an operational blade.

Stall flutter was analyzed as a single degree-of-freedom aeroelastic instability that self-excites the torsional mode of soft blades. It occurs at high local angles of attack when aerodynamic pitching moments become nonlinear due to flow separation. Moment hysteresis loops generate net positive work on the blade, illustrated in Figure 16, and further described in Reference 3. Parameters that primarily influence stall flutter are torsional frequency, airfoil profile shape, tip speed, blade loading, and local angle of attack.

Wind turbine blade angles of attack at rated wind speed and rated power conditions are approximately 11 - 12 degrees, including the effect of a 30 percent wind shadow from the tower. Also, wind turbine blades are torsionally stiff, typically having a natural frequency near 30/rev. These factors, high angle of attack and torsional stiffness, in combinations with the tower shadow effect, were examined for the possibility of stall flutter.

Several wind velocities from 22 to $60 \mathrm{mph}$, and rotor speeds of 18 and $22.5 \mathrm{rpm}$ were examined around the rotor azimuth for stall flutter. The results shown in Figure 17 reveal that the operating regime of the $150 \mathrm{ft}$ blade lies clear of the negative damping area associated with stall flutter for the most critical operating case, $60 \mathrm{mph}$ wind and $22.5 \mathrm{rpm}$.

Pitch-flap stability was analyzed using the classical two degree-of-freedom flutter and divergence code long used for helicopter rotor blades, Reference 4 . Simultaneous solution of the flapping and feathering equations yields stability boundaries defined as functions of torsional natural frequency and product of inertia. 







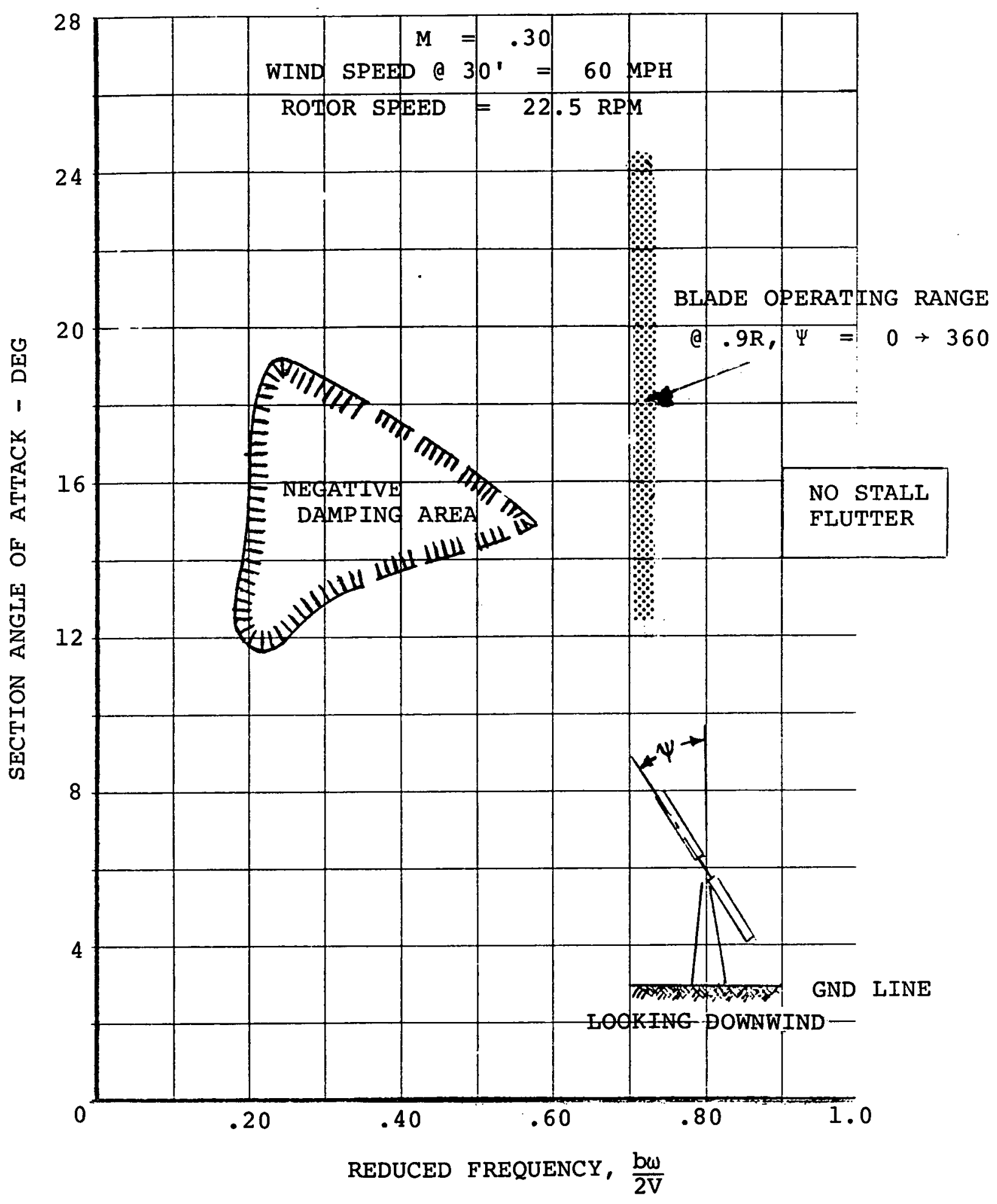

Figure 17. Location of Stall Flutter Boundary (Negative Damping Area) vs Blade Operating Range for Most Critical Condition. 
As expected, the high torsional stiffness of the blade, and the low wind velocity result in no tendency for flutter or divergence instability at any operating condition, as illustrated in Figure 18.

Pitch-flap-lag aeroelastic stability was analyzed using a six degree-of-freedom aeroelastic code that provides time histories of rotor blade motions after an initial disturbance. Five degrees-of-freedom were included in the analysis of the $150 \mathrm{ft}$ blade: two flatwise bending modes, one chordwise bending mode, elastic torsion, and a pitch control spring. The servo flap degree-of-freedom in the code was not applicable and, therefore, suppressed.

The analysis was done for the $20 \mathrm{rpm}, 60 \mathrm{mph}$ wind gust condition, and for the $16 \mathrm{rpm}, 18 \mathrm{mph}$ rated wind condition. In this analysis, the torsional natural frequency was varied and a Floquet anlays is (Reference 5) was performed to establish the stability of the system via complex eigenvalue solutions. Figure 19 shows the results of the analysis in which the damping of the most critical mode from the Floquet analysis was plotted vs blade torsional frequency. It can be seen that the $150 \mathrm{ft}$ blade is very stable and free from flutter for the critical operating conditions.

\subsection{Materials}

Materials were selected for the $150 \mathrm{ft}$ blade on the basis of low cost, adequate strength, and adaptability to automated fabrication processes. Well known, readily available materials having proven mechanical and environmental properties were chosen in preference to newer, but less well known and less wellcharacterized materials. These criteria resulted in selection of the materials listed in Table 4.

Some difficulty was encountered in selection of an epoxy resin system capable of being cured at room temperature and having acceptable mechanical properties and manufacturing ease. Consequently, NASA LeRC and Lawrence Livermore Laboratories personnel participated in and gave guidance to the selection of the wellcharacterized resin system 7 isted in Table 4 , which is capable of being cured at a moderately higher temperature $\left(180^{\circ} \mathrm{F}\right)$. Epoxy resin was selected over polyester because of superior properties under hot-wet environmental conditions.

Transverse Filament Tape (TFT) has been used for many years in the manufacture of commercial, fiberglass, filament wound pipe. Small quantities (about 10 percent) have been added to pipe to improve axial strength and bending stiffness. In the $150 \mathrm{ft}$ blade spar, the percentage of TFT is much greater than in pipe; TFT comprises approximately 90 percent of the spar to provide much greater bending strength and stiffness. As a consequence of this primary structural requirement, laminate characterization tests were conducted to provide material allowables for design.

Static characterizations were obtained via small specimen tests of TFT laminates. Thin laminates were laid up in the laboratory for tests at room temperature and $160^{\circ} \mathrm{F}$, under both wet and dry conditions. Laminates having $20 \%$ and $35 \%$ resin content were tested. Hot-wet specimens were heat-soaked at $160^{\circ} \mathrm{F}$ and 95 percent relative humidity for 500 to 1000 hours before being tested within 15 minutes after removal from the environmental chamber. 


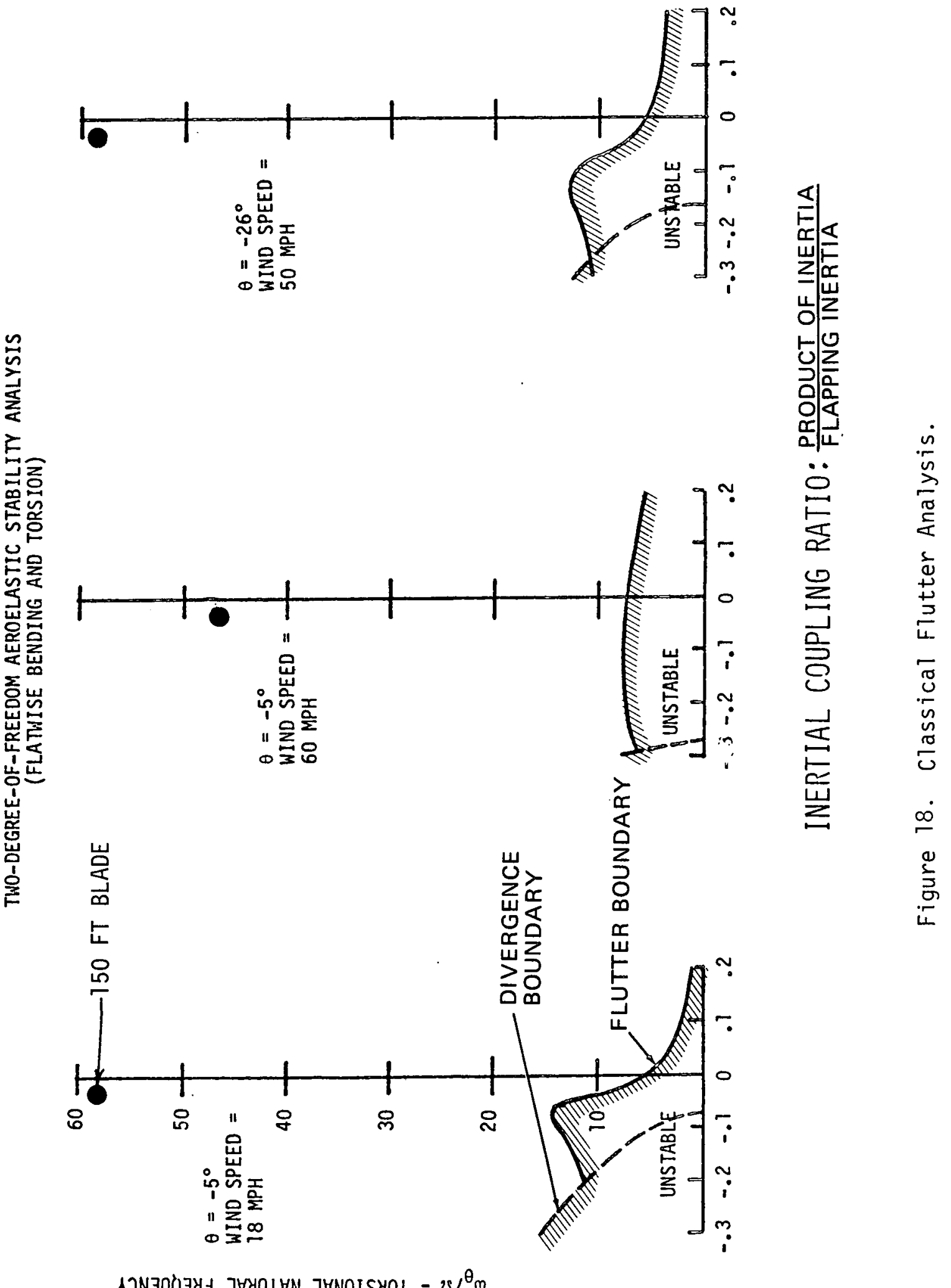

AJNJחOJYA TVUחLUN TYNOISYOL - $2 /^{\theta_{m}}$ 


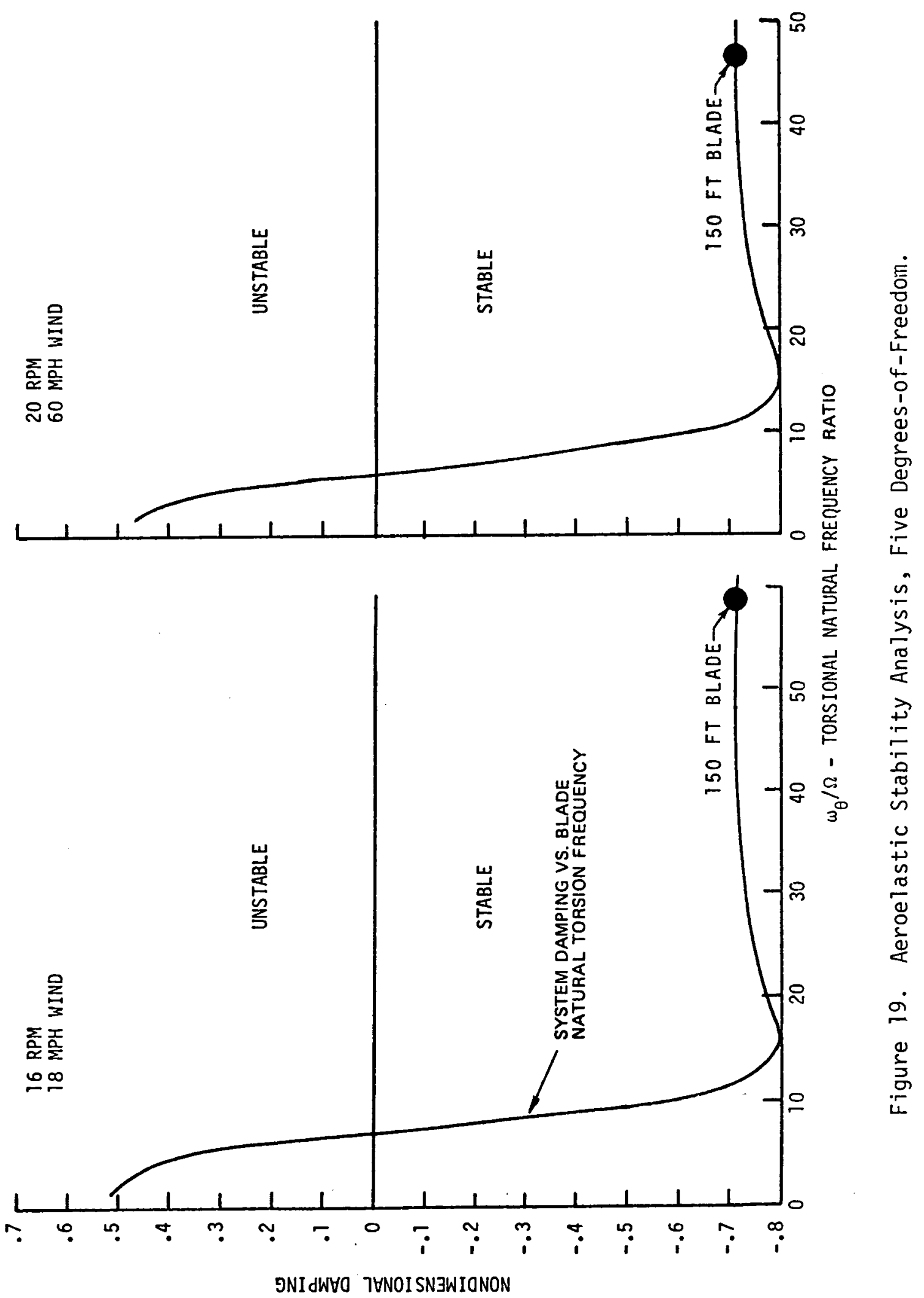




\section{TABLE 4. MATERIALS SELECTION}

Resin System

Cure Temperature

Transverse Filament Tape (TFT)

Hoop Rovings

$\pm 45^{\circ}$ Reinforcement

Trailing Edge Spline

Core

Adhesive

Syntactic Foam

Skins

Adapter
DER 332 Resin (80 PBW)

RD-2 Diluent (20 PBW)

TONOX 6040 Hardener (22.5 PBW)

$180^{\circ} \mathrm{F}, 5$ Hours

Style D360 Weft Unidirectional

Glass (OCF 410 AA-450)

$36 \mathrm{oz}$ per sq. yd.

Glass Roving (OCF 410 AA-450)

$450 \mathrm{yds} / 1 \mathrm{~b}, 48$ Rovings in 8 inch band

$45^{\circ}$ Bias Tape, 12 oz per sq. yd. (24 oz per sq. yd. for both $\pm 45^{\circ}$ layers)

E-Glass/Polyester Pultrusion

Phenolic Resin impregnated Paper Honeycomb, $2.31 \mathrm{~b} / \mathrm{ft}^{3}$

EA 913 and EA 934NA Paste Epoxy

R371

1583 Glass Cloth Pre-preg, F159 Resin

1025 Steel 
Static properties obtained for 35 percent resin content, under the $160^{\circ} \mathrm{F}$, wet conditions are shown below, along with the values used for design allowables derived from the hot-wet tests. Additional static test results are shown in Figures $20-26$.

\begin{tabular}{lccc} 
& $160^{\circ} \mathrm{F}$, WET & $\begin{array}{c}\text { DESIGN } \\
\text { ALLOWABLES }\end{array}$ \\
\cline { 2 - 2 } Ultimate tensile strength, ksi & 52.7 & 33.7 \\
Tensile modulus, $10^{6} \mathrm{psi}$ & 5.4 & 5.4 \\
Ultimate compressive strength, ksi & 44.2 & 41.4 \\
Compressive modulus, 10 psi & 4.8 & 4.8 \\
In-plane shear strength, ksi & 3.46 & 3.16 \\
Shear modulus, 10 ${ }^{6}$ psi & 0.305 & 0.305 \\
Short beam shear strength & & \\
(Interlaminar shear), ksi & 3.32 & 3.12 \\
Poisson's ratio & 0.33 & 0.33
\end{tabular}

Design allowables for strength were reduced 3-sigma from the mean, whereas elastic properties were mean values.

Fatigue characterization was obtained from small specimen fatigue tests of sandwich beams having a TFT laminate on one side and a stainless steel sheet on the other, separated by aluminum honeycomb core. This configuration placed the neutral axis of the beam close to the stainless steel side, so that bending moments imposed on the beam by a Krouse testing machine resulted in primarily axial loads in the TFT laminate. The laminate was made with a TFT overlap in the center, fully representative of the overlap obtained in the winding pattern for the spar. The objective of the fatigue tests was to determine whether there was a significant reduction in fatigue strength in the TFT structure when compared with a continuous-filament structure. TFT depends solely upon the resin matrix for tensile load transfer from one layer of glass rovings to an adjacent layer. The effect on fatigue strength of abruptly ending a roving layer across the primary stress direction was also of interest.

Fatigue testing these specimens proved to be a difficult task. Many tests were terminated because the specimens failed in the grip area and not in the test section, as a consequence of specimen design. Initially, the TFT specimens were machined from flat laminate plates and then bonded to the sandwich beam, shown in Figure 27, for the bending fatigue tests. The machining operation produced cut fibers which became failure loci at the edges of the specimen. Later, TFT laminates were molded to shape to avoid the cut edges of the machining operation. The molded specimens, shown in Figure 28, were better, but still produced failures in the vicinity of retention grips. A better solution appears to be the use of wound tubular specimens which eliminate cut edges. Kaman-funded fatigue testing of tubular specimens has shown this approach to produce failures in the test section which provide better fatigue characterization than flat panel tests of composite laminates. 




0० TENSILE PROPERTIES

\begin{tabular}{|c|c|c|c|c|}
\hline $\begin{array}{l}\text { RESIN } \\
\text { CONTENT } \\
\end{array}$ & $\begin{array}{c}\text { TEST } \\
\text { CONDITION } \\
\end{array}$ & $\begin{aligned} & \text { NUMBER } \\
& \text { OF } \text { SPECIMENS } \\
&\end{aligned}$ & $\begin{array}{l}\text { TENSILE } \\
\text { STRENGTH (PSI) } \\
\end{array}$ & $E\left(x \quad 10^{6}\right)$ \\
\hline $35 \%$ & $R T, D R Y$ & 6 & 53,200 & 5.1 \\
\hline $35 \%$ & RT, WET & 3 & 44,300 & 5.3 \\
\hline $35 \%$ & $160 F$, DRY & 3 & 55,400 & 4.8 \\
\hline $35 \%$ & 160F, WET & 3 & 52,700 & 5.4 \\
\hline $20 \%$ & $R T, D R Y$ & 3 & 63,400 & 6.1 \\
\hline $20 \%$ & 160F, WET & 3 & 59,100 & 5.9 \\
\hline
\end{tabular}

Figure 20. TFT Laminate Static Characterization, $0^{\circ}$ Tensile Test, ASTM D 3039. 

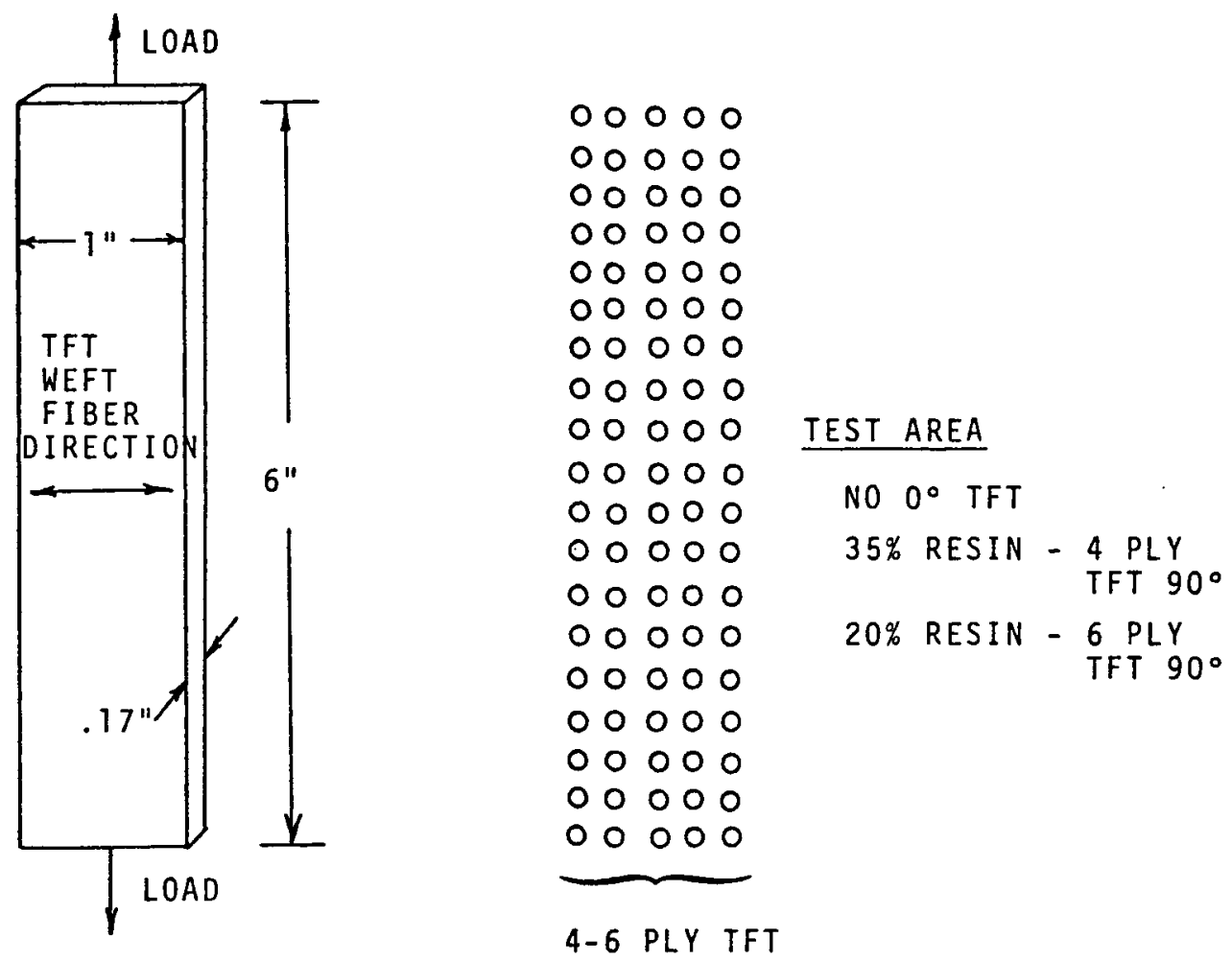

4-6 PLY TFT

90० TENSILE PROPERTIES

\begin{tabular}{|c|c|c|c|c|}
\hline $\begin{array}{l}\text { RESIN } \\
\text { CONTENT }\end{array}$ & $\begin{array}{c}\text { TEST } \\
\text { CONDITION } \\
\end{array}$ & $\begin{array}{ll} & \text { NUMBER } \\
\text { OF } & \text { SPECIMENS } \\
\end{array}$ & $\begin{array}{l}\text { TENS ILE } \\
\text { STRENGTH (PSI) }\end{array}$ & $E\left(\times 10^{6}\right)$ \\
\hline $35 \%$ & $R T, D R Y$ & 3 & 1300 & 1.2 \\
\hline $35 \%$ & RT, WET & 3 & 1860 & 1.4 \\
\hline $35 \%$ & 160F, DRY & 3 & 900 & 1.1 \\
\hline $35 \%$ & 160F, WET & 3 & 1300 & 1.1 \\
\hline $20 \%$ & $R T, D R Y$ & 3 & 1200 & 2.0 \\
\hline $20 \%$ & 160F, WET & 3 & 975 & 1.1 \\
\hline
\end{tabular}

Figure 21. TFT Laminate Static Characterization, $90^{\circ}$ Tensile Test, ASTM D 3039. 

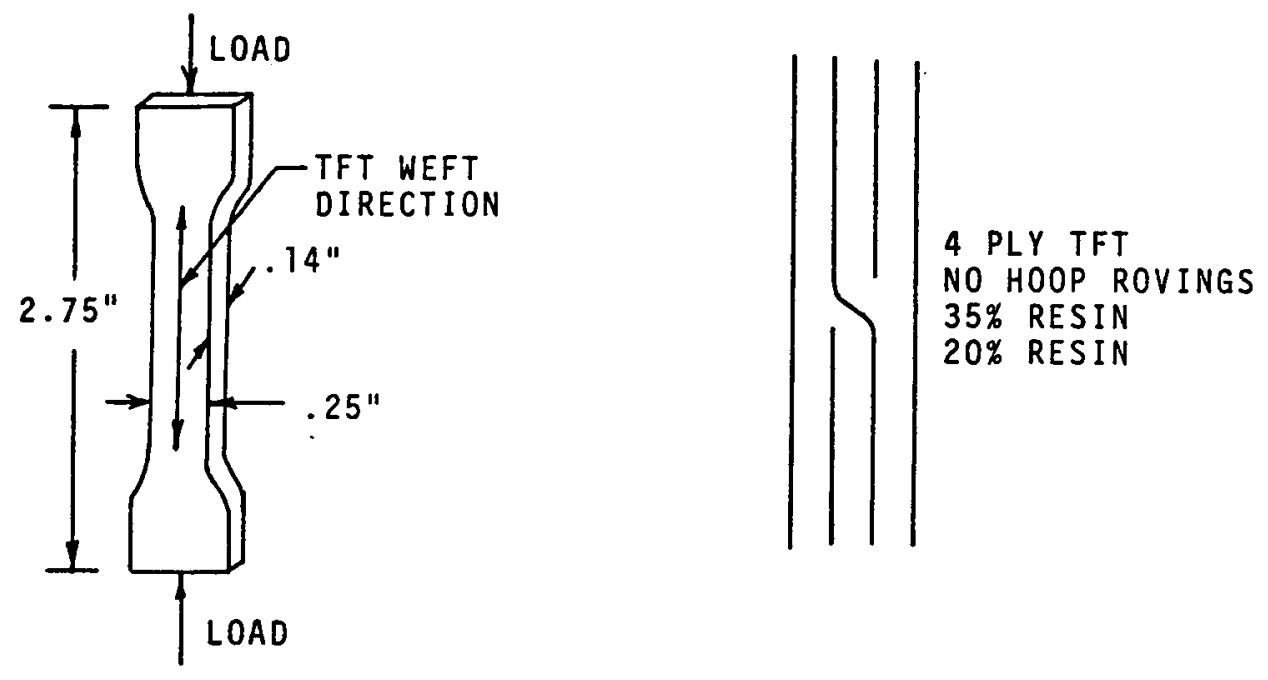

\section{$0^{\circ}$ COMPRESSION PROPERTIES}

\begin{tabular}{|c|c|c|c|c|}
\hline $\begin{array}{r}\text { RESIN } \\
\text { CONTENT } \\
\end{array}$ & $\begin{array}{c}\text { TEST } \\
\text { CONDITION } \\
\end{array}$ & $\begin{array}{l}\text { NUMBER } \\
\text { OF SPECIMENS } \\
\end{array}$ & $\begin{array}{c}\text { COMPRESSION } \\
\text { STRENGTH (PSI) } \\
\end{array}$ & $E\left(\times 10^{6}\right)$ \\
\hline $35 \%$ & RT, DRY & 4 & 63,500 & 4.4 \\
\hline $35 \%$ & RT, WET & 3 & 58,200 & 5.2 \\
\hline $35 \%$ & 160F, DRY & 2 & 45,300 & 5.1 \\
\hline $35 \%$ & 160F, WET & 3 & 44,200 & 4.8 \\
\hline $20 \%$ & RT, DRY & 3 & 66,500 & 5.0 \\
\hline $20 \%$ & 160F, WET & 3 & 52,300 & 6.5 \\
\hline
\end{tabular}

Figure 22. TFT Laminate Static Characterization, $0^{\circ}$ Compression Test, ASTM D 695. 

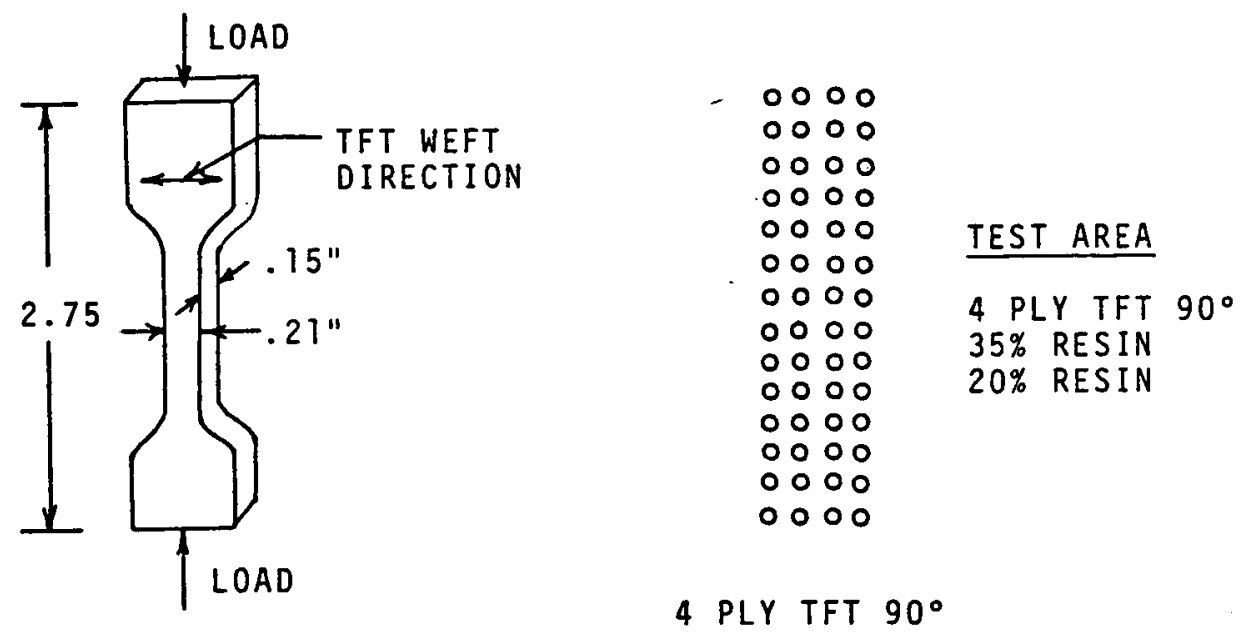

\section{$90^{\circ}$ COMPRESSION PROPERTIES}

RES IN CONTENT

$35 \%$

$35 \%$

$35 \%$

$35 \%$

$20 \%$

$20 \%$
TEST CONDITION

$$
\text { RT, DRY }
$$$$
\text { RT, WET }
$$

160F, DRY

160F, WET

$R T$, DRY

160F, WET
NUMBER OF SPECIMENS

3

3

3

3

3

3
COMPRESSION STRENGTH (PSI)

7990

9300

7250

7530

10900

8100

$E\left(\times 10^{6}\right)$
1.3
1.4
1.4
1.0
1.7
1.3

Figure 23. TFT Laminate Static Characterization, $90^{\circ}$ Compression Test, ASTM D 695. 




POISSON'S RATIO

\begin{tabular}{cccc}
$\begin{array}{ccc}\text { RESIN } \\
\text { CONTENT }\end{array}$ & $\begin{array}{c}\text { TEST } \\
\text { CONDITION }\end{array}$ & OF SPBER & POISSON'S \\
\cline { 3 - 4 } $35 \%$ & RT, DRY & 3 & .33 \\
$35 \%$ & $160 \mathrm{~F}$, WET & 3 & .33 \\
$20 \%$ & RT, DRY & 3 & .32 \\
$20 \%$ & $160 \mathrm{~F}$, WET & 3 & .29 \\
PATENT PENDING & & &
\end{tabular}

Figure 24. TFT Laminate Static Characterization, Poisson's Ratio Test, ASTM E 132. 

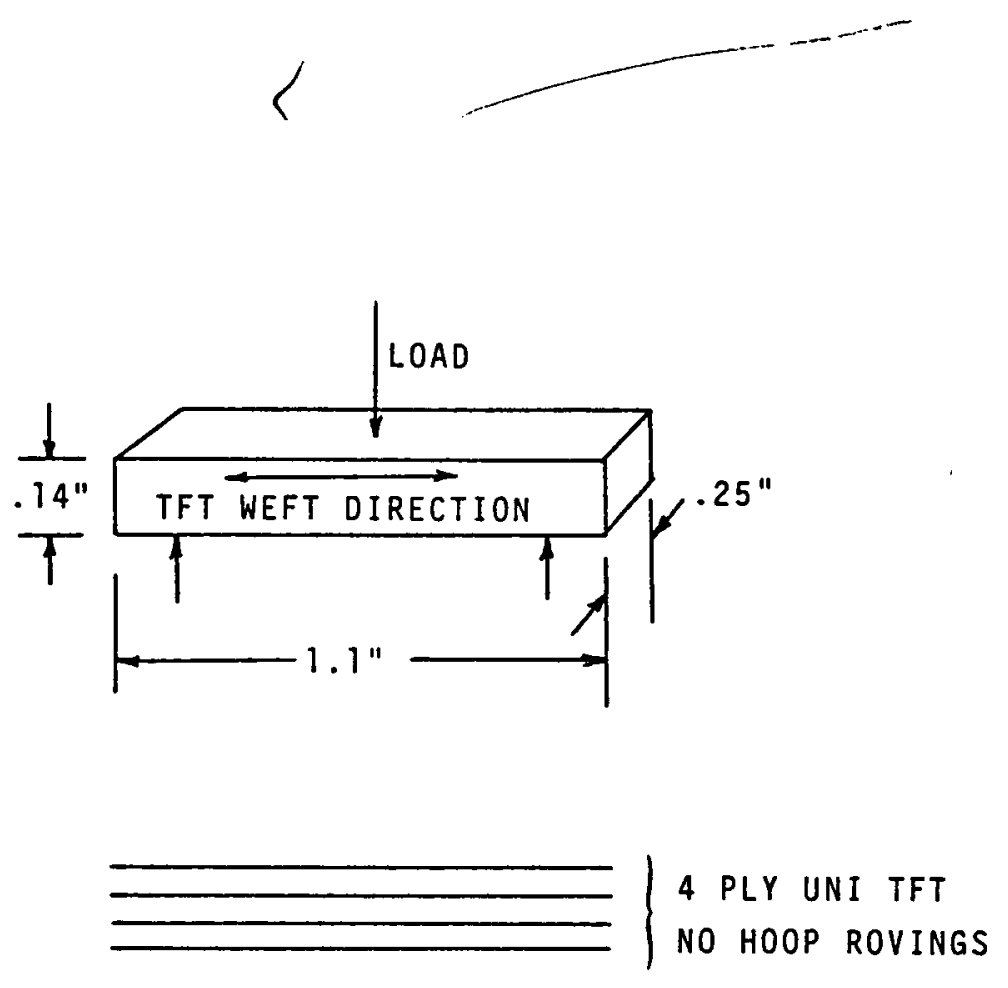

\section{SHORT BEAM SHEAR STRENGTH}

\begin{tabular}{c} 
RESIN \\
CONTENT \\
\hline $35 \%$ \\
$35 \%$ \\
$35 \%$ \\
$35 \%$ \\
$20 \%$ \\
$20 \%$ \\
$20 \%$ \\
$20 \%$
\end{tabular}

\begin{tabular}{cc} 
TEST & NUMBER \\
CONDITION & OF SPECIMENS \\
\cline { 2 - 2 } RT, DRY & 7 \\
RT, WET & 6 \\
160F, DRY & 6 \\
160F, WET & 6 \\
RT, DRY & 6 \\
RT, WET & 6 \\
160F, DRY & 6 \\
160F, WET & 6
\end{tabular}

SHEAR

STRENGTH (PSI)

6730

6370

4470

3310

6500

6050

4490

3410

Figure 25. TFT Laminate Static Characterization, Short Beam Shear Test, ASTM D 2344. 


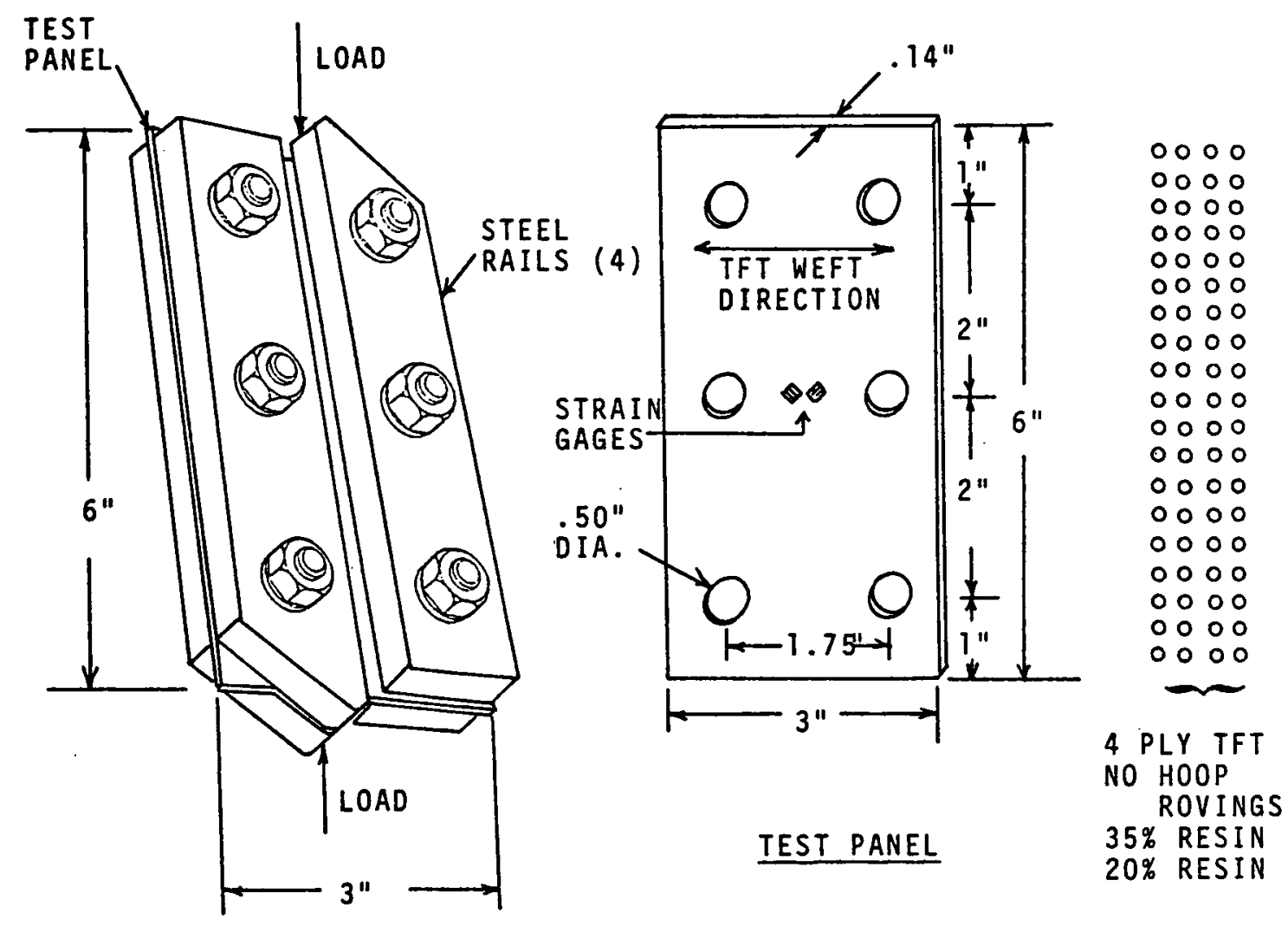

INPLANE (RAIL) SHEAR PROPERTIES

\begin{tabular}{|c|c|c|c|c|}
\hline $\begin{array}{l}\text { RESIN } \\
\text { CONTENT } \\
\end{array}$ & $\begin{array}{c}\text { TEST } \\
\text { CONDITION } \\
\end{array}$ & $\begin{array}{c}\text { NUMBER } \\
\text { OF SPECIMENS } \\
\end{array}$ & $\begin{array}{l}\text { ULT. SHEAR } \\
\text { STRESS (PSI) } \\
\end{array}$ & $\begin{array}{l}\text { SHEAR MODULUS } 01 / 3 \\
\text { ULT. STRESS (PSI) }\end{array}$ \\
\hline $35 \%$ & $R T, D R Y$ & 2 & 4610 & 478,000 \\
\hline $35 \%$ & 160F, WET & 2 & 3460 & 305,000 \\
\hline $20 \%$ & $R T, \quad D R Y$ & 2 & 5150 & 690,000 \\
\hline $20 \%$ & 160F, WET & 2 & 3120 & 357,000 \\
\hline
\end{tabular}

Figure 26. TFT Laminate Static Characterization, In-plane (Rai1) Shear Test, Northrop Specification IT-58, Rev. 8. 








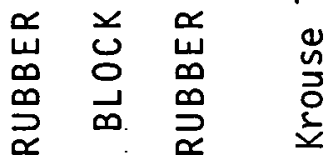

잉 o
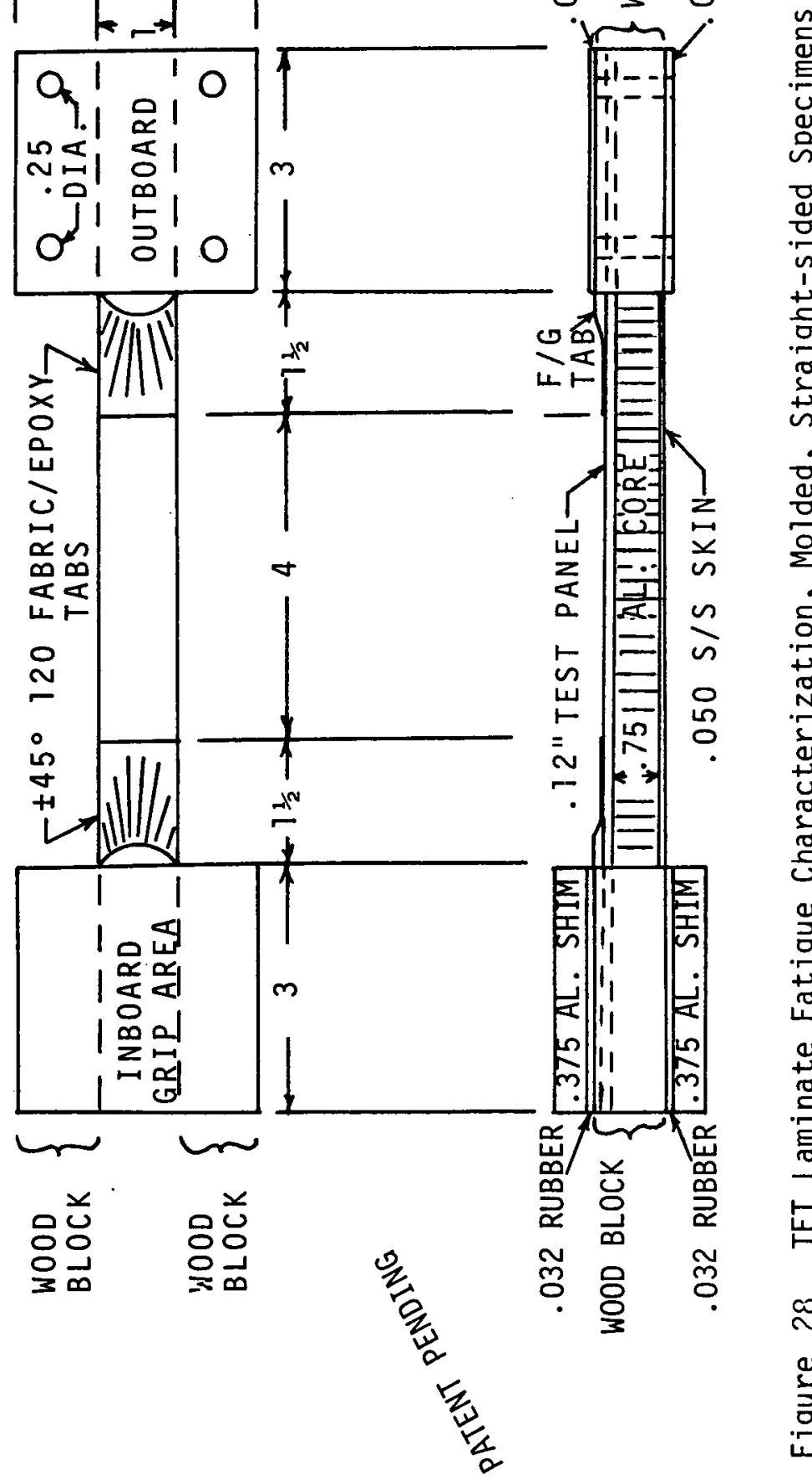
Although many tests were terminated early by invalid failures, the fatigue cycles accumulated on the specimens were used to establish the basis for fatigue allowables.

Results of the sandwich beam tests and a tubular specimen test are shown in Figure 29. The shape of the mean curve was based upon historical data from industry sources and its location was based upon the sandwich beam tests. The data point for the single tubular specimen falls close to the mean curve, tending to validate the series. It is believed that the fatigue data presented in Figure 29 can be used with reasonable confidence that additional testing will not result in large changes in the position of the curve, and that it is unlikely that any such change would be toward lower values. To the degree that small specimen data are useful for design, it is believed that these data are conservative.

The mean curve was reduced three standard deviations (3-sigma) to provide safe values to be used for design. The allowable vibratory stress is obtained by applying the Goodman Diagram correction for steady stress using the 3-sigma reduced fatigue endurance limit of $9000+7000 \mathrm{psi}$, and the 3-sigma-reduced ultimate stress of 48,900 psi for the $35 \%$ resin content, room temperature, dry condition.

In addition to the laminate characterizations described above, four quarterscale specimens (Figure 30) representing the blade root end attachment were fatigue tested to provide substantiation for the single-shear retention method. Specimens were made by Structural Composites Industries, Inc., as part of a subscale spar, wound in the same manner as the full scale spar. Four specimens were cut from the subscale spar for the fatigue test. The double-ended specimens contained the same proportions of TFT, hoop rovings and $+45^{\circ}$ bias tape as in the full-scale spar. Hardware details and installation procedures were also representative of the full-scale structure.

Specimens were tested in a tension-tension mode. Two were tested to 2 million cycles at normal operating loads, and two were tested to 10 million cycles. In an attempt to produce a failure, the last of the four specimens was tested at the Case 2 gust condition for 10 million cycles. Bearing stress range in the bolt holes was $6500-19,400$ psi during that test. No failures were produced in any of the specimens. It was concluded that the design values and interleaved laminate construction used for the root end composite structure were satisfactory for the full-scale spar.

Material allowables for the afterbody structure and its attachment in final assembly were based upon handbook data (Reference 6) and industry practice for the well-established designs employed. As a check, several sub-element tests were run to verify the bond strengths obtained from the fabrication process proposed for the complete blade. These tests included measurement of skin strength and various bond line strengths listed below, and illustrated in Figures 31 - 34: 







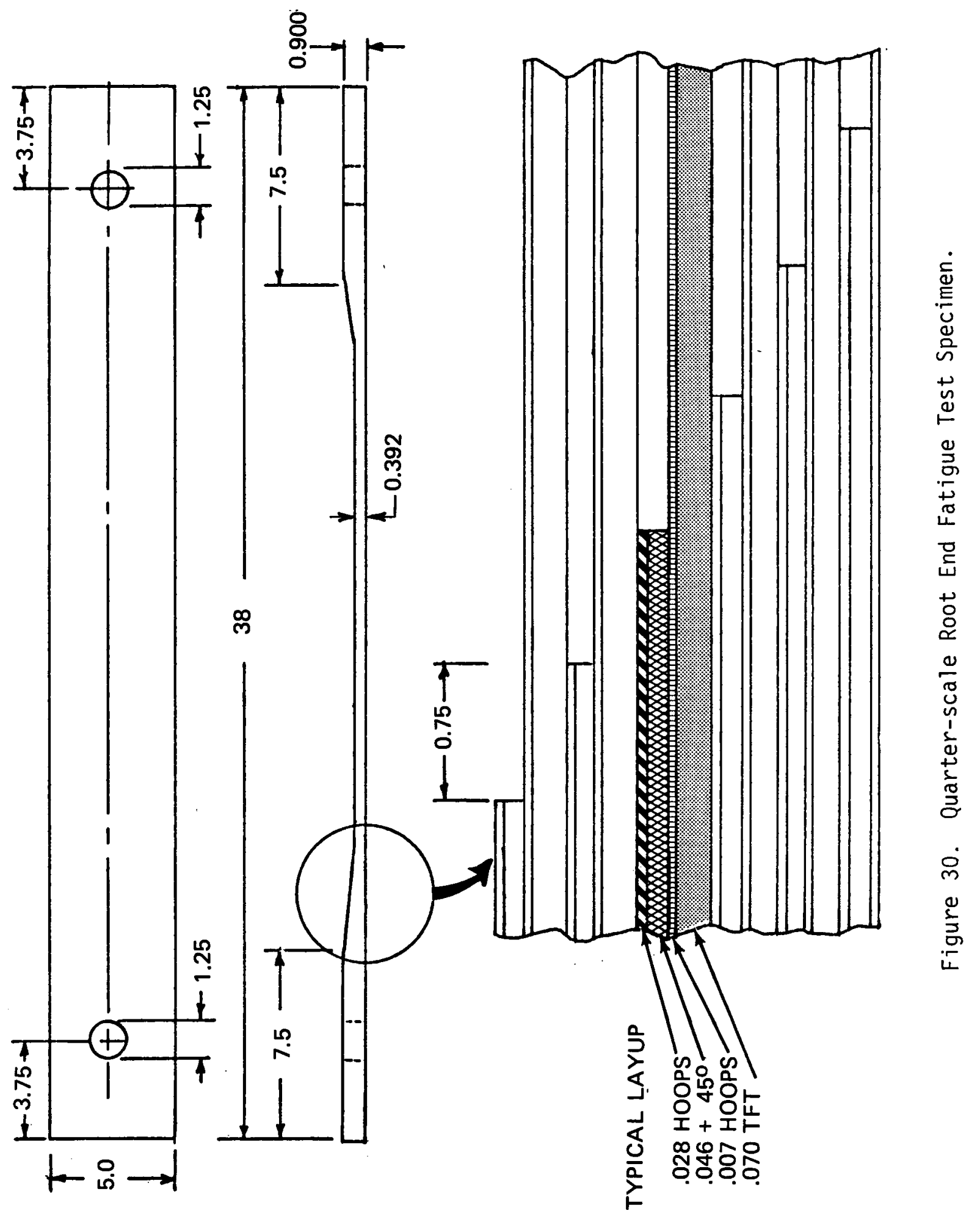








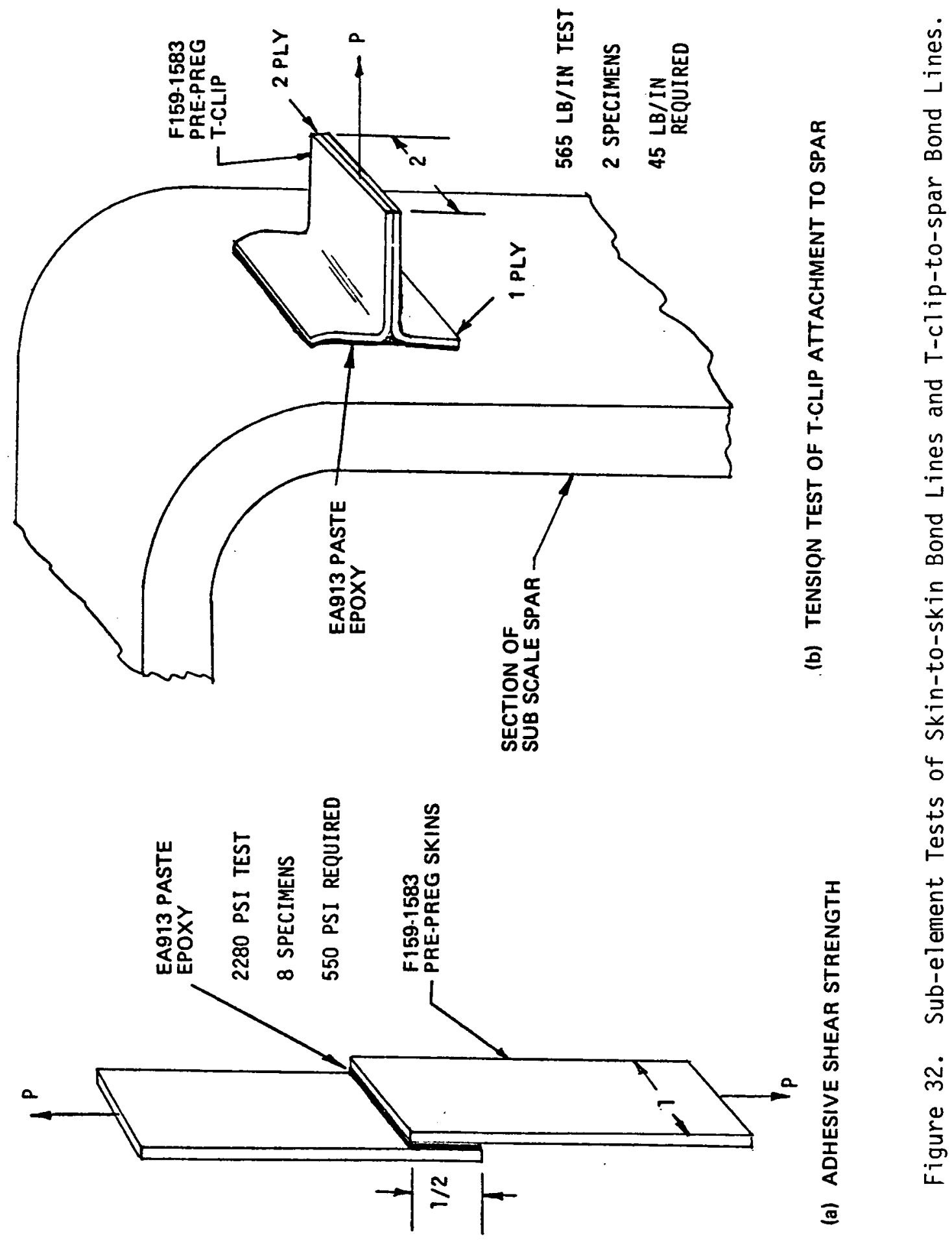


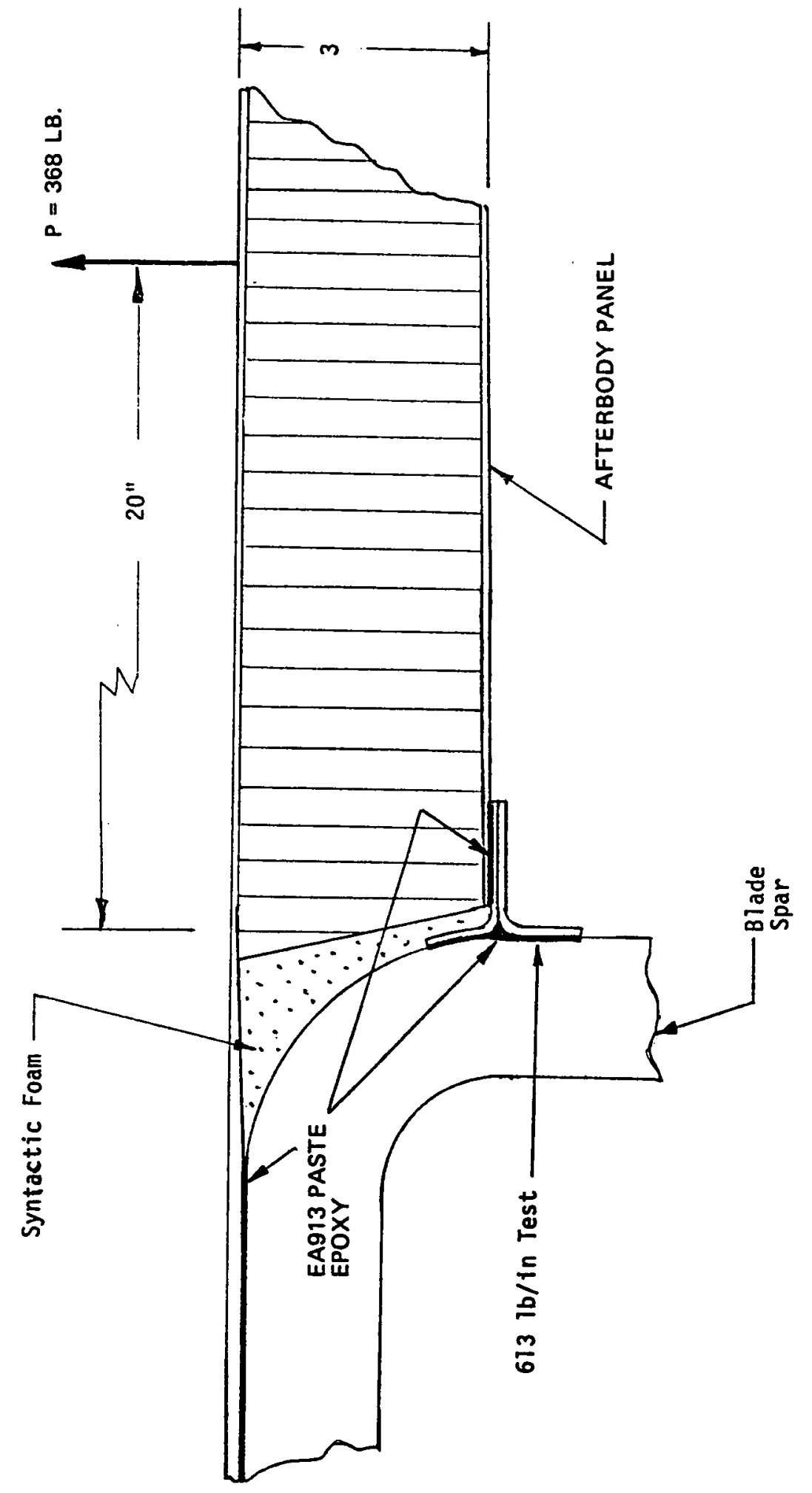

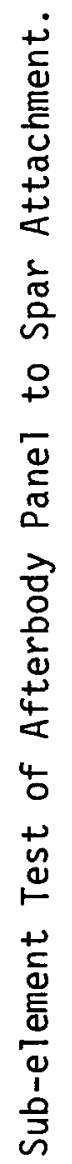

$m$
$m$
$\frac{1}{3}$
$\frac{\pi}{4}$ 


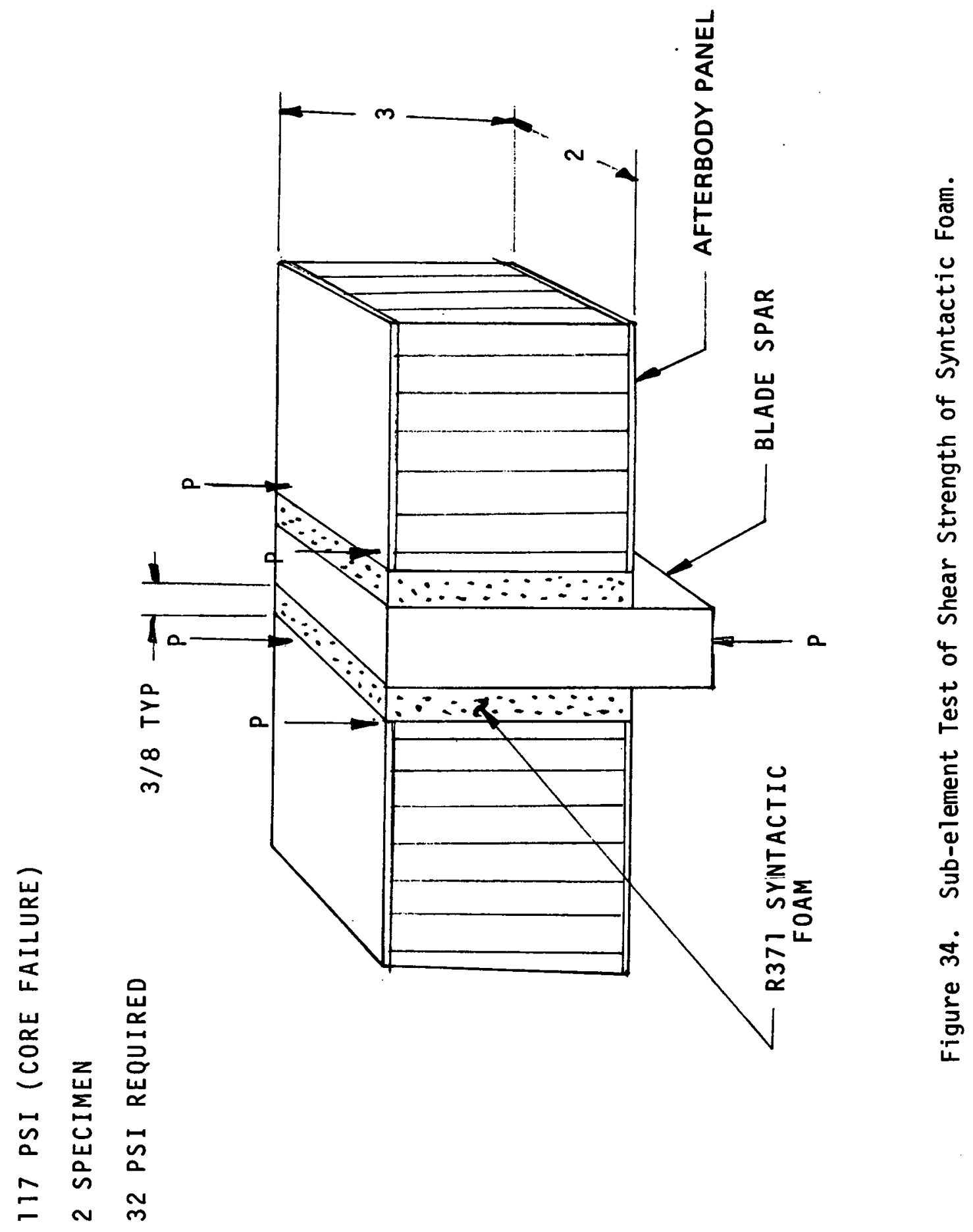




$\begin{array}{cccc}\begin{array}{c}\text { NUMBER } \\ \text { OF SPECIMENS }\end{array} & \begin{array}{c}\text { AVERAGE } \\ \text { STRENGTH }\end{array} & \begin{array}{c}\text { REQUIRED } \\ \text { STRENGTH }\end{array} \\ 2 & & 51,000 \mathrm{psi} & 10,000 \mathrm{psi} \\ 8 & 175 \mathrm{psi} & 10 \mathrm{psi} \\ 2 & 2,280 \mathrm{psi} & 550 \mathrm{psi} \\ 1 & 565 \mathrm{lb} / \mathrm{in} . & 45 \mathrm{lb} / \mathrm{in} . \\ 2 & \begin{array}{c}117 \mathrm{psi} \\ \text { (core failure) }\end{array} & 32 \mathrm{psi} .\end{array}$

\subsection{Structural Analysis}

Structural analysis of the $150 \mathrm{ft}$ blade was conducted primarily by large scale finite element analysis using the NASTRAN computer code. Loads, including inertial and aerodynamic shears, were defined using Kaman's existing rotor analysis methods. Four major NASTRAN rigid routines were utilized: Static Analysis, Static Analysis with Differential Stiffness, Buckling Analysis, and Natural Frequencies and Modes. Orthotropic and anisotropic composite properties were established by materials characterization and processing with an existing Kaman computer code (CMAB) for use in prescribing element materials constants for the NASTRAN work. CMAB is based on the equations and notations given in Reference 7. Results were processed to yield stresses and margins of safety for shell elements for direct and shear panel stresses and for interlaminar shear stresses. Margins of safety were calculated for each layer and for the shear stresses between layers. Blade bending stress distributions for the load cases specified by NASA are shown in Figures $35-40$, and maximum spar stresses are shown in Table 5 .

Blade deflection and stiffness calculations were made using the NASTRAN model shown in Figure 41 . The resulting deflections are shown in Figure 42 , for both the Static Analysis and the Static Analys is with Differential Stiffness NASTRAN routines.

Structural design of the spar was based on the mechanical properties of the spar laminate established by material characterization tests and by industry data on E-glass composites. Minimum values of mechanical properties obtained under hotwet test conditions were used as described on page 33. Specific layup geometry 

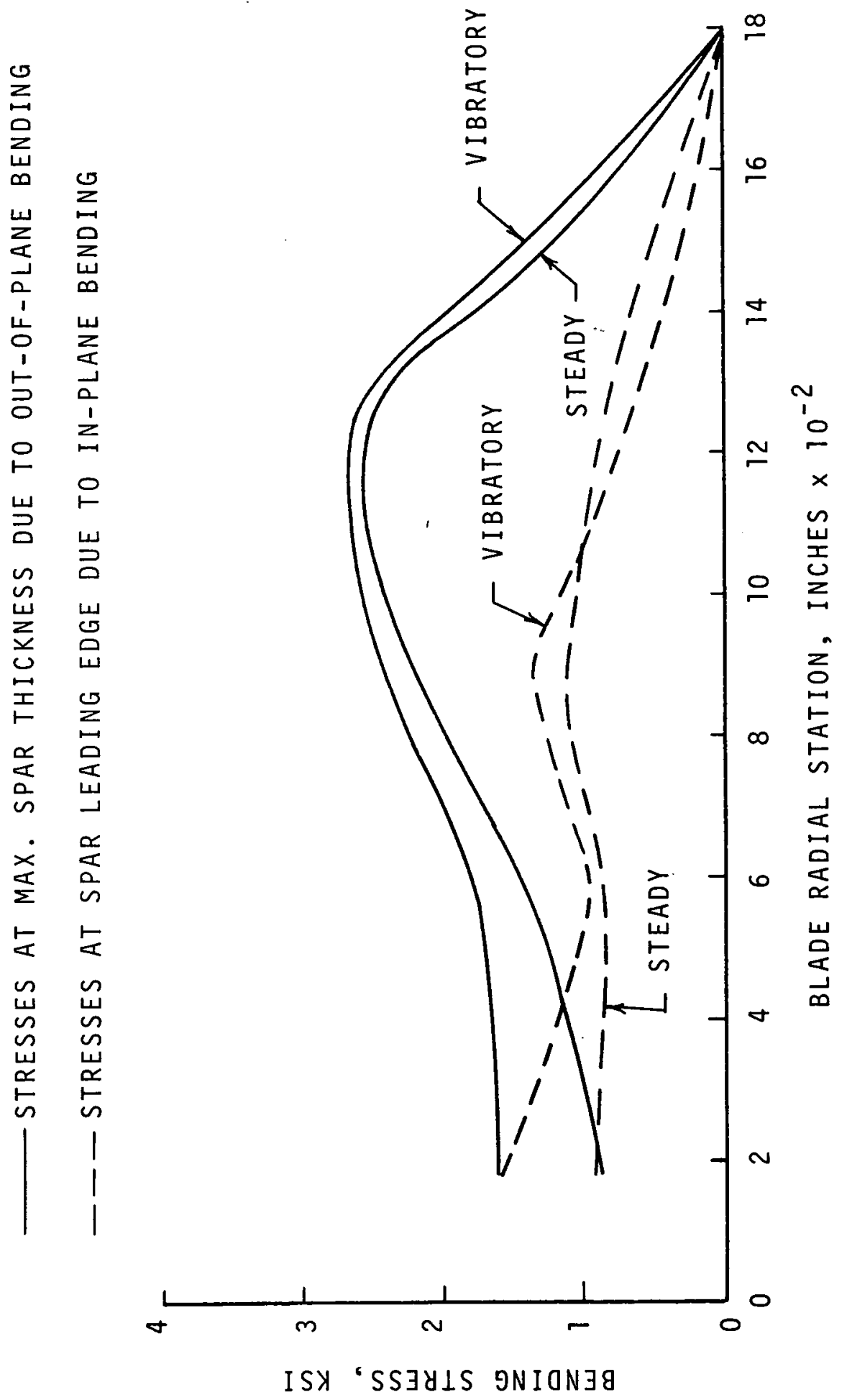

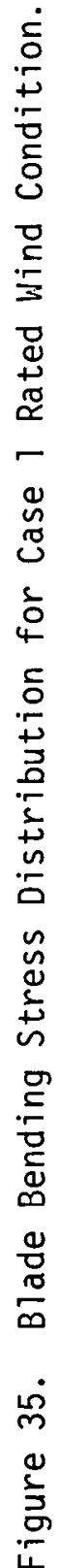




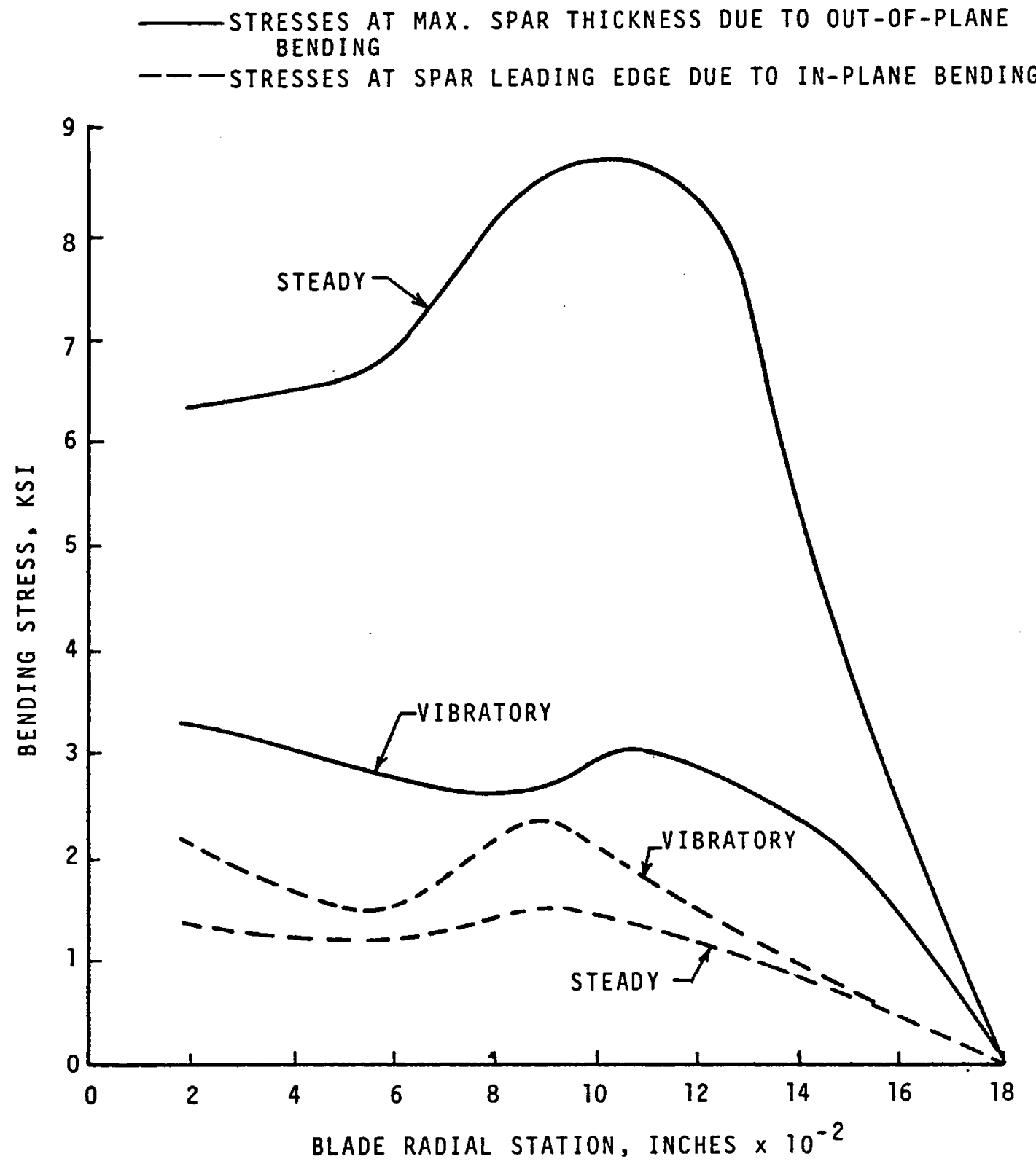

Figure 36. Blade Bending Stress Distribution for Case 2 Gust Condition. 


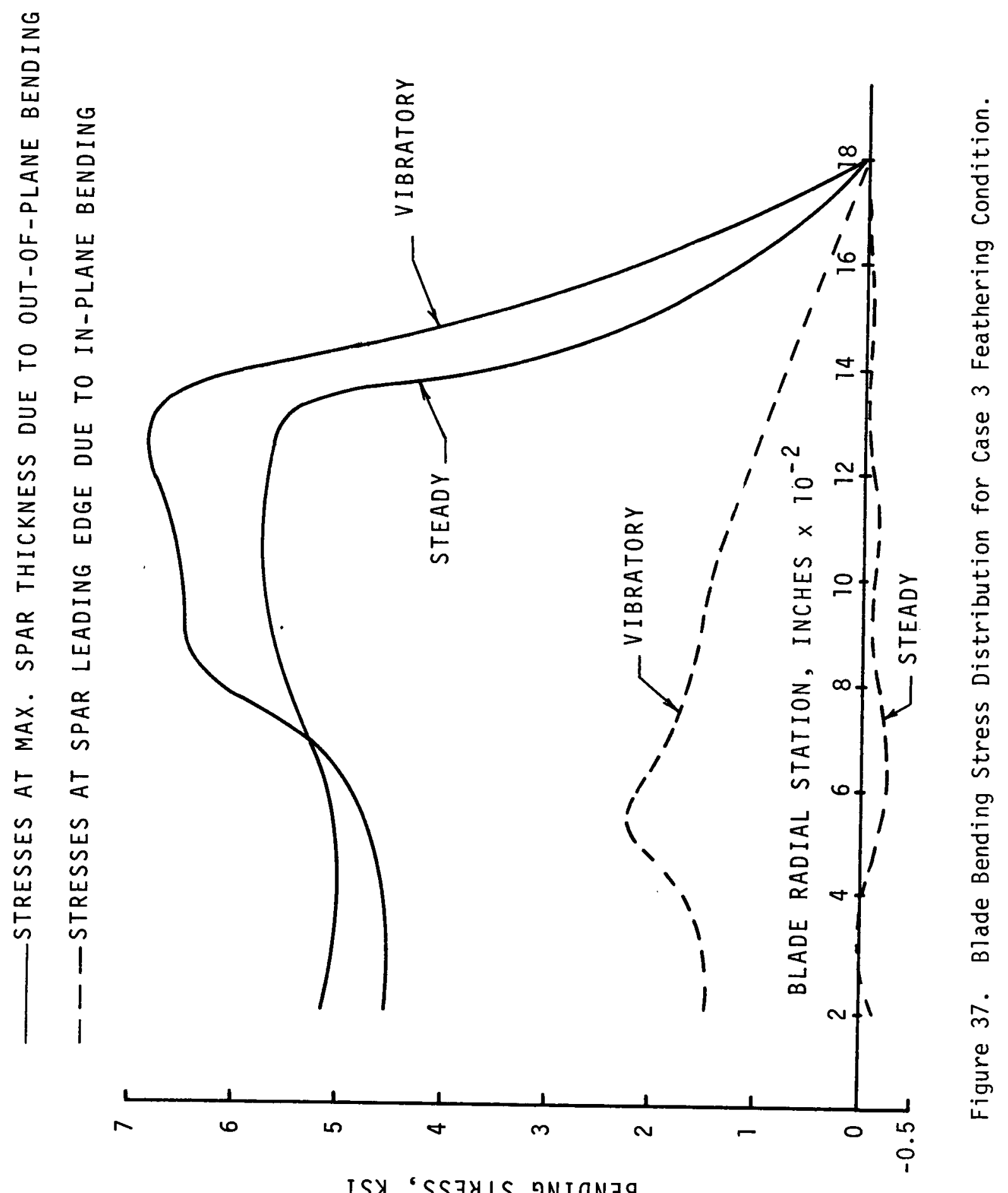






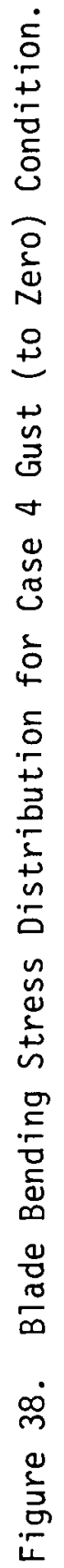




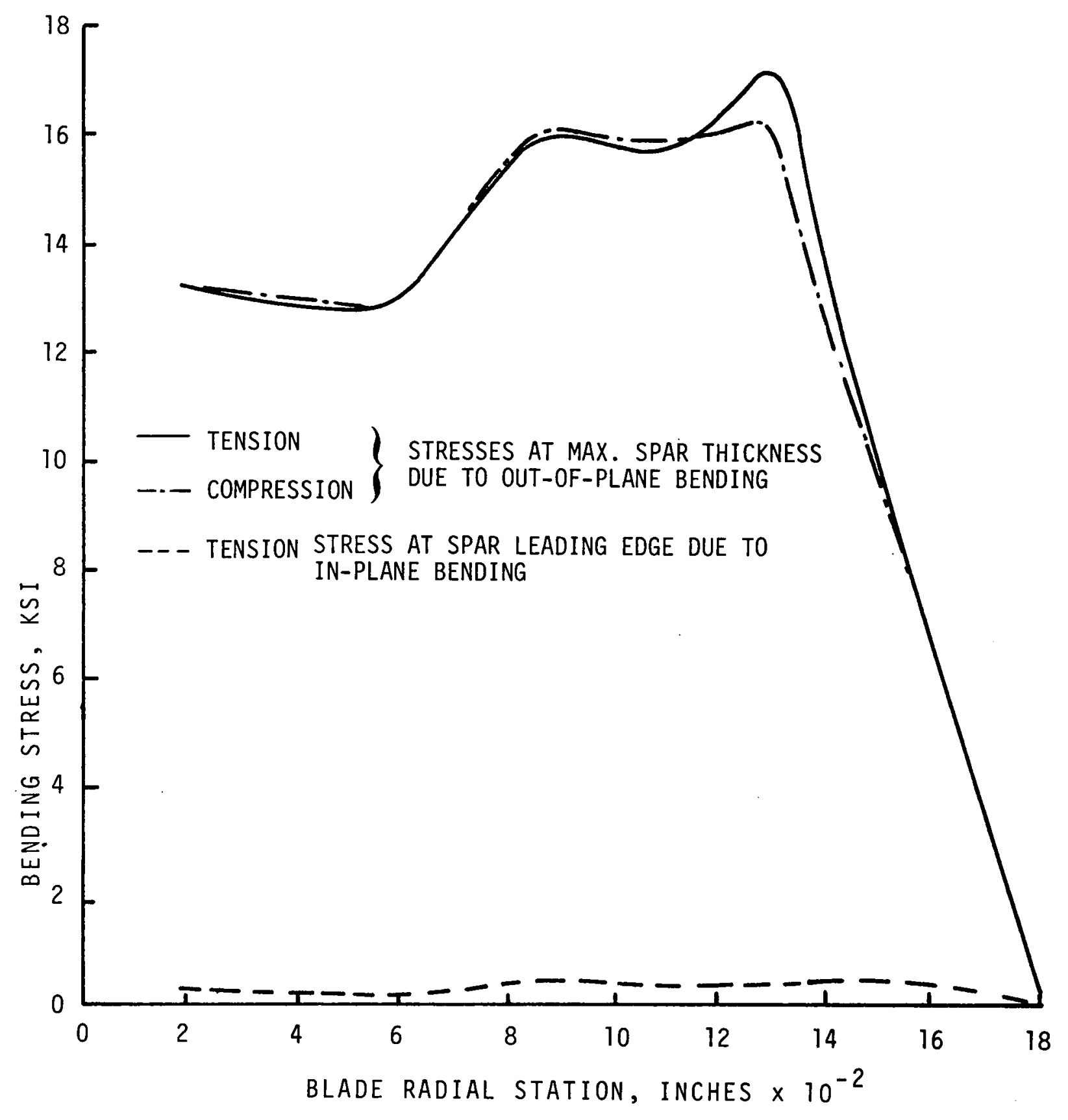

Figure 39. Blade Bending Stress Distribution for Case 5b Static Condition. 

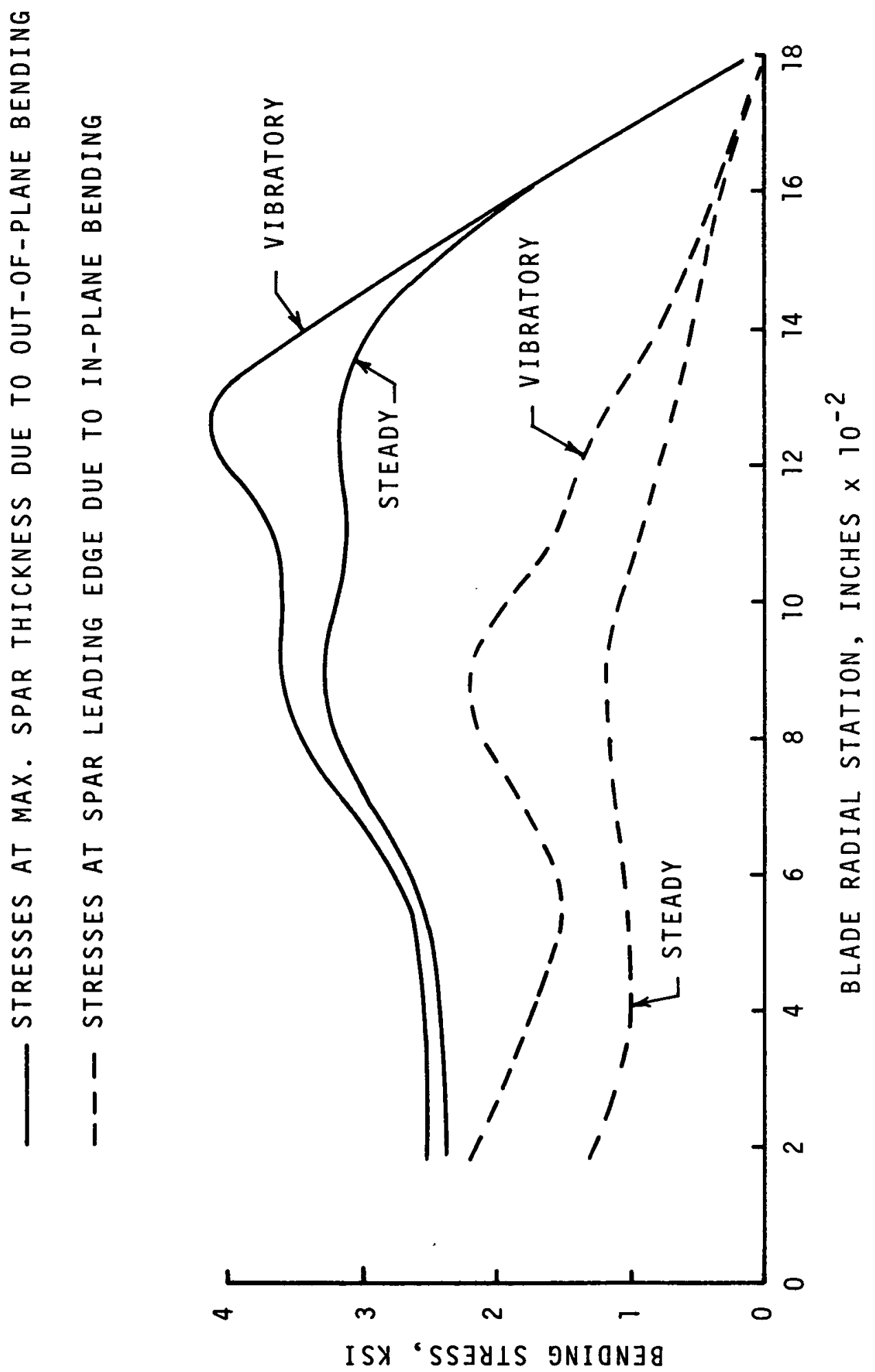

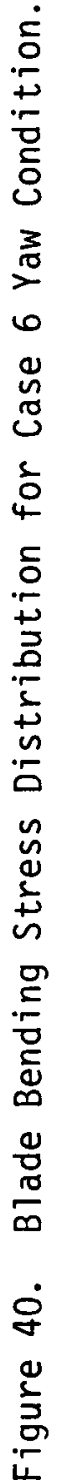




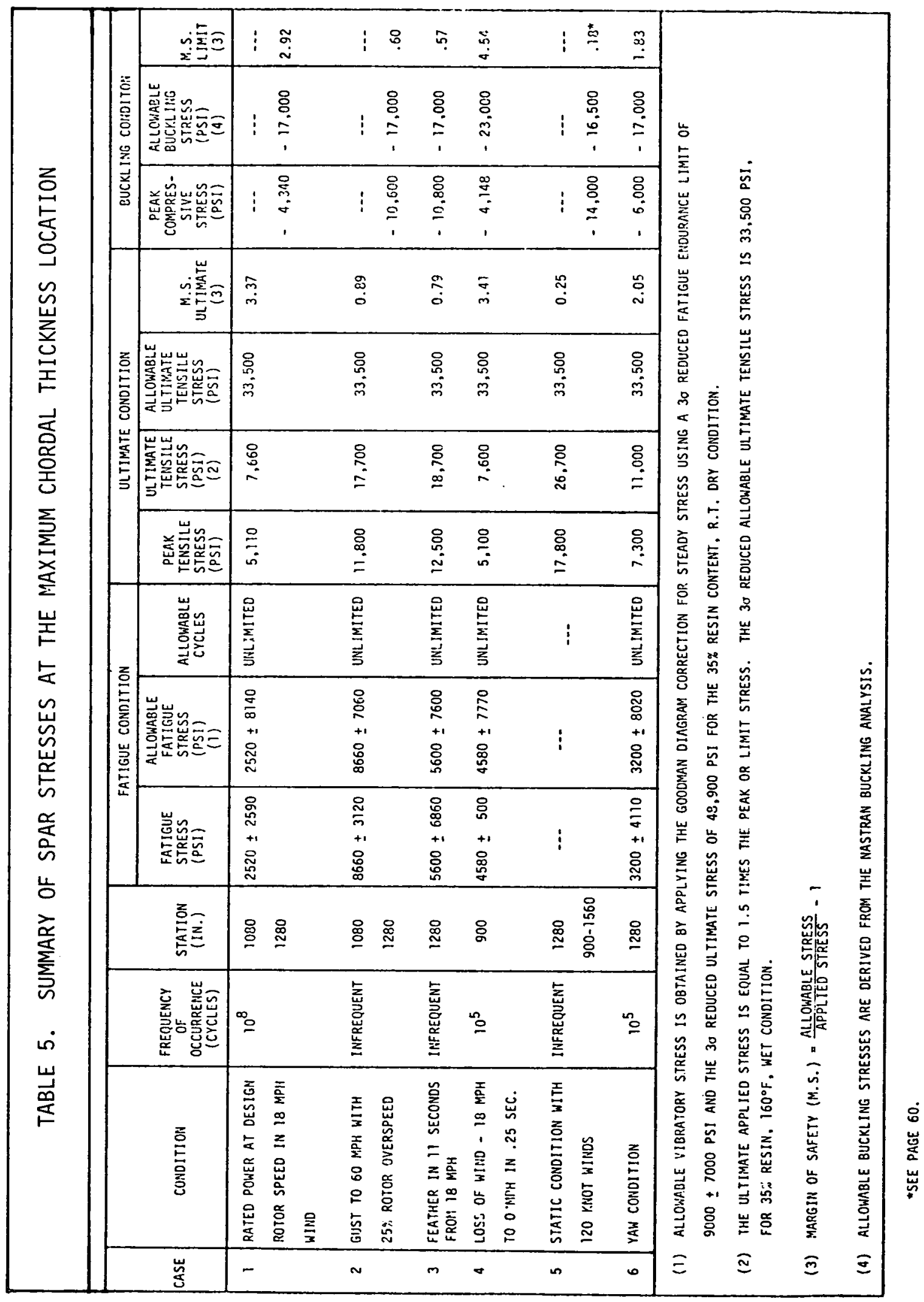





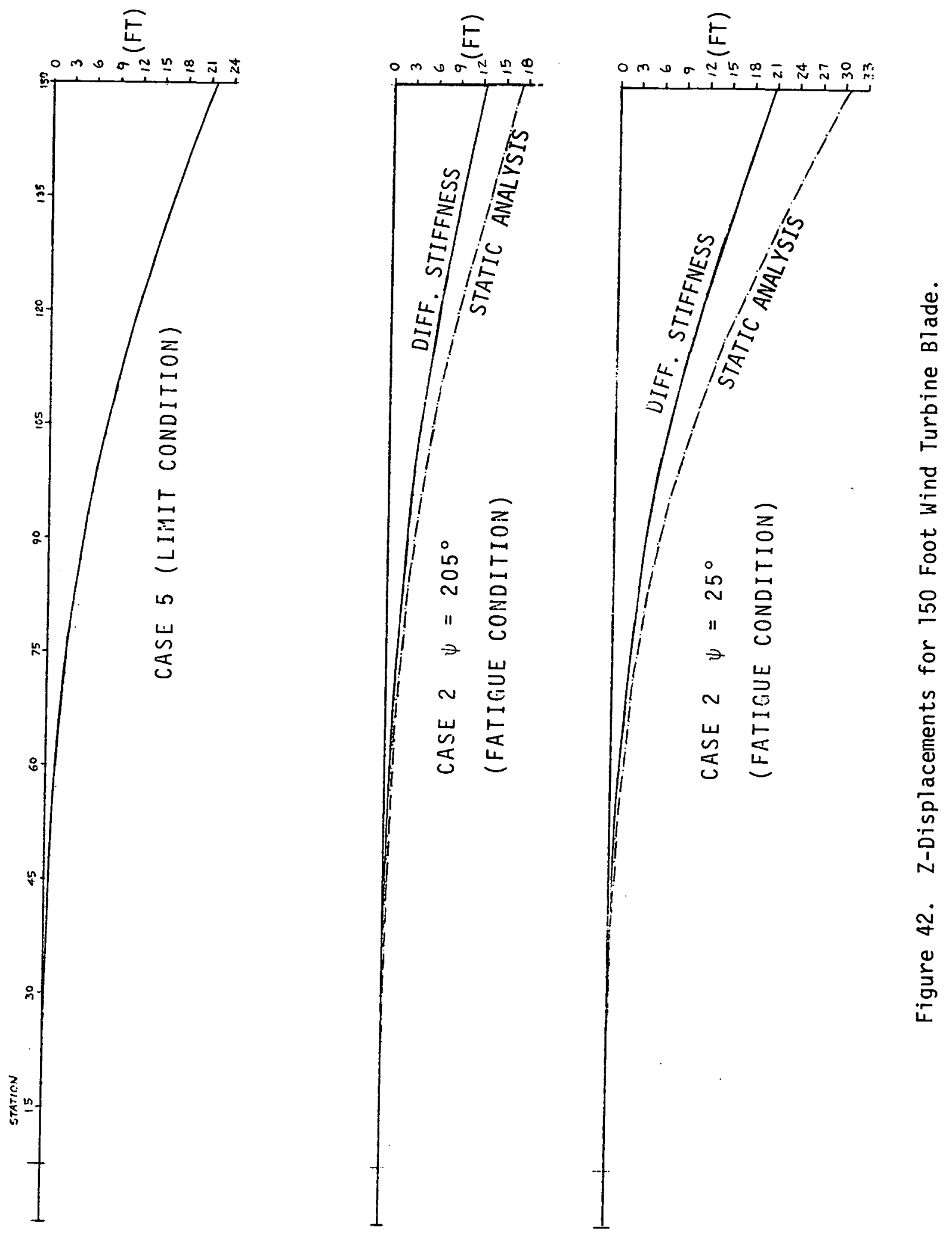
of the TFT material was derived by Kaman to insure proper wall thickness taper and avoidance of placing tape edges in the same chordwise plane in adjacent courses of laminate. This geometry was developed by full scale design layouts, 1/18-scale model tests and subscale winding trials, the latter performed by Structural Composites Industries, Inc.

A spar buckling analysis was performed using a NASTRAN static analysis with differential stiffness which includes the stiffening effect associated with large deflections. The NASTRAN model is shown in Figure 43 and the associated buckling mode shapes are shown in Figure 44. Section properties included the effect of additional wall thickness caused by low compaction forces on the laminate in regions of large radius of curvature, such as the spar upper and lower surfaces. The flatter lower surface of the spar in the region from blade station 75 to 130 feet was critical for buckling under the hurricane wind load plus gravity condition. The initial analys is performed for the spar configuration having a 0.1 inch wall thickness at the blade tip produced negative margins on buckling. Consequently, the spar wall was increased to 1.0 inch at the blade tip, and a modest 18 percent positive margin was predicted as shown for Case 5 in Table 5 . Subsequently, at NASA request, a more refined finite element model was derived which predicted a large positive margin in the critical buckling region for the 1.0 inch thick spar wall at the blade tip. Because the refined model was only 6 feet long, it could not be inferred that the same margin would be applicable to the entire blade. However, it was concluded that the blade analysis was very conservative. The large positive margin indicated by the refined model analysis was later substantiated by a buckling test of the outboard half of the blade, which was loaded up to 280 percent of design 1 imit load without failure.

Structural design of the reinforced root end of the spar was based upon mechanical properties of individual layers of glass fiber, combined according to their fiber orientations to derive predicted mechanical properties of the semiisotropic reinforced laminate. Stresses around bolt holes and along the depth of the laminate were predicted using finite element methods. It was determined that tapered bushings were needed to distribute bolt loads uniformly in the composite, and that very high bolt preloads were required to avoid angular misalignment of bushings due to elastic deflections.

The two-dimensional finite element model of the two-bolt element is shown in Figure 45. Loads and deflections in the composite are shown in Figure 46, and the resulting stress distributions around the perimeter of the holes are shown in Figure 47. The stress gradients in directions radially from the holes are shown in Figure 48.

The two-dimensional finite element model through the thickness of the laminate is shown in Figure 49. This model was used to determine the angular rotation of the bolt/bushing axis with respect to the spar laminate, and resulted in the selection of the taper built into the bushings to achieve a uniform stress distribution through the laminate depth. The linear displacement at the top of the 4-inch bushing due to deflections of the bolt, bushing, and adapter is shown in Figure 50 for each of the 18 bolt locations. A nominal taper was selected for the bushings, based on deflections of the most highly loaded bolts. 

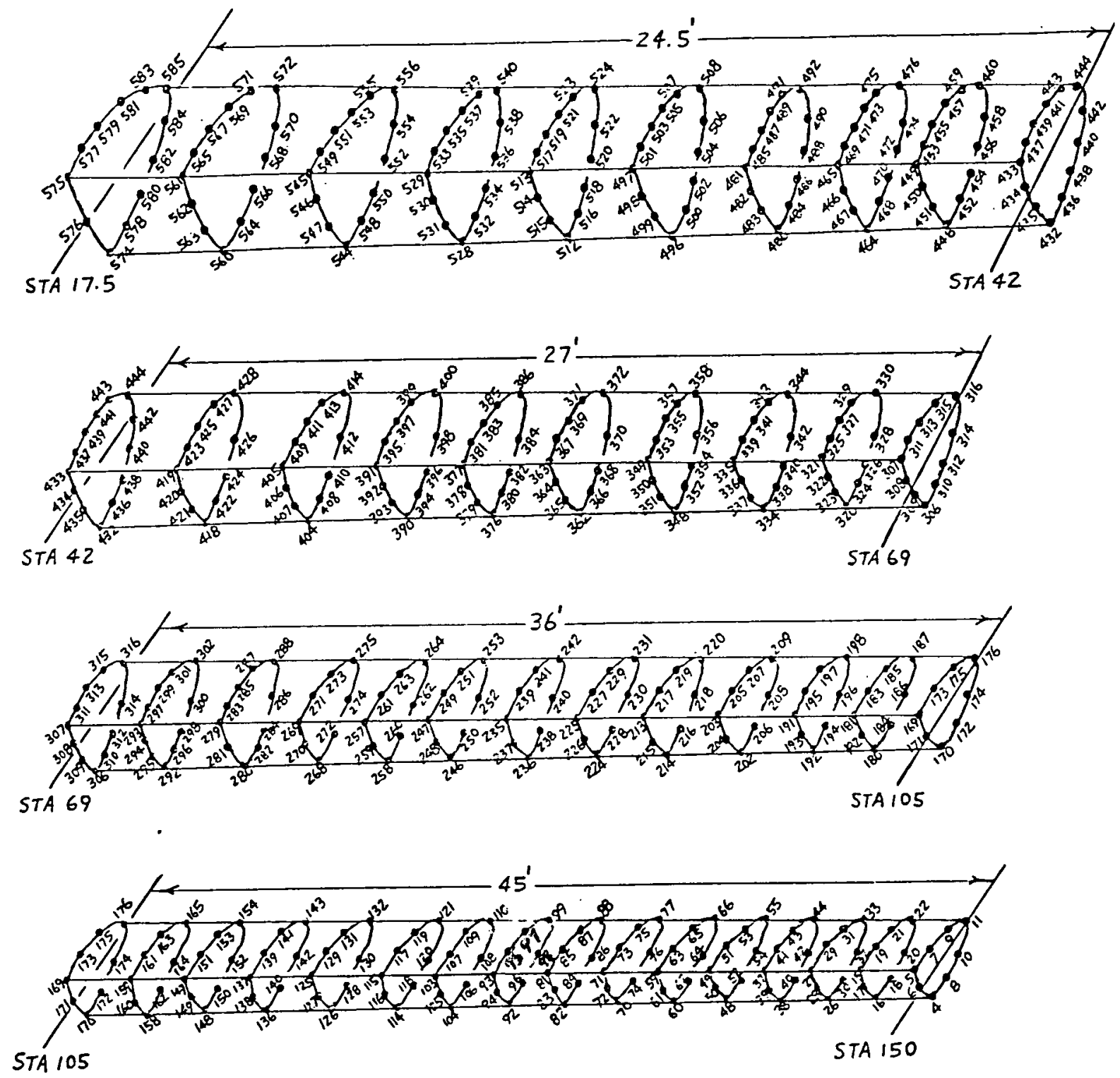

Figure 43. NASTRAN Buckling Model for the Spar of the 150 Foot Wind Turbine Blade. 


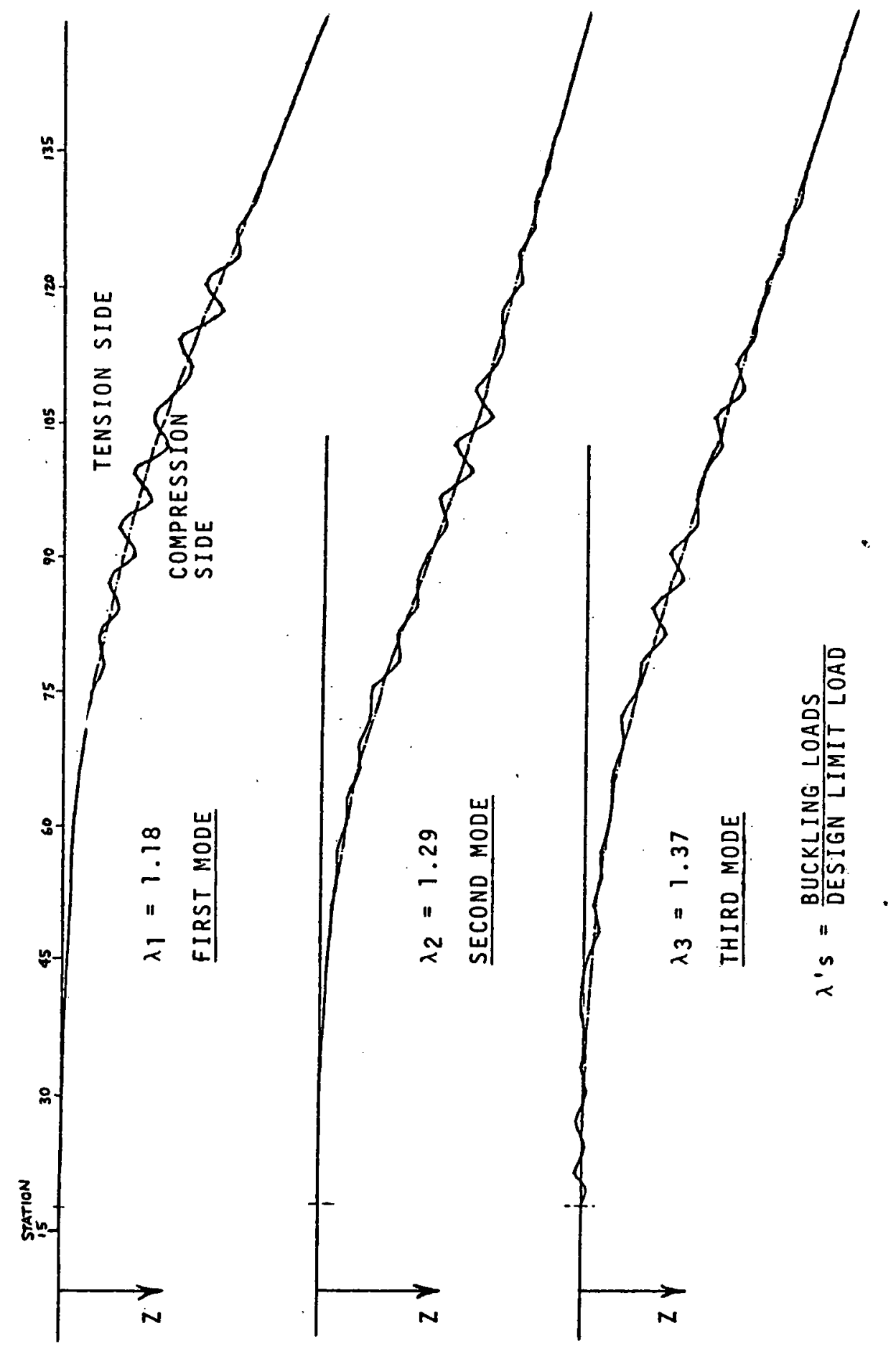

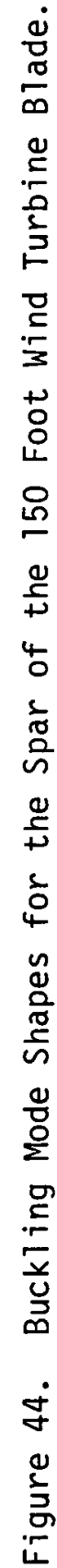



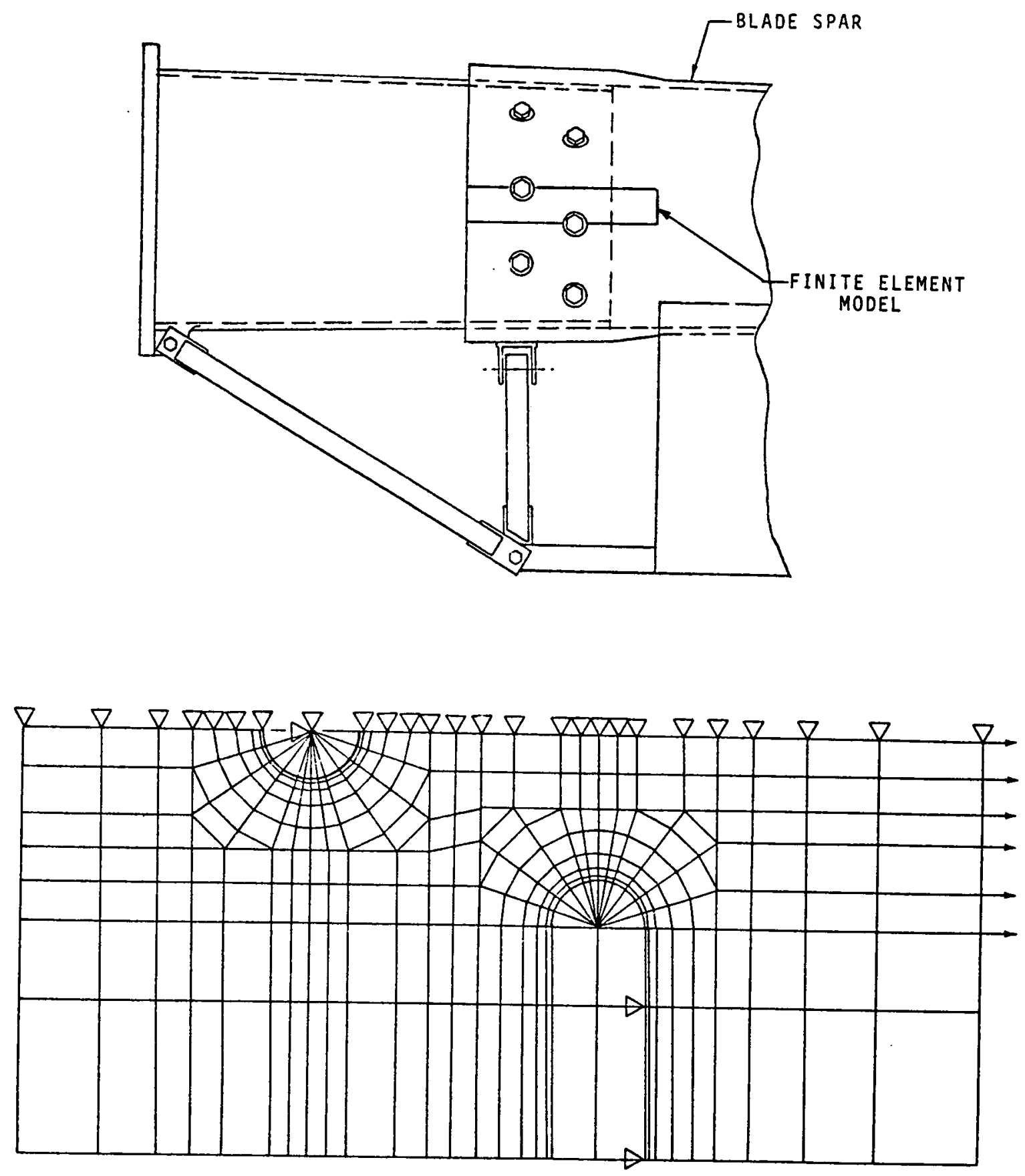

Figure 45. Finite Element Model of Spar Root End Attachment. 


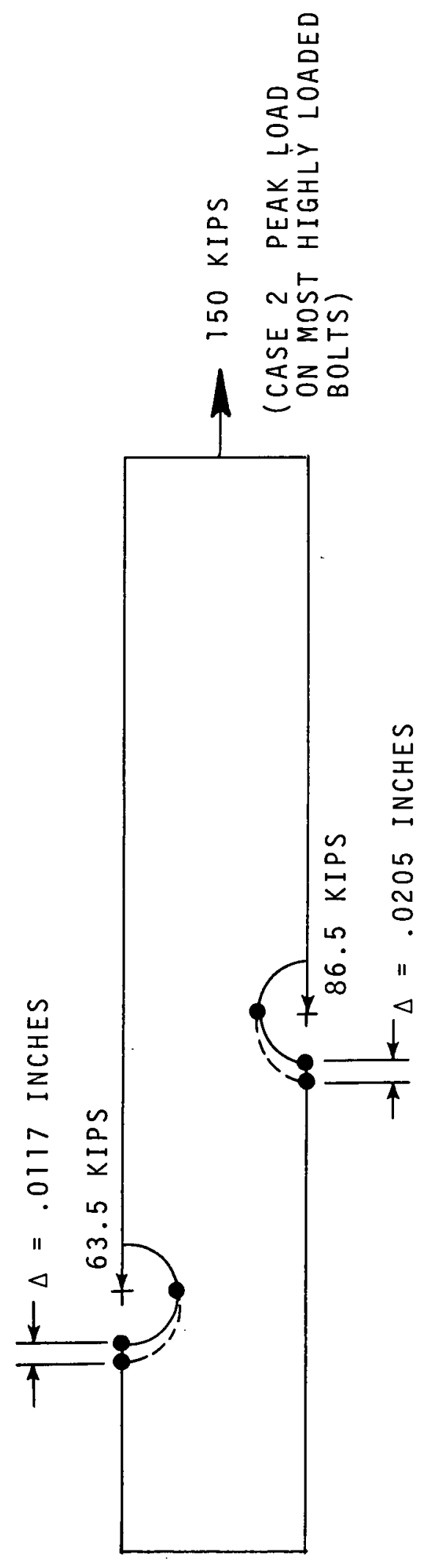

몸

总

ì

E

它的

중

.

ro

능

ज㐫

ธธ

I

耐

$\stackrel{\square}{=}$

닌

눋

오를

$+y$

ㅍ

$\dot{q}$

竞 


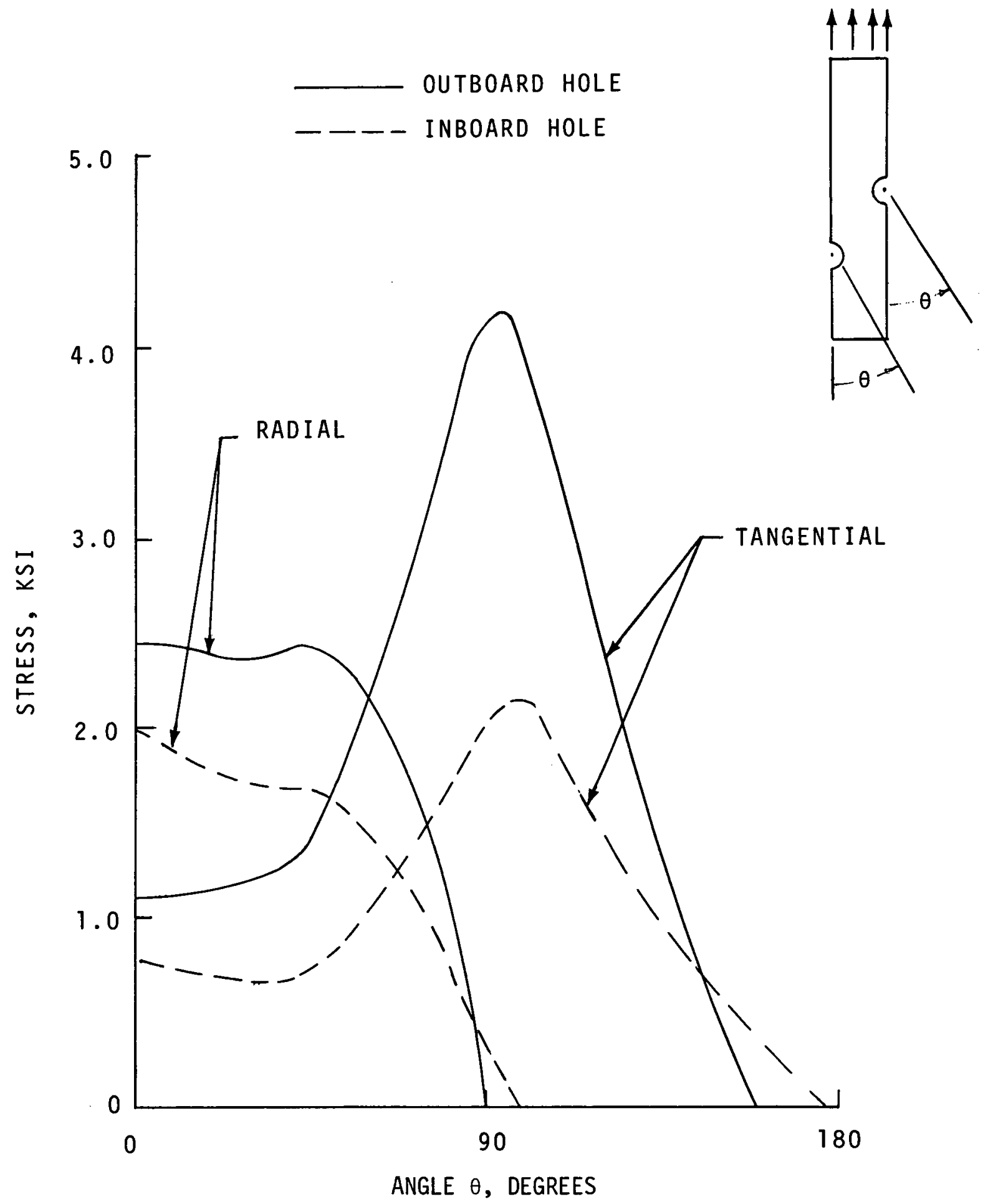

Figure 47. Cyclic Radial Bearing and Tangential Stresses for Case 1 - Normal Fatigue Condition. 


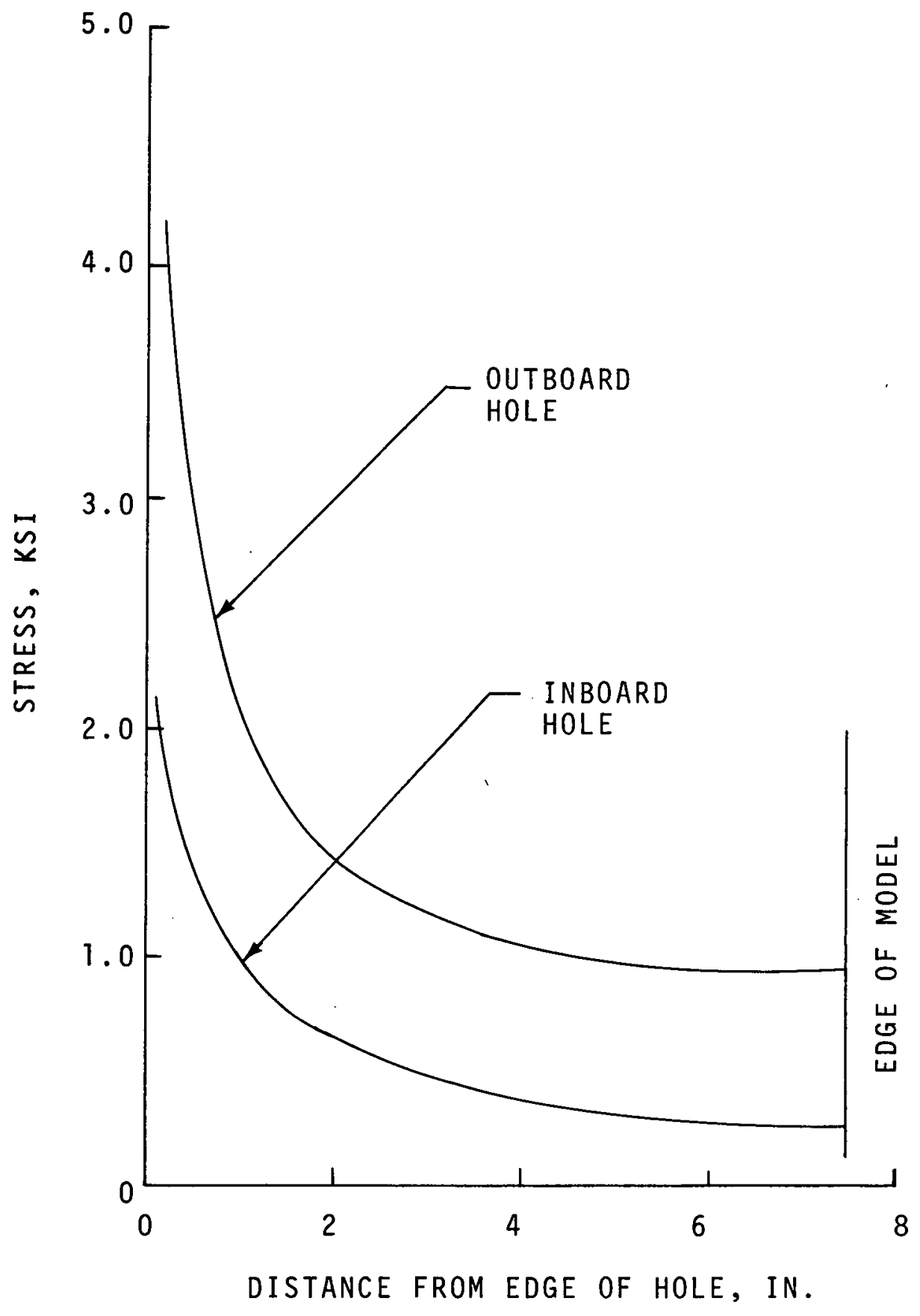

Figure 48. Net Area Cyclic Stress Distribution for Case 1 - Normal Fatigue Condition. 

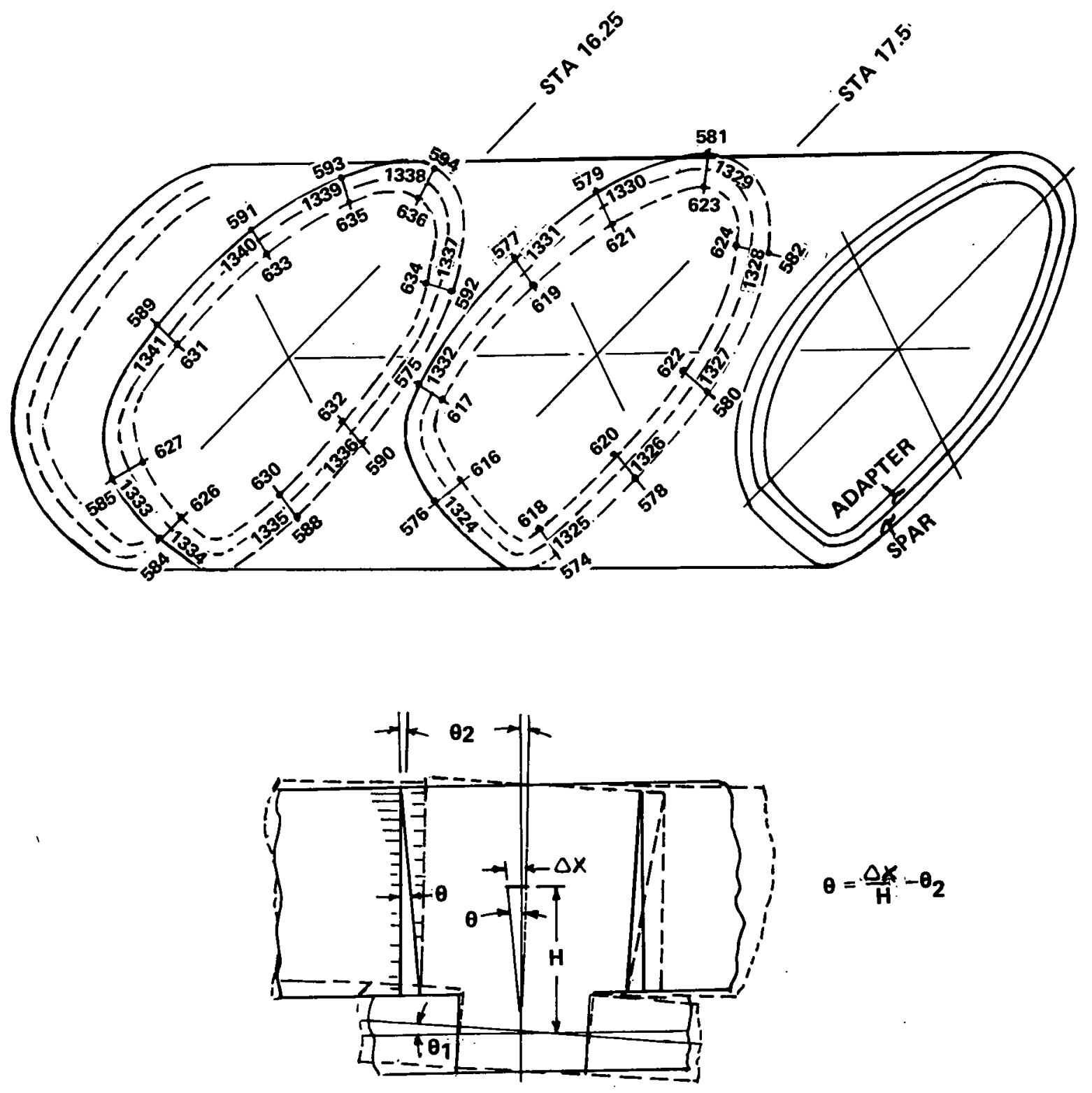

Figure 49. Finite Element Model of Spar-to-Adapter Bolt Joints. 

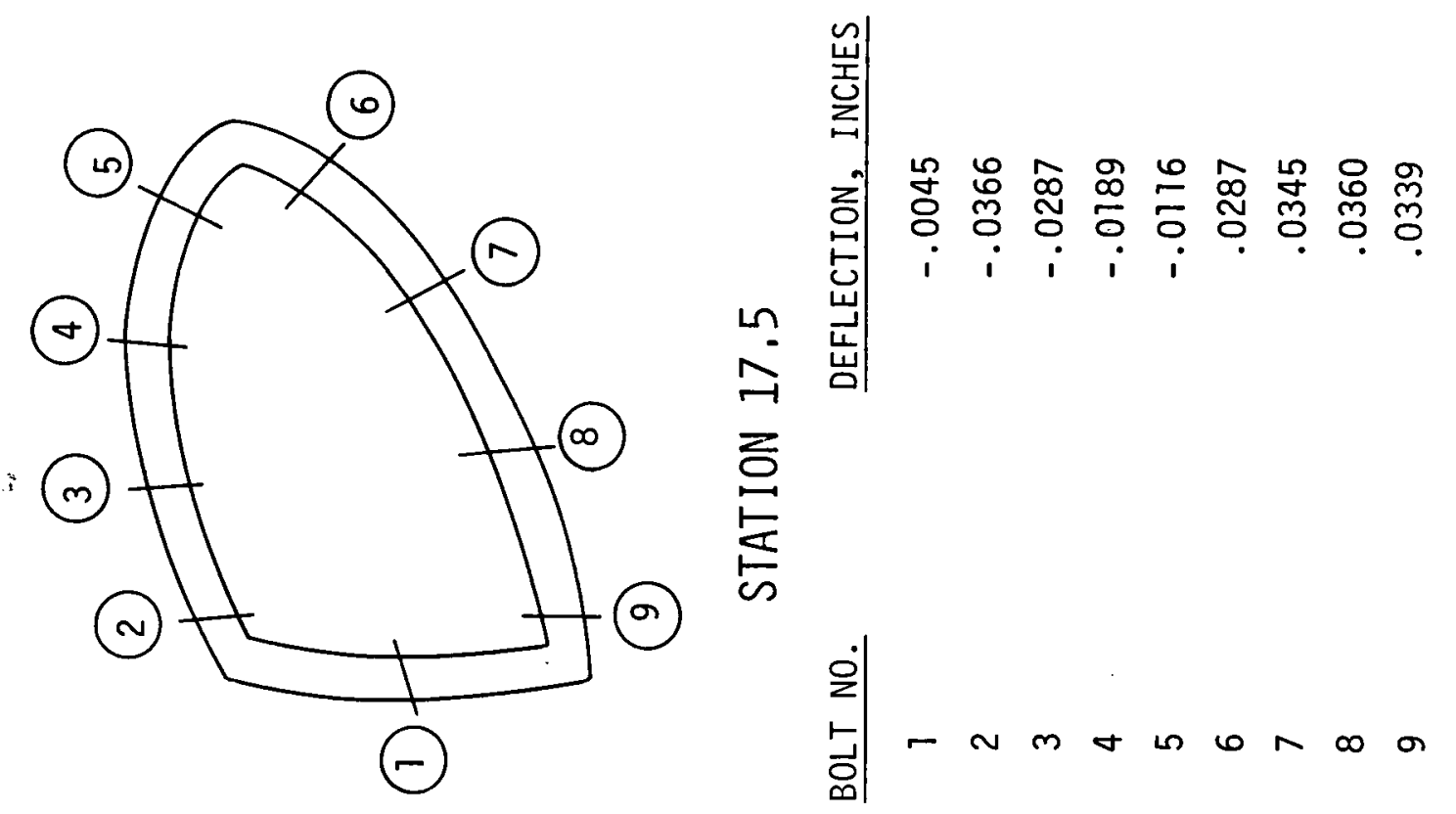

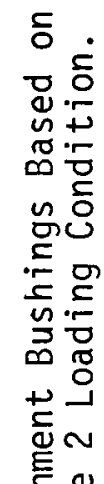
它芯 艺㞱

언 은 n

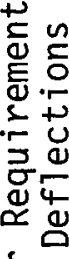
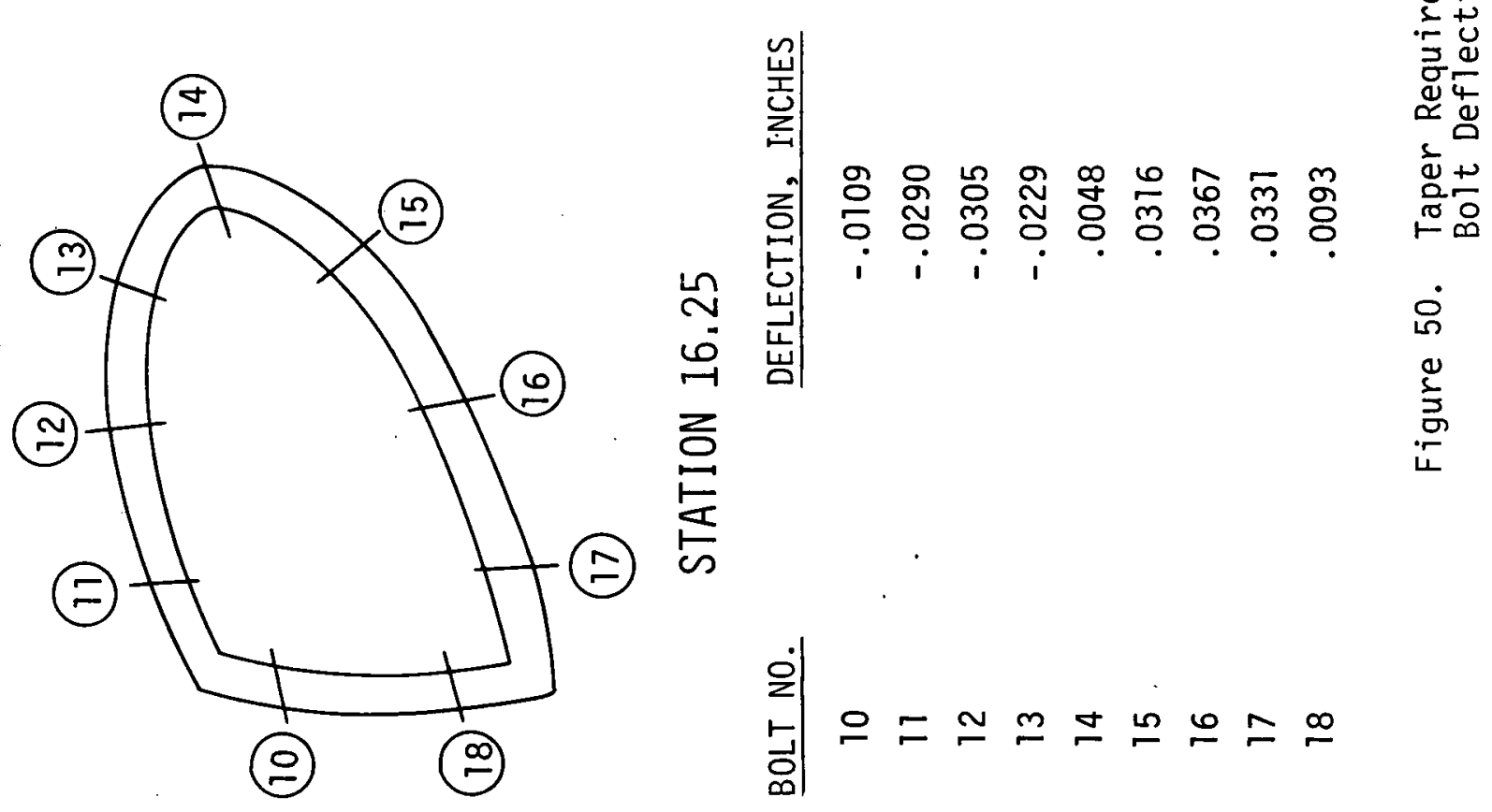
Structural design of the afterbody was based upon predicted airloads which must be carried by afterbody panels bridged between the spar and the their trailing edge attachments. The internal loads are shown in Figure 51. The panels were constructed to carry these airloads as a beam, with the supported inner and outer skins being effective load carrying structures. Concern for the peel strength of the original panel-to-spar joint, shown in Figure 52 , led to a redesign which provides attachment of the inner skin to the spar via a clip bonded to the spar, shown in Figure 53. Syntactic foam was injected into the area between the inner and outer panel skins adjacent to the spar to provide a shear connection between the honeycomb core and the spar. The panel structure was also designed to support the trailing edge spline and provide edgewise stiffness for blade tuning. 



$F_{X}, F_{z}(K I P / I N)$
$M_{X}(I N-K I P / I N)$

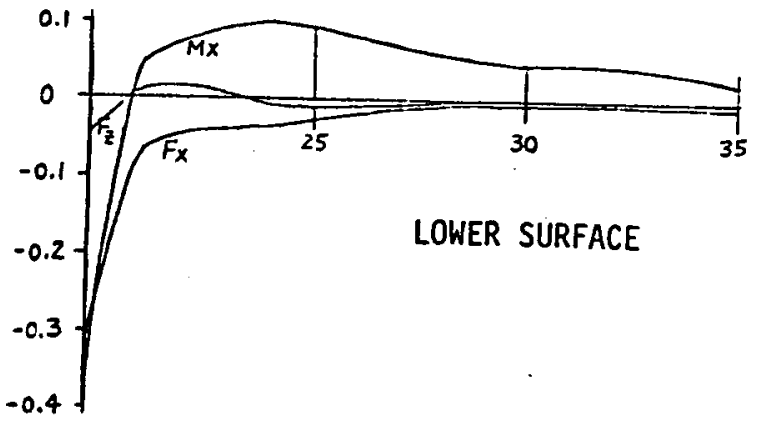

Figure 51. Internal Loads Analysis of Afterbody Panel at Blade Root for Case 5 . 


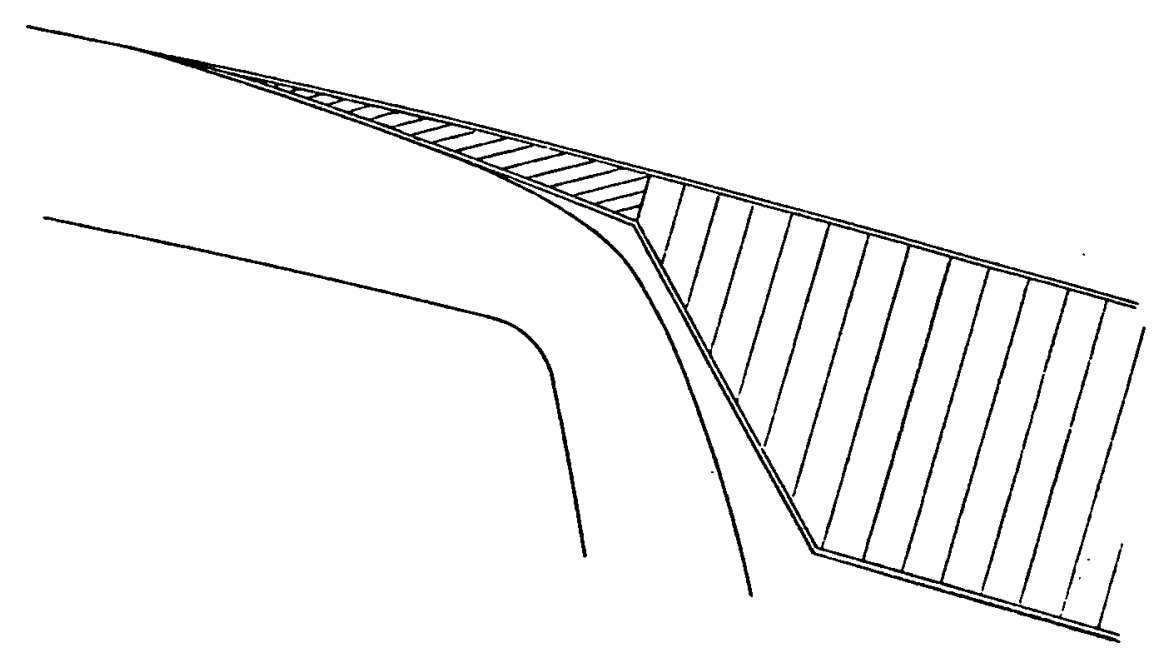

Figure 52. Original Afterbody-to-Spar Attachment.



Figure 53. Final Afterbody-to-Spar Attachment. 


\subsection{TOOLING}

Spar Mandrel

The spar was wound on a low cost steel mandrel, which is a stressed-skin/ stringer design similar to aircraft wing structures, shown schematically in Figure 54. The mandrel was designed by SCI and fabricated by Rettig Machine Company, Redlands, California. Full scale airfoil contours of the spar interior surface were generated by Kaman for 51 spanwise blade stations at which mandrel ribs were located. The interior lines were derived from predicted variations in wall thickness around the perimeter of the spar. Spar wall thickness varies as a function of radius of curvature which affects the laminate compaction force of circumferential windings. Results of subscale winding trials were used as a basis for laminate thickness predictions.

Mandrel ribs were flame-cut from steel plate, using mylar airfoil contours provided, and strung along a central pipe member to establish the twist distribution of the spar. Longitudinal stringers were welded to the ribs for bending stiffness, as shown in Figure 55 . Three-foot wide steel skin panels were wrapped around the mandrel framework and butt-welded to each other and to the ribs, and were plug-welded to the stringers.

The mandrel was simply supported at the ends, and a center steadyrest was provided to limit bending deflections and cyclic stresses. A large bucking ring at the root end facilitated spar extraction. The nearly-completed mandrel is shown in Figure 56, in which the steadyrest can be seen near mid-span. Results of static deflection and fatigue stress analyses are given in Figure 57.

\section{Winding Machine}

A large Kaman company-funded winding machine, illustrated in Figure 58, was designed and built by SCI for use in fabricating the spar for the $150 \mathrm{ft}$ blade. The machine was located in Mira Loma, California, for the $150 \mathrm{ft}$ blade program, but has since been moved to the Kaman plant in Bloomfield, Connecticut, for other wind turbine blade work.

The machine consists of a drive motor and gear train which rotate the mandrel, while simultaneously propelling a tape-and-roving dispensing carriage along a track parallel to the mandrel axis. Government-owned equipment was added to the basic machine to complete its operational utility for winding the spar.

\section{Impregnation Equipment}

Large rolls of TFT were impregnated with resin in a pressurized tank prior to installation on the carriage for spar winding. The tank was equipped to apply aiternate cycles of vacuum and 100 psi pressure to impregnate rolls of TFT immersed in pre-mixed resin. The schedule of vacuum/pressure cycles was determined empirically by impregnating several rolls of TFT before spar winding actually began. A pre-wetting phase was included in the impregnation process, wherein a roll of dry TFT, as recieved from the supplier, was unrolled through a trough containing resin and rerolled onto another spool prior to immersion in 


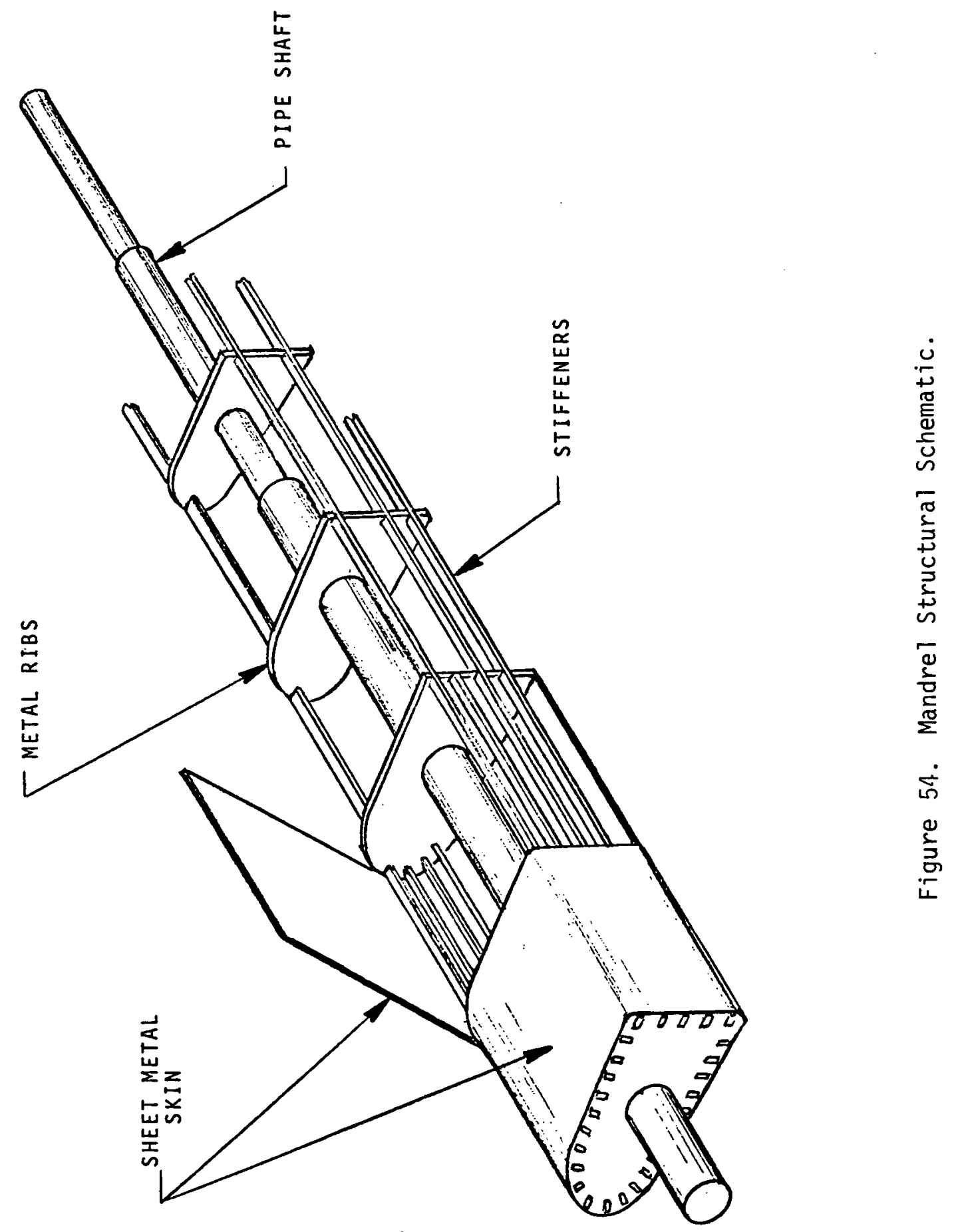




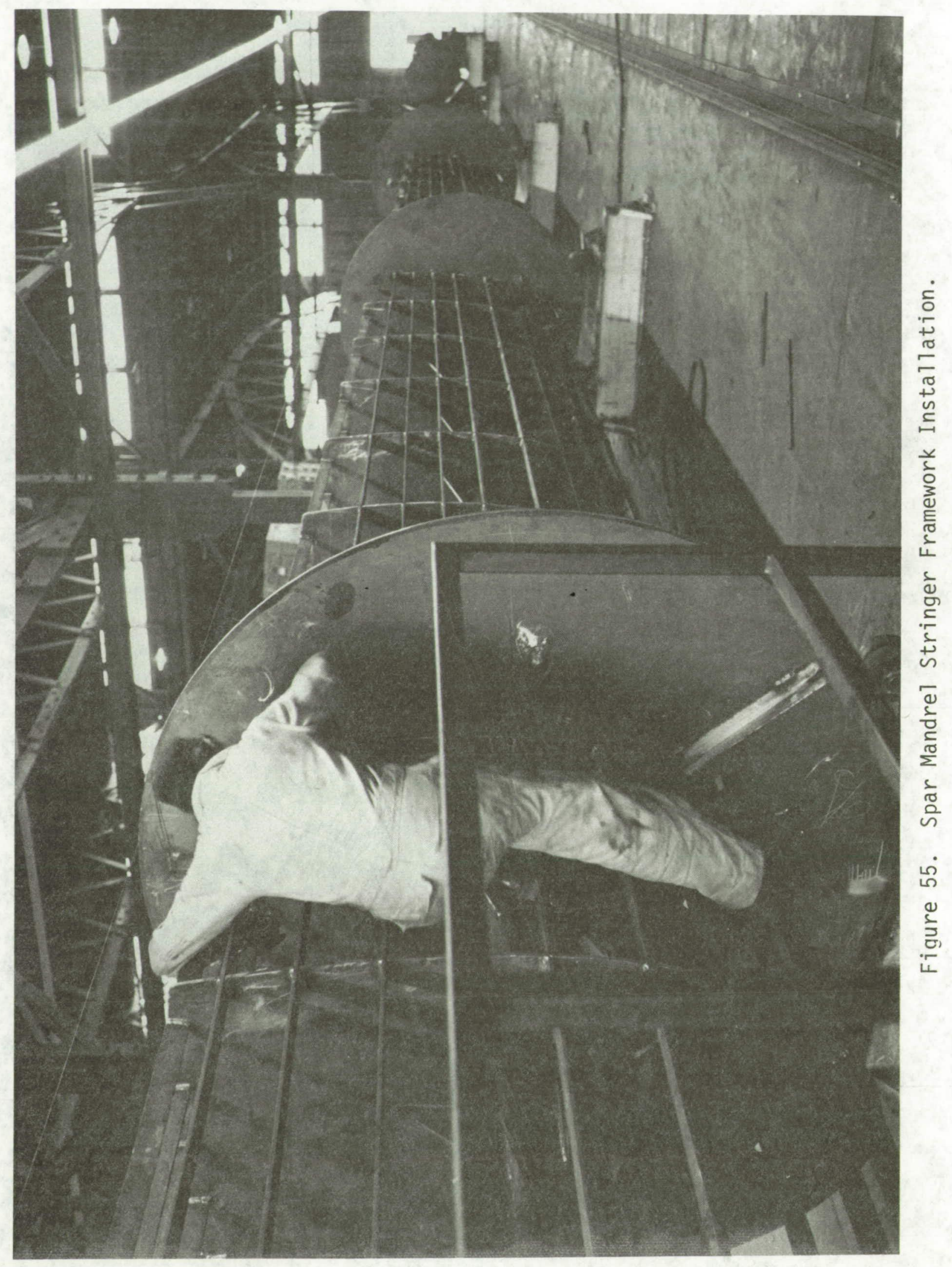




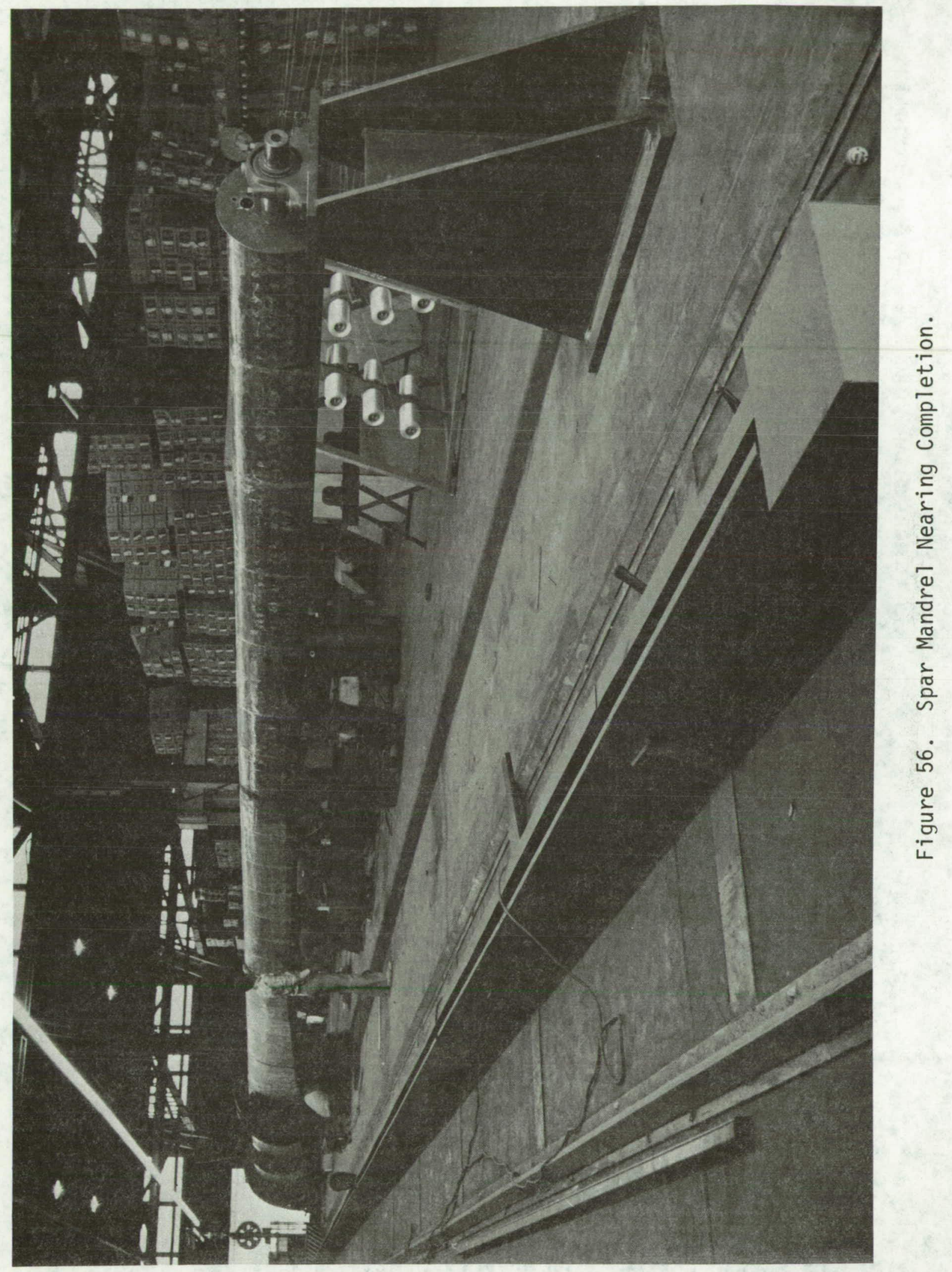





Figure 57. Spar Mandrel Deflection, Shear and Bending Stress Distributions. 





the pressurized tank. This insured that an adequate amount of resin was distributed throughout the roll for the vacuum/pressure cycles which would then force resin into the fiber strands.

Rovings for the circumferential hoop winding were impregnated in the normal manner, through a dip tank on the winding machine carriage. The additional layers of $\pm 45^{\circ}$ material applied at the blade root were impregnated manually.

Curing Oven

A low cost oven was constructed to cure the blade spar after winding. The oven consisted of four twenty-foot portable sections made with a unistrut framework and asbestos cement board panels. Additional fiberglass insulation was applied to the inside of the oven to reduce heat loss through the oven walls. Heat was provided by two Unimatic 600 diesel-fired space heaters, each capable of delivering 450,000 BTU per hour. Oven temperatures were $180^{\circ} \mathrm{F}$ minimum, and reached $280^{\circ} \mathrm{F}$ near the heater outlet ducts which were aimed to avoid direct impingement of hot air on the spar. Temperature of the composite was maintained between $180^{\circ} \mathrm{F}$ and $240^{\circ} \mathrm{F}$ during cure. This was monitored by means of thermocouples embedded in the spar wall.

Afterbody Panel Fixture

Investigation of blade section contours of the $230 \times x$-series airfoil aft of the spar revealed that upper and lower surfaces have the same chordwise curvature. Further comparisons of the curvature of inboard and outboard sections showed only minor differences between afterbody panels from root to tip. These findings led to the conclusion that the fixture shown in Figure 59, having a nominal curvature for the mid-span location, could be used for all afterbody panels for the $150 \mathrm{ft}$ blade. Provisions were made to adjust the twist angle of the fixture to accommodate the different twist angles of the upper and lower panels.

Afterbody panels were laid up on the fixture in a clean room, and the fixture was then wheeled into an autoclave for curing. Afterbody panel and fixture sizes were governed by autoclave dimensions.

Blade Assembly Fixture

The blade assembly fixture was a simple plywood and steel structure fabricated to support the spar, afterbody panels and trailing edge spline in their proper orientations for bonding, and to provide the necessary reactions for bonding pressures. Plywood headers were optically aligned along the shop floor to position the spar and afterbody panels for assembly. An array of steel beams above and below the blade provided the reaction for pneumatic hoses which applied pressure to the afterbody panel-to-spar bondlines. Mechanical clamping pressure was used for trailing edge bondlines.

A Bridgeport vertical milling machine was mounted directly on the hub adapter to avoid the expense of constructing a separate tool to bore holes in the spar and steel hub adapter for the attachment bolts. A support fixture welded to 


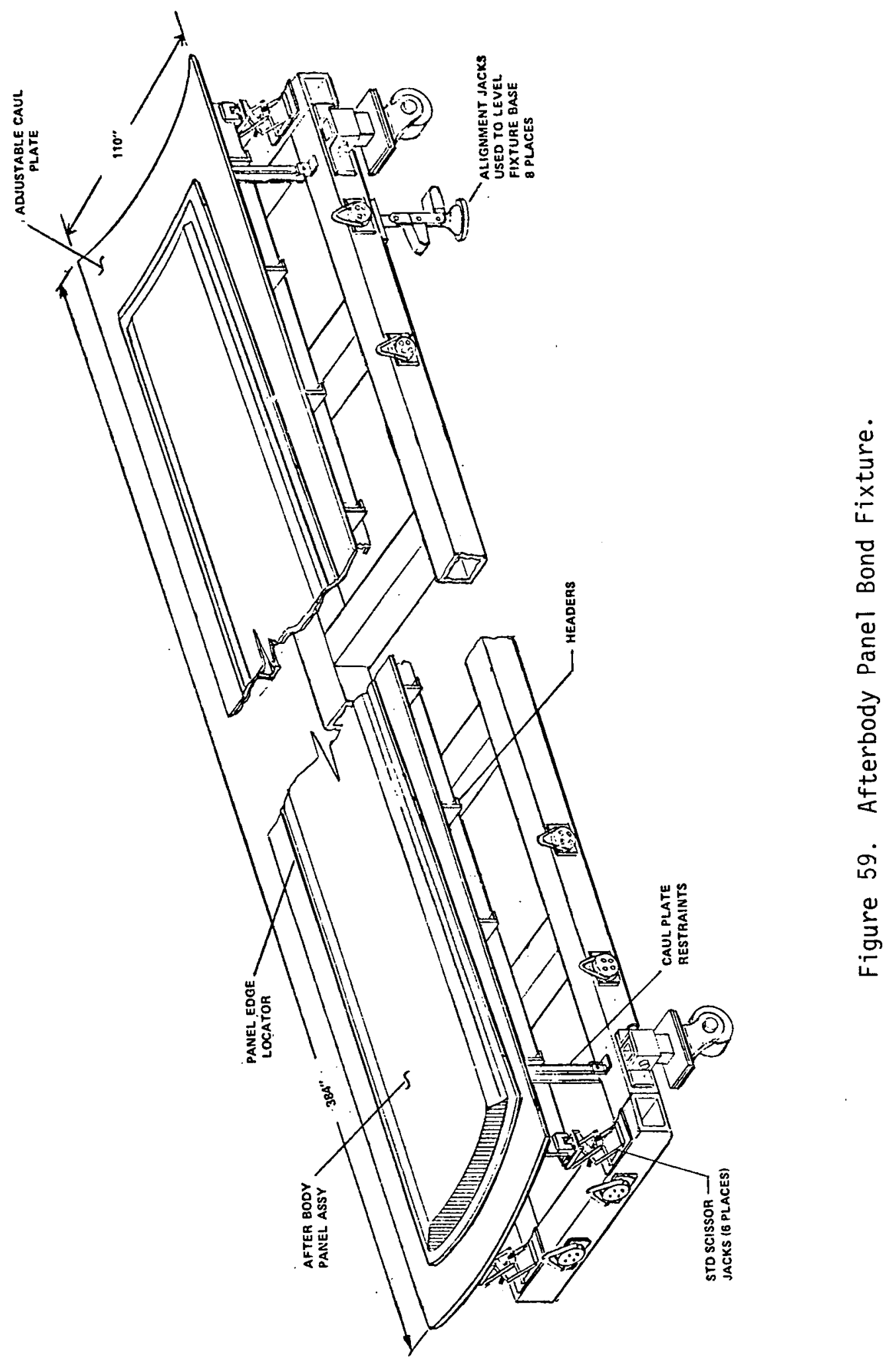


the adapter was successively repositioned around the spar to drill all 18 holes. It was required that a single machine setup for each hole be maintained for all cutting operations on that hole to insure dimensional control of critical tolerances. For this program, it was considered acceptable to weld the milling machine supporting structure directly to the steel adapter because the adapter was not a critical part of the blade, and was overdesigned to preclude test failures. The supports were removed and the adapter surface was ground smooth after the adapter installation was complete. 


\subsection{BLADE FABRICATION}

Spar

The spar for the $150 \mathrm{ft}$ blade was wound by SCI in four stages, as shown in Figure 60 , with a complete cure cycle after each stage.

In stage one, the inboard half of the spar from the root to the mandrel steadyrest was wound to one-half inch thickness and cured. The steadyrest was moved. inboard over the cured laminate and, in stage two, the outboard half of the spar from the steadyrest to the blade tip was wound to one-half inch thickness and cured. The outboard shell overlapped the inboard shell with a five-foot scarf joint.

The intermediate step of winding and curing the half-inch spar wall was used in the winding process to insure that the mandrel could be removed after the spar was completed. Mandrel extraction after stage two was attempted by direct force application at the blade root. A force of approximately 300,000 pounds was applied at the root end (estimated via torque applied to bolts around the bucking ring), which was the maximum force that could be applied with existing equipment. It was not possible to effect mandrel extraction at this force level, so a pre-planned backup extraction procedure was implemented. This consisted of slitting the aft vertical web of the half-inch shell and prying the shell away from the mandrel, as illustrated in Figure 61 . The axial force at the root end was maintained as the shell was slit and pried open from the tip toward the blade root. When the slit had been extended inboard to station 55, the spar shell became loose, so further slitting was avoided. The aft web of the spar shell was repaired with a fiberglass wet layup, as illustrated in Figure 62, and cured. Finally, in stages three and four, the inboard and the outboard lengths of spar were wound to full wall thickness which included a ten-foot scarf joint. Mandrel extraction, following completion of step four, was readily effected. Typical views of the spar winding operation are shown in Figures 63 and 64.

Local reinforcement was applied at the root end of the spar to provide additional structure for the bolt area. Fiberglass tape having $\pm 45^{\circ}$ bias was interleaved between courses of TFT and hoop rovings, and wet $\bar{t} e d$ manually with resin.

Overwrap layers of peel ply cloth, perforated Teflon film and dry hoop rovings were applied to the spar surface at each step before curing, to extract surplus resin from the laminate and to maintain a clean surface for subsequent winding or bonding operations. The final overwrap was left on the spar for protection during handling and rail shipment.

\section{Afterbody Panels}

The afterbody panels were fabricated at the Kaman facility on a sinale fixture adjusted to the required twist angle for each panel. Pre-impregnated glass skins, doublers, honeycomb core, and adhesives were cut, dry-fitted, and then 




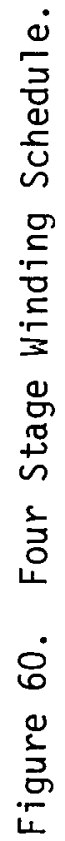




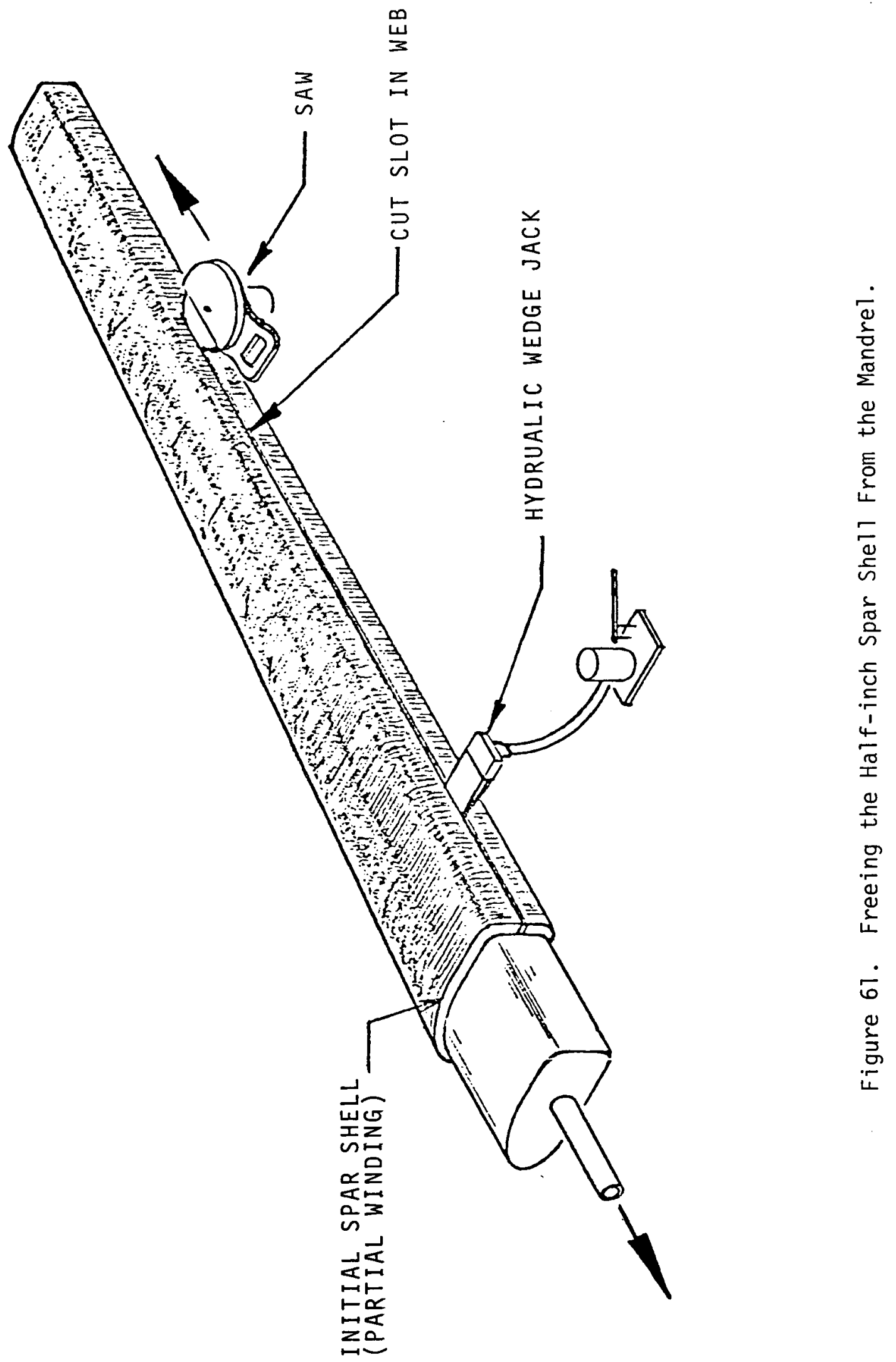




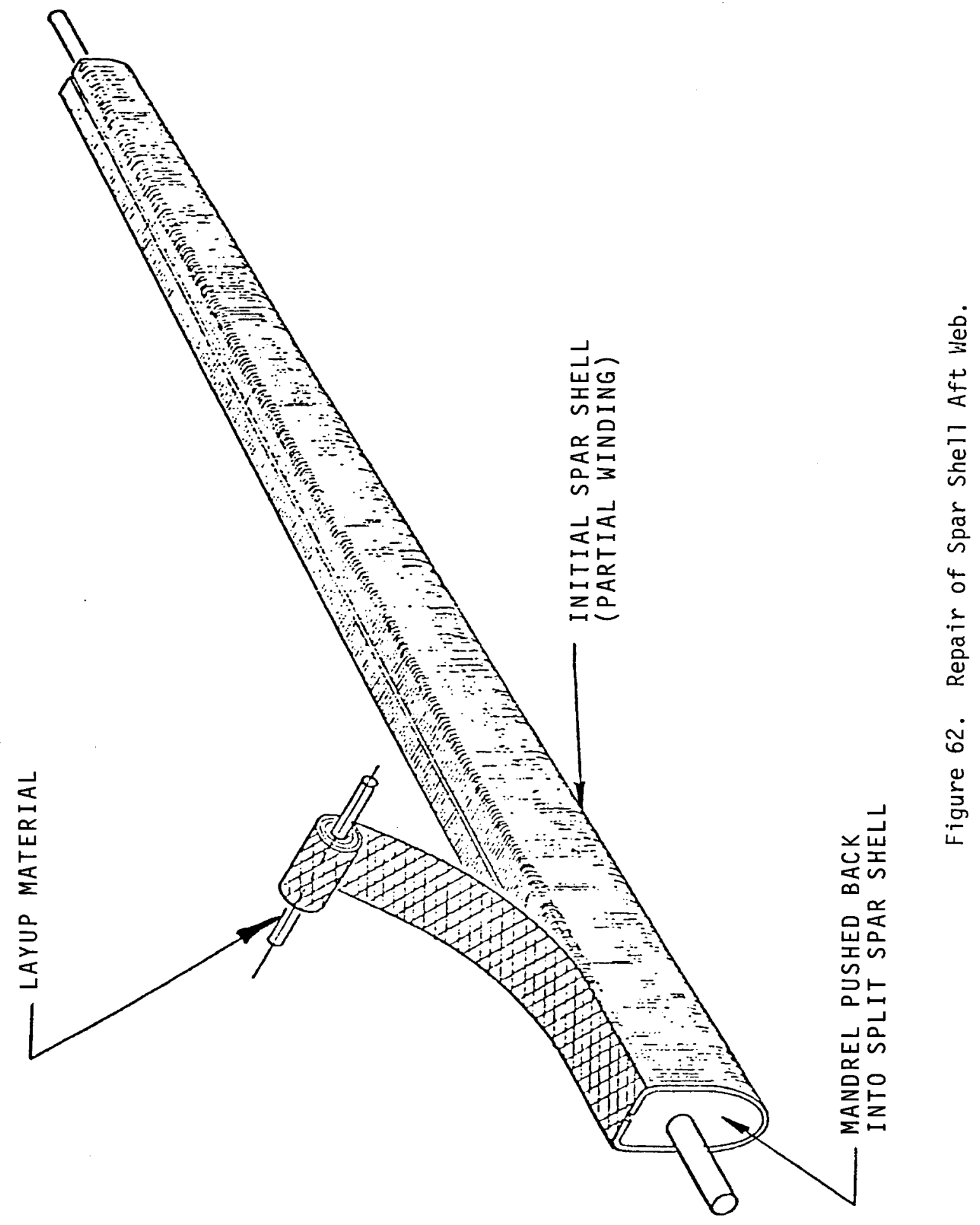









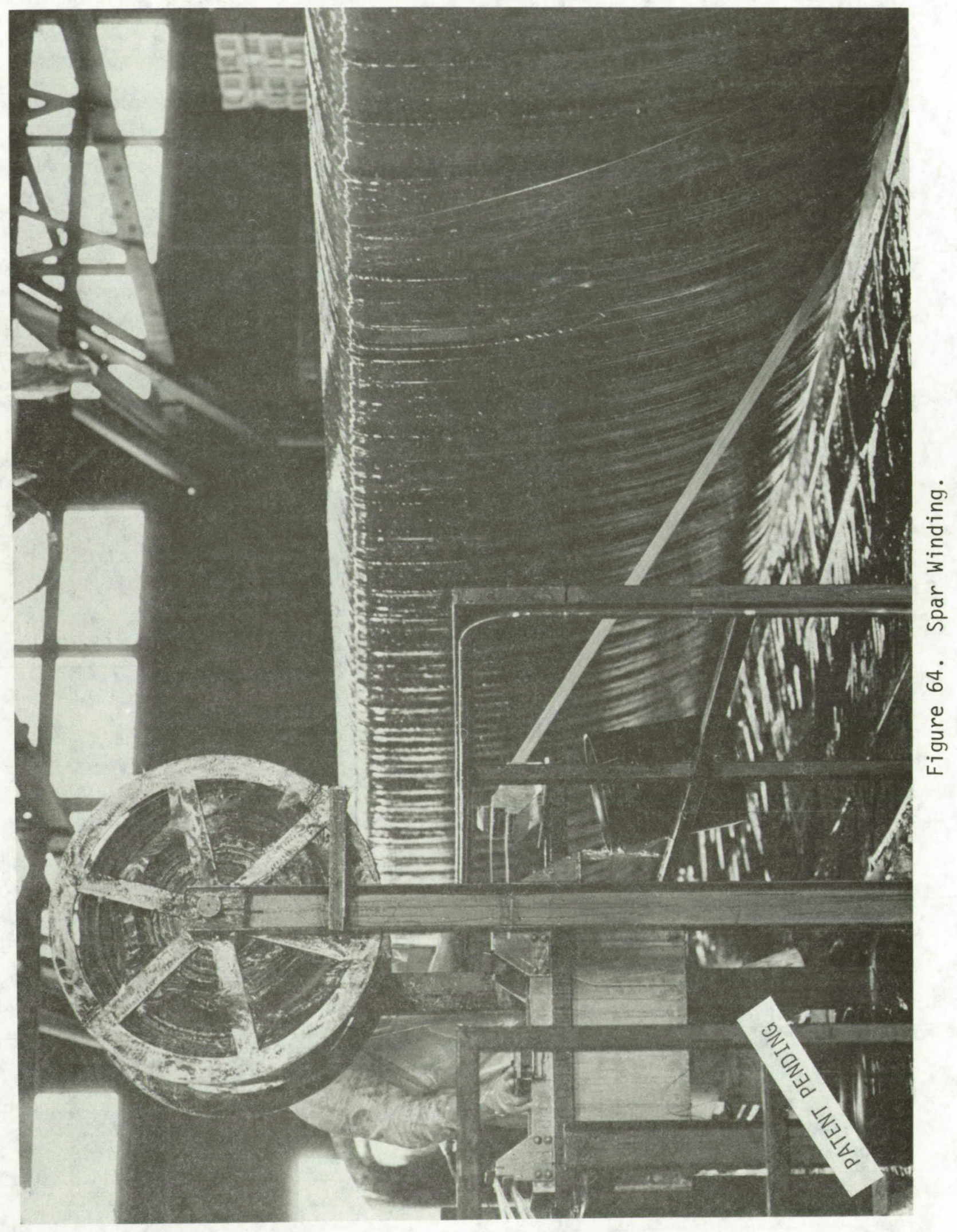


assembled for bonding, as shown in Figure 65. The assembly was vacuum bagged and cured in an autoclave at $250^{\circ} \mathrm{F}$ for two hours. The finished panel after autoclave cure is shown in Figure 66.

Trailing Edge Spline

The trailing edge spline was made from $1 \times 6$ inch commercially available planks of E-glass/polyester pultrusions bonded together and shaped to the required trailing edge angles. Chordwise cuts were made in the spline block, excess material was chipped away, and the final surface was ground to the proper contour. Although labor-intensive, this technique was selected for the prototype $150 \mathrm{ft}$ blade to avoid tooling costs of a molded spline suitable for a production run. Fiberglass doublers and steel cheek plates were bonded and bolted to the inboard end of the spline for attachment to the root end truss.

\section{Hub Adapter and Truss}

The hub adapter was made from rolled steel plate, 1-1/2 inches thick, welded together in three-foot sections. Each section was made up of elements welded spanwise to form the D-spar shape. Full penetration welds were required at all locations. The adapter was not stress-relieved after welding. The outboard section of the adapter was tapered to fit into the tapered spar cavity. The flange designed for the inboard end was deleted for the test program to facilitate attachment to the test fixture. The adapter was pre-drilled and spotfaced as a detail part.

The adapter was structurally representative of an operational configuration in the important region of the spar-to-adapter connection. Plate stiffnesses, machining tolerances, hardware details (bolts, bushings), and assembly procedures were those representative of an operational wind turbine blade.

The root end truss was a pin-ended tripod that provided a rigid hard-point for transferring axial trailing edge spline loads into the root end adapter. The truss was made of tubular members with plates welded to the ends for pin connections. Welding was done at assembly to achieve proper alignment.

\section{Blade Assembly}

The spar was set up on its trailing edge web for installation of the hub adapter. The adapter was inserted into the spar and pilot holes were drilled from inside out through the composite spar using pre-drilled holes in the adapter as guides. One-inch bolts were inserted to hold the adapter in place while the full size holes were machined in the spar from the outside using the tooling setup shown in Figure 67. A single setup was employed for all machining on each hole, which included boring the hole in the composite, increasing the size of the pilot hole in the steel adapter, and spotfacing both sides of the adapter plate. This procedure insured achievement of tolerance control required for the single shear spar-to-adapter connection. 


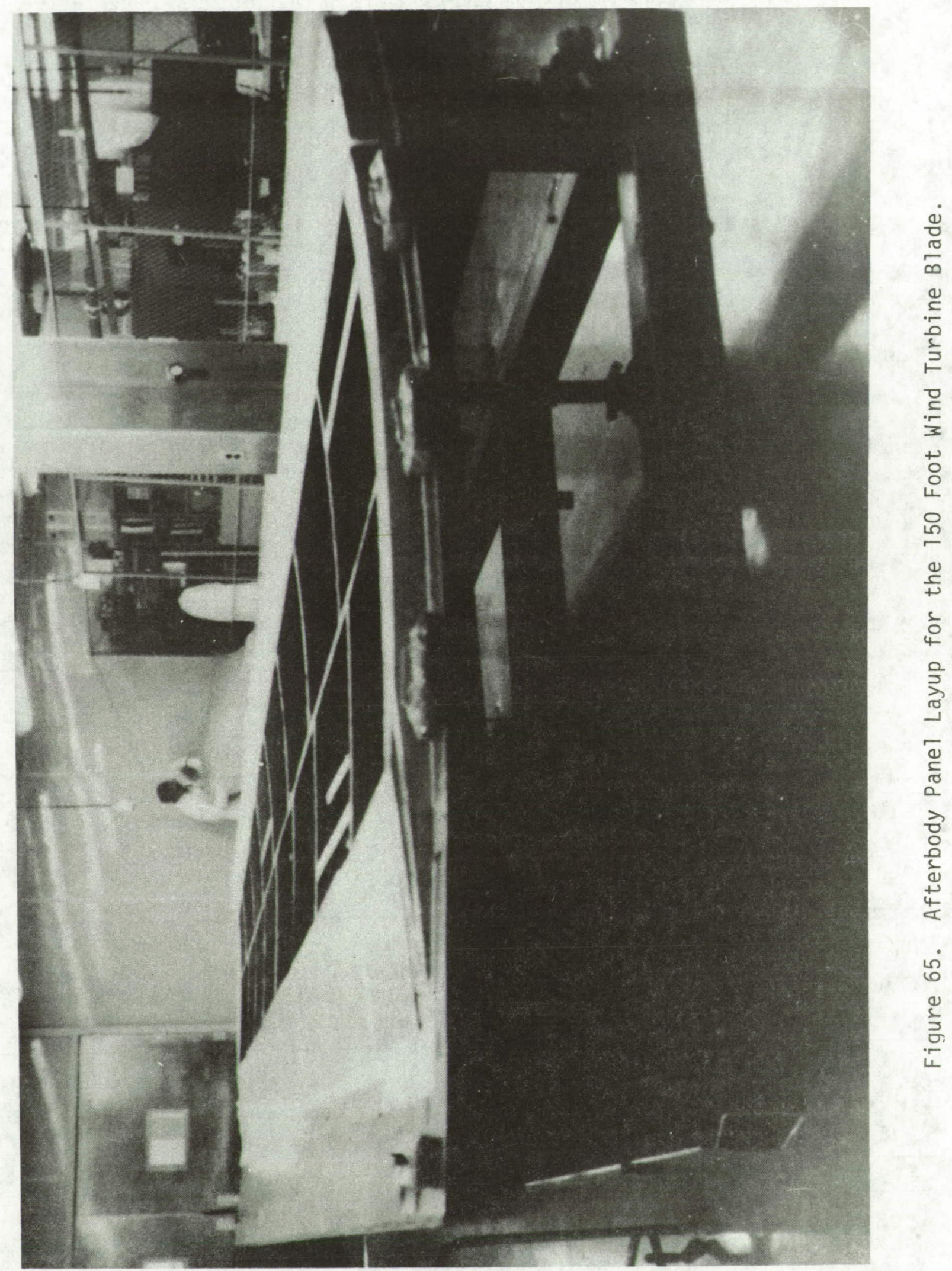




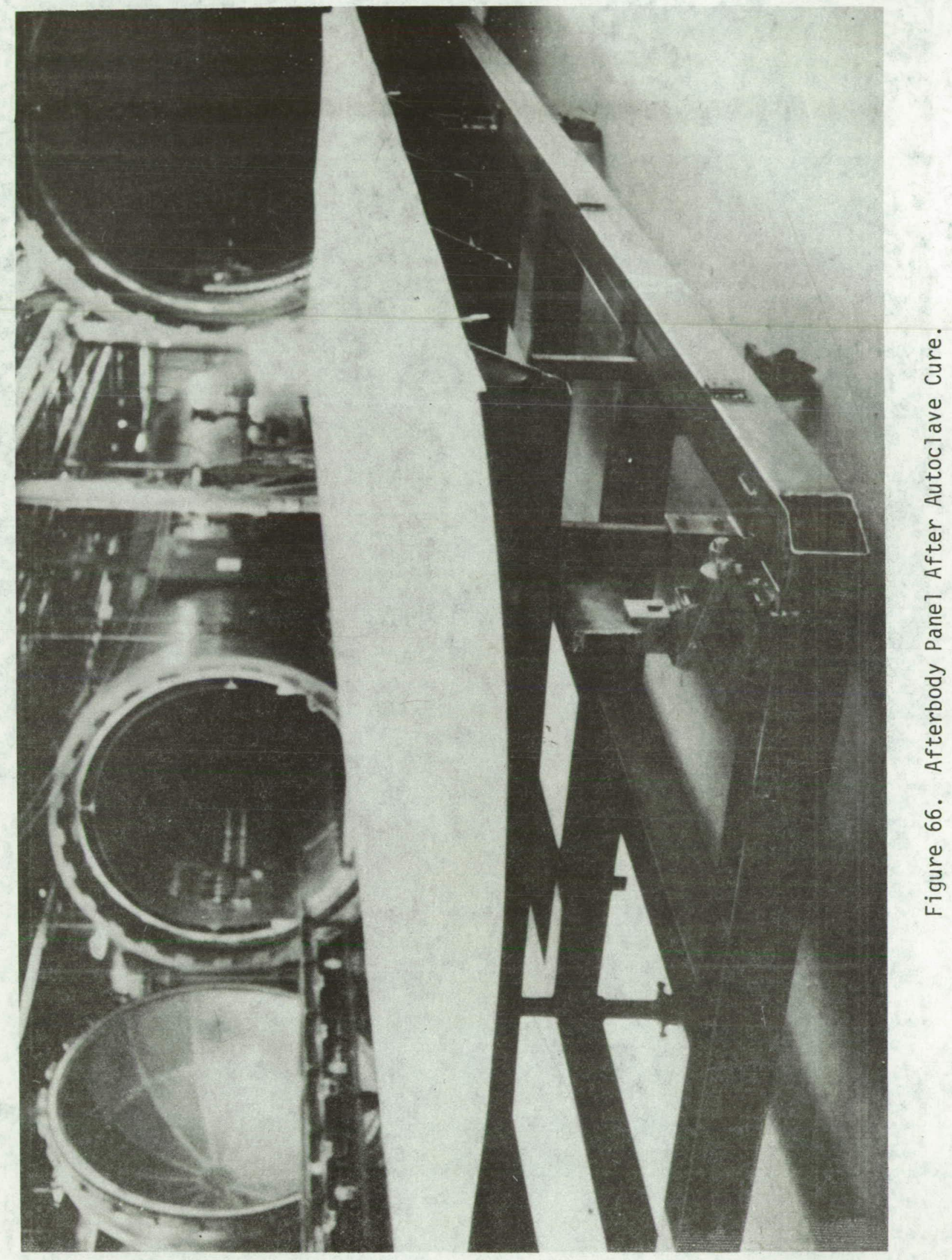






Figure 67. Machining Holes in Composite Spar for Hub Adapter Bolts. 
As machining of each hole was completed, attaching hardware was installed and torqued. A hydraulic torque wrench was used to obtain 400,000 pounds axial preload in the 3 -inch diameter steel stud.

The spar and adapter were repositioned into a final assembly fixture for installation of the afterbody panels and trailing edge spline. The panels were dryfitted to the spar to insure proper alignment prior to applying adhesive for bonding. Figure 68 shows the two lower panels being fitted to the spar, and the spline being fitted to the panels. Fiberglass T-clips which connect the panel inner skins to the spar were fitted during this phase. The machining setup for the adapter bolt holes is also visible. Figure 69 shows the plywood contour supports of the final assembly fixture, and the steel backup structure for the pneumatic hoses which supply 35 psi pressure to the panel-to-spar bondlines. C-clamps supplied bonding pressure for the trailing edge spline. The pneumatic hoses are visible in Figure 70.

After the panels and spline were bonded to the spar, syntactic foam was injected into the cavity between the spar and the afterbody panel core, to provide the shear connection between the core and the spar.

The completed blade was instrumented and moved to the Kaman test area for natural frequency measurements and static bending tests. 


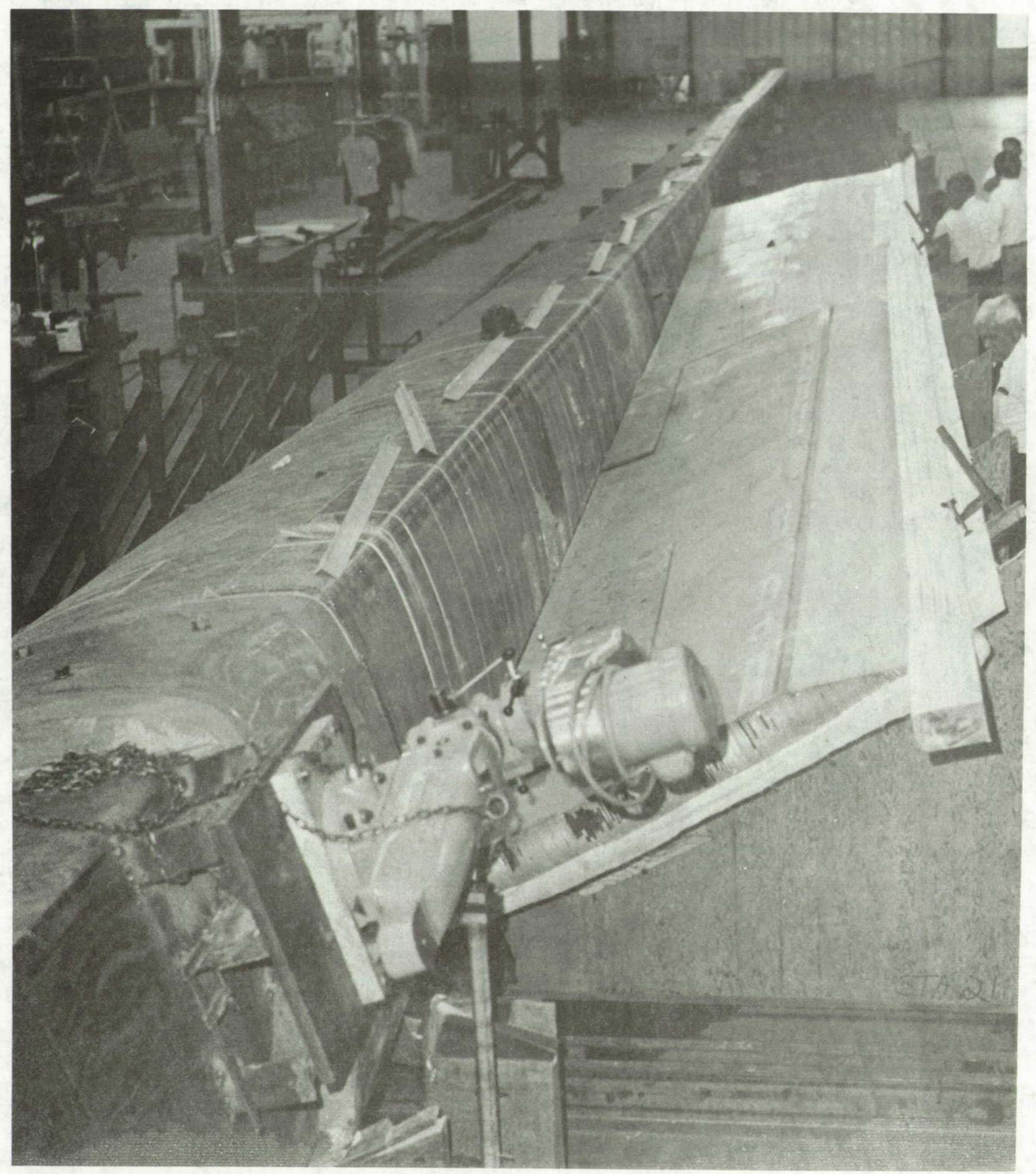

Figure 68. Dry-fitting Afterbody Panels to Spar. 


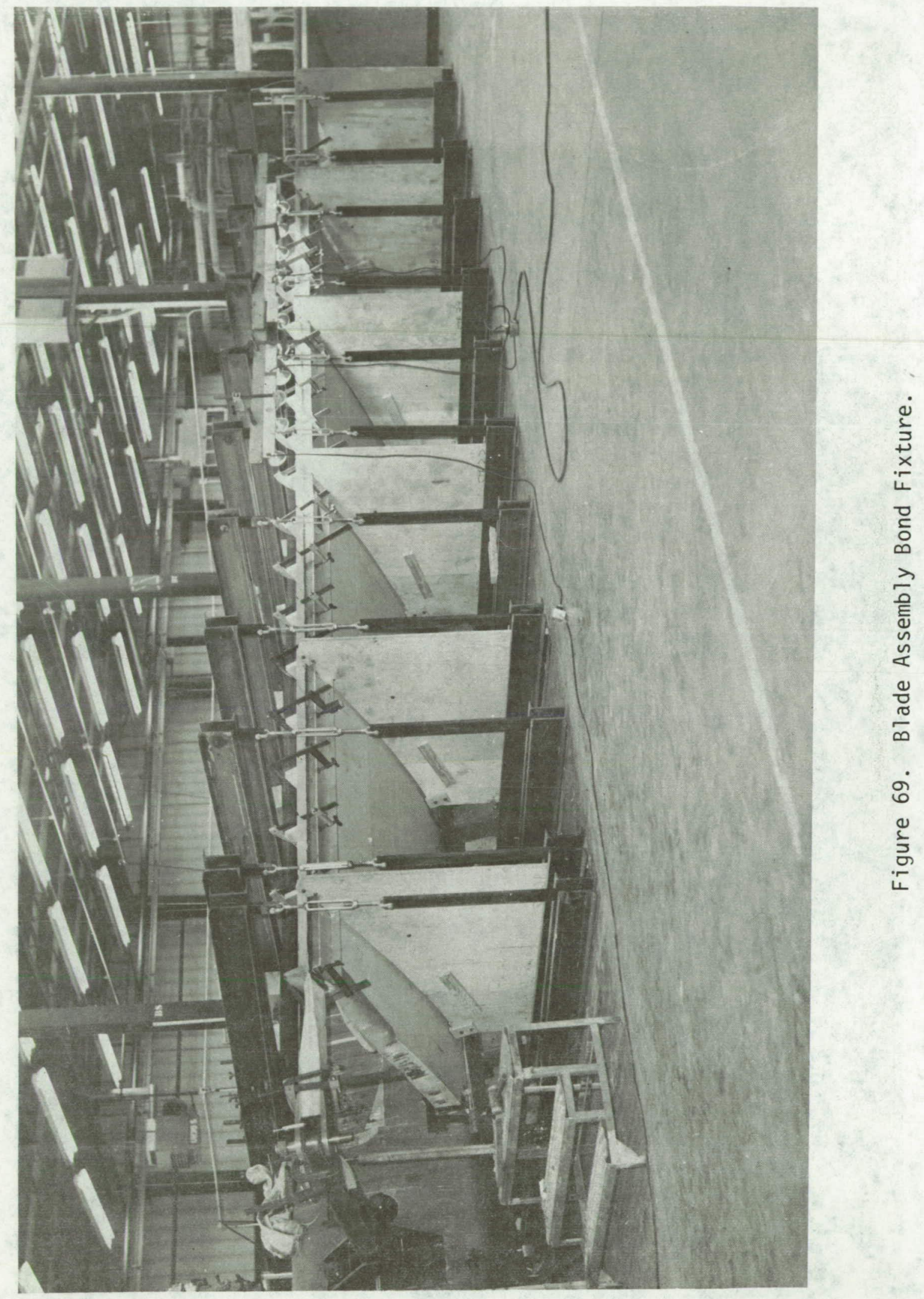




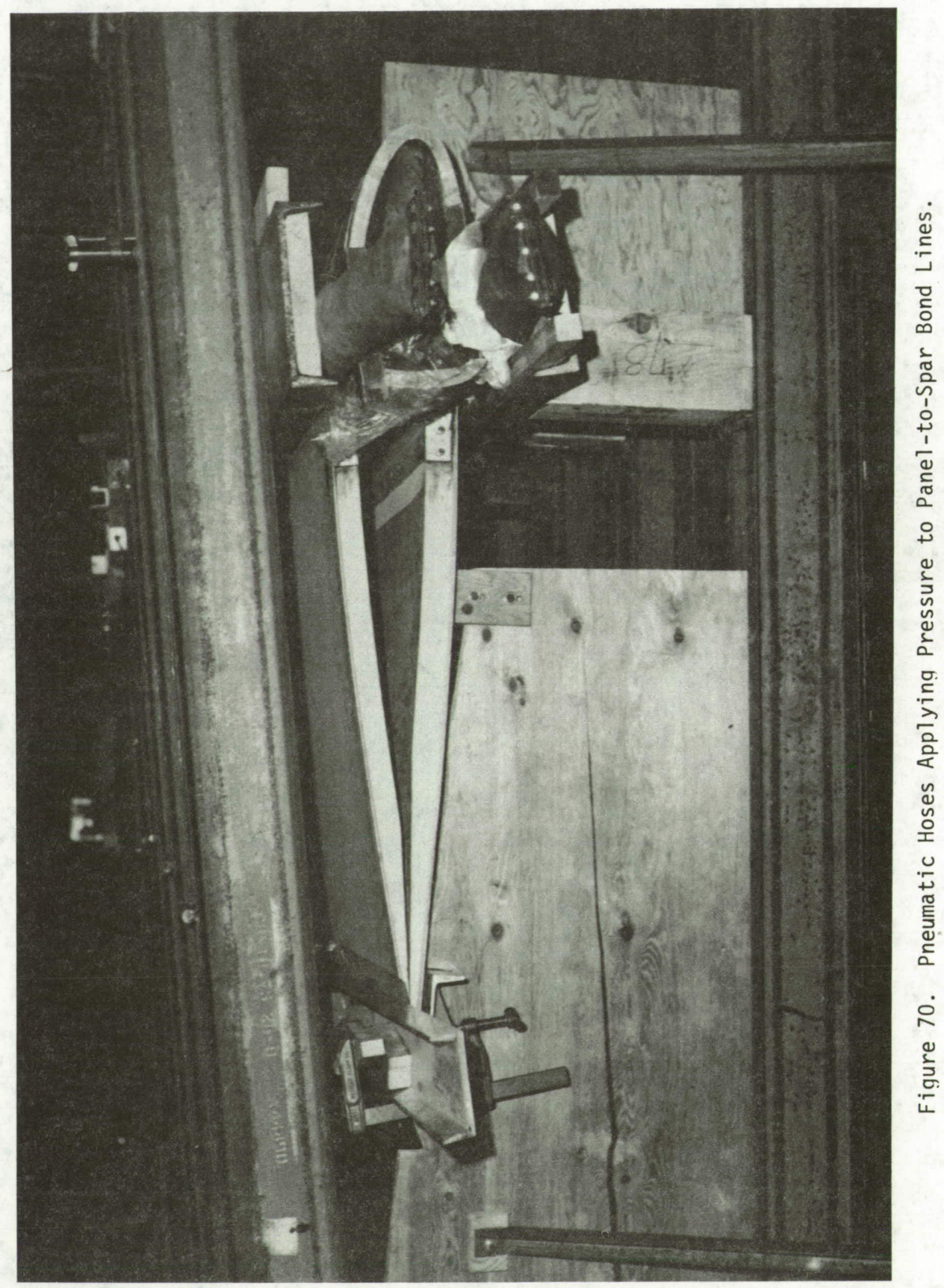




\subsection{QUALITY ASSURANCE}

Blade Spar

Development of quality assurance procedures and non-destructive inspection (NDI) methods for large composite wind turbine blades was included as an important task in the $150 \mathrm{Ft}$ NASA Blade Program. Special attention was focused on the spar, which represents the most difficult, and most critical, inspection requirement. A comprehensive fabrication plan was prepared by Structural Composites Industries, Inc., based on the design supplied by Kaman. This plan was followed closely during the spar winding process, although some minor deviations were taken as knowledge was acquired during fabrication. Table 6 lists receiving inspection and in-process inspection items which were used for spar quality assurance on this project.

Based on the results of this project, it is generally concluded that for quality assurance in very large tape or filament wound spars, a combination of strict in-process control and observation, along with post-fabrication checks of excess length samples and X-ray of suspect areas, constitute an effective approach. The primary QA emphasis is in preventing, rather than detecting and correcting problems. For example, it was found that visual observation readily detected areas of marginal resin wetting while the tape was being applied. This is due, in part, to the rather slow carriage rate inherent in the TFT process which does not require many carriage traverses, as does conventional filament winding. As a further benefit of the slow tape application rate, it was possible to apply additional resin to marginal areas during winding.

Frequent resin samples were taken during the spar winding operation to check resin cure time and to verify proper resin mix of each batch. Resin viscosity checks were also made to insure thorough resin impregnation into laminate fibers. Thorough wetting of laminate fibers was evident in photomicrographs of laminate cross sections taken from the spar.

Although it had been hoped that back lighting might prove to be a feasible means of inspecting for resin voids, light passage through the nearly opaque epoxy resin was found to be insufficient for this purpose in thick sections. As part of the spar winding operation, extra length sections were fabricated, at each end, so that destructive inspection could be carried out on actual aswound samples. Using these samples, X-ray experiments, resin content checks, BARCOL hardness tests, and other inspection methods were evaluated, and valuable information gained. Deliberate defects were introduced into the specimens for evaluation of the various inspection methods. It was verified that $X$-ray inspection can detect small voids in a thick composite laminate, and also reveal fiber orientation patterns. BARCOL hardness checks of the resin matrix indicated the degree of cure achieved in the laminate. Resin burn-off tests of samples cut from the excess length at each end of the spar revealed the resin content of the part as wound, at several points around the perimeter of the spar. 


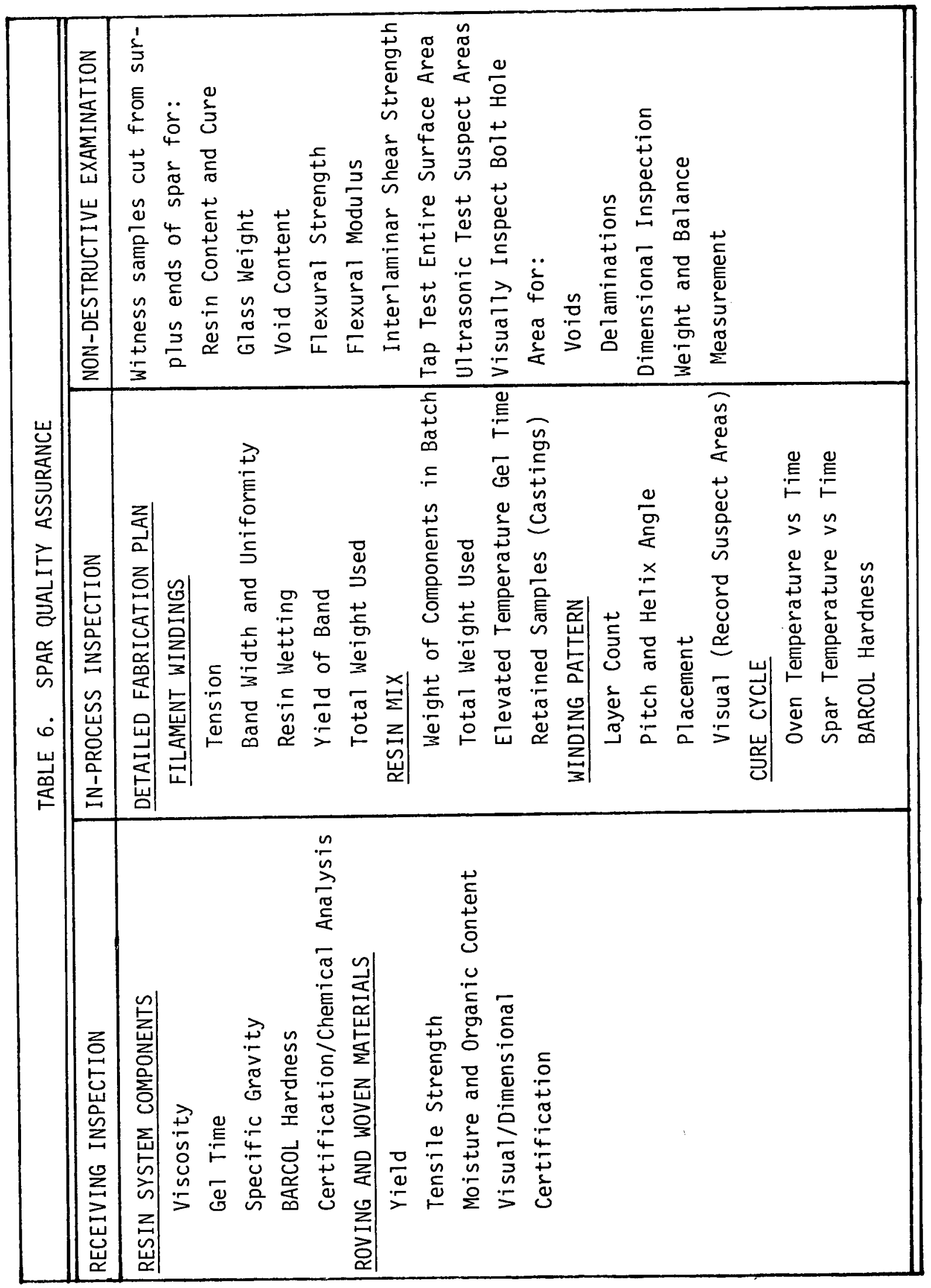


Tap testing is a useful inspection technique for detection of voids and delaminations near the surface of a laminate, and in assembly bondlines, but it is not effective for detection of such defects within a thick laminate. Ultrasonic inspection provides the necessary capability, if required.

Kaman experience with ultrasonic inspection of composite structures indicates that it is a practical method to inspect for voids and/or delaminations in fairly heavy wall sections. On composite helicopter rotor blade spars, Kaman relies on thru-transmission, immersion " $C$ " scanning to inspect and print out the results for wall thickness up to five inches. Destructive examinations of spars during the development of ultrasonic techniques confirmed the "C" Scan findings. Consideration may be given to utilizing this non-destructive test method for a production program where the non-recurring cost of a large immersion system could be amortized. For this prototype blade program, however, the immersion ultrasonic inspection technique was not used.

Testing by $X$-ray is costly and, therefore, not as production applicable as ultrasonic inspection. However, $X$-ray may be useful for examination of specific localized areas, such as the root end. X-ray examinations of heavy wall sections up to three inches were made and were found to reveal fiber orientation and void conditions.

\section{Blade Afterbody}

For the afterbody section, quality assurance involved both the panel subassemblies and the final assembly of panels to the spar. Tap testing and visual examination are the basic techniques that were employed on completed assemblies. Ultrasonic testing, or X-ray, can be used on suspect areas requiring further examination. Typical inspection procedures appropriate for various areas of the completed blade are illustrated in Figure 71, and listed in Table 7.

One of the significant advantages of composite structures is their repairability, even for thick sections, by conventional, well established methods. Typical repair procedures are listed in Table 8 . This feature, along with established NDI methods, gives early promise that adequate quality assurance can be readily effected for large wind turbine blades. 

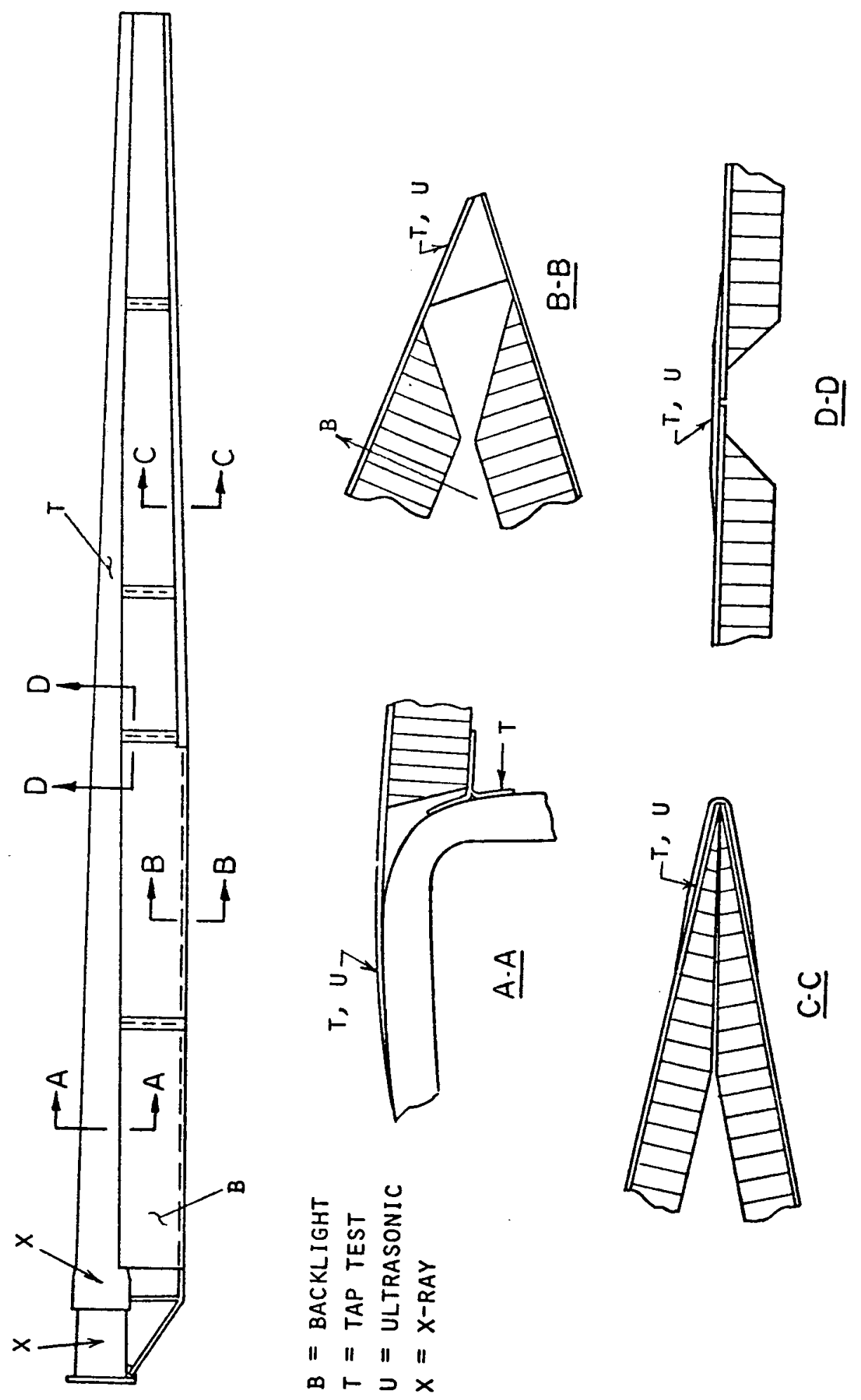

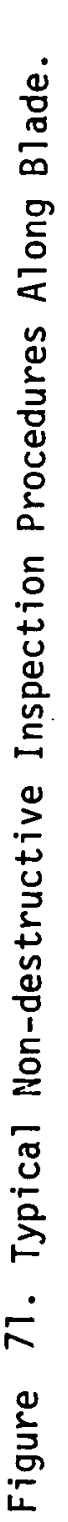

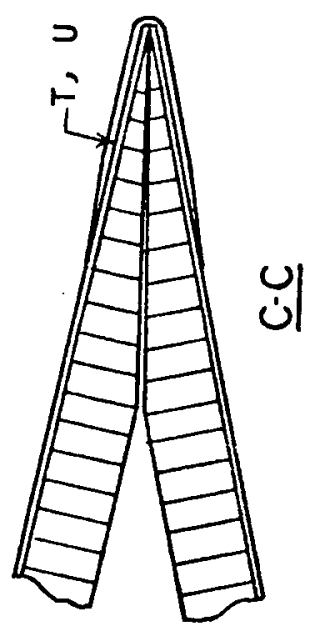


TABLE 7. RUALITY ASSURANCE OF BLADE ASSEMBLY AND SUBASSEMBLIES

\section{AFTERBODY PANELS}

IN-PROCESS CONTROLS

Utilize Detailed Fabrication Plan for Proper Layup

Inspect Prior to Autoclave Cure

Monitor Temperature and Pressure in Autoclave

NON-DESTRUCTIVE EXAMINATION

Back Light Through Panel to Check Core Adhesive Fillets

Tap Test Panel Edges for Voids

U1trasonic Test Questionable Areas

Use Witness Samples Process with Each Panel:

Lap Shear Test of Adhesive Bond, Climbing Drum Peel

Tests of Skin-to-Core Bond

TRAILING EDGE SPLINE

IN-PROCESS CONTROLS

Utilize Detailed Fabrication Plan for Proper Layup

Inspect Prior to Cure

NON-DESTRUCTIVE EXAMINATION

U1trasonic Test of Bond Lines

Provide Witness Samples: Lap Shear Tests

Dimensional Inspection

BLADE-TO-HUB ADAPTER

IN-PROCESS CONTROLS

Via Vendor Accreditation and Certification

NON-DESTRUCTIVE EXAMINATION

$X$-Ray Critical. Welds

Dimensionally Inspect 
TABLE 7. QUALITY ASSURANCE OF BLADE ASSEMBLY AND SUBASSEMBLIES (continued)

\section{BLADE ASSEMBLY}

\section{IN-PROCESS CONTROLS}

Inspect for Alignment of Adapter into Spar

Dimensionally Inspect Holes Machined into Adapter and Spar

Inspect for Alignment of Afterbody Panels and Spline During

Dry-fit and Subsequent Bonding Operations

Inspect for Adhesive and Foam Squeeze-out Along Bondlines to

Insure Adequate Quantity

Monitor Bondline Pressures During Cure

\section{NON-DESTRUCTIVE EXAMINATION}

Tap Test Panel-to-Spar and Panel-to-Spline Bondlines

UTtrasonic Test Questionable Areas

Provide Witness Samples: Lap Shear Tests

Dimensionally Inspect:

Airfoil Contour

Surface Finish

Twist Angle 
TABLE 8. CORRECTIVE ACTION FOR DEFECTS

$\underline{\text { SPAR }}$

Small Defects - Inject Resin into Void or Delaminated Area and Cure

Large Defects - Excise Defect and Apply Structural Repair Designed for Specific area affected, e.g., Precured E-Glass Patch Hot-Bonded to Repair Area

AFTERBODY PANEL

Damage, Voids in Core or Skin - Apply Standard Core/Skin Patch Bondlines - Inject Adhesive and Cure, or Remove Defective Area and Apply Standard Structural Repair Patch

TRAILING EDGE SPLINE

Apply Structural Repair, e.g., Precured E-Glass Patch, Hot-Bonded to Repair Area

ADAPTER INSTALLATION

Use Special Bolts or Bushings to Achieve Proper Fit 


\subsection{SHIPPING AND HANDLING}

Shipping and handling the $150 \mathrm{ft}$ blade during its various phases of fabrication and testing were accomplished with conventional commercial equipment; no special cradles, protective enclosures or blade supports were required. The 141 ft spar was extracted from the mandrel by a local rigging and machinery moving company, and loaded onto a railroad flatcar for shipment from California to Connecticut. Another rigging company unloaded the spar from the rail car and transported it 2-1/2 miles from the rail siding to the Kaman plant. Handling the blade during assembly was accomplished with relative ease by Kaman personnel using fork lift trucks. Local rigging companies were again used to transport the blade to the Kaman test area and for installation on the test fixture. Figure 72 illustrates a typical handling procedure employed in these tasks.

An investigation undertaken during the Preliminary Design Task resulted in the conclusion that the $150 \mathrm{ft}$ blade spar, as well as the completed blade, could be transported across the country by either rail or truck. Specialized motor carriers routinely transport steel bridge girders up to $175 \mathrm{ft}$ long over Federal, State and local. roads using equipment such as illustrated in Figure 73 . Special clearances and permits must be obtained from the Department of Transportation of each state through which oversize loads must travel by road.

The $141 \mathrm{ft}$ blade spar was shipped by rail from Structural Composites Industries, Inc., Mira Loma, California, facility to a rail siding in Bloomfield, Connecticut. The spar was loaded, blocked and tied down on an 89-ft flatcar, which it overhung almost 38 feet on each end. (Overhang is measured from the rail car wheels.) A 50-ft idler flatcar was positioned at each end of the 89-ft car to accommodate the spar overhang, as shown in Figure 74 . Provisional route clearances for the entire trip were obtained in advance of the anticipated departure date by the railroad company (Union Pacific) at the point of origin. Clearances were verified after the spar was loaded on the flatcar and measured dimensionally. No unusual problems were encountered during the 13-day rail shipment. 


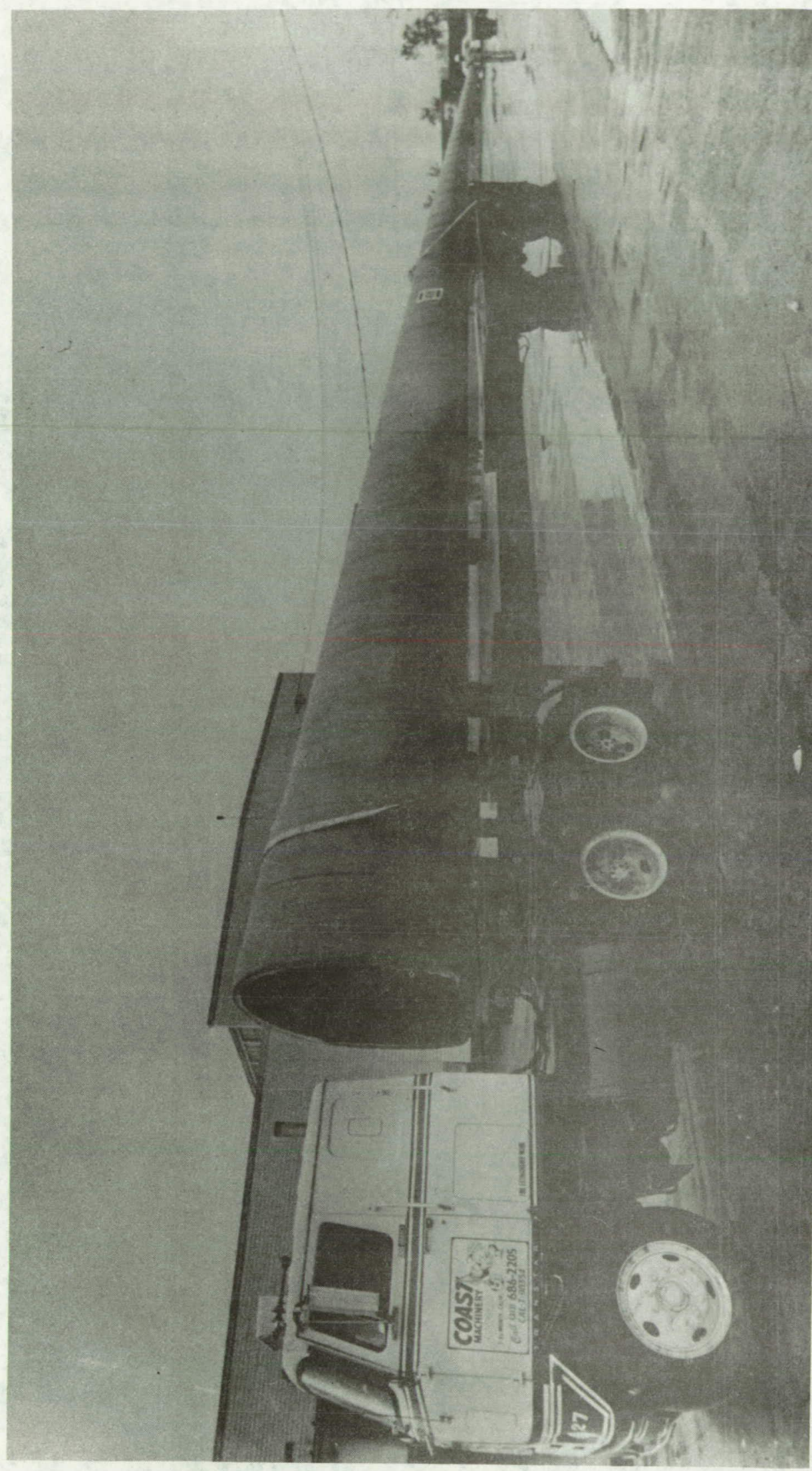

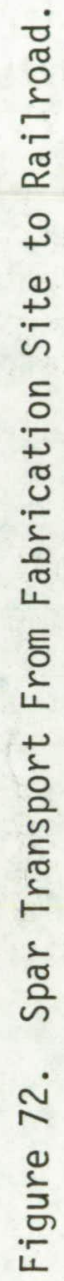









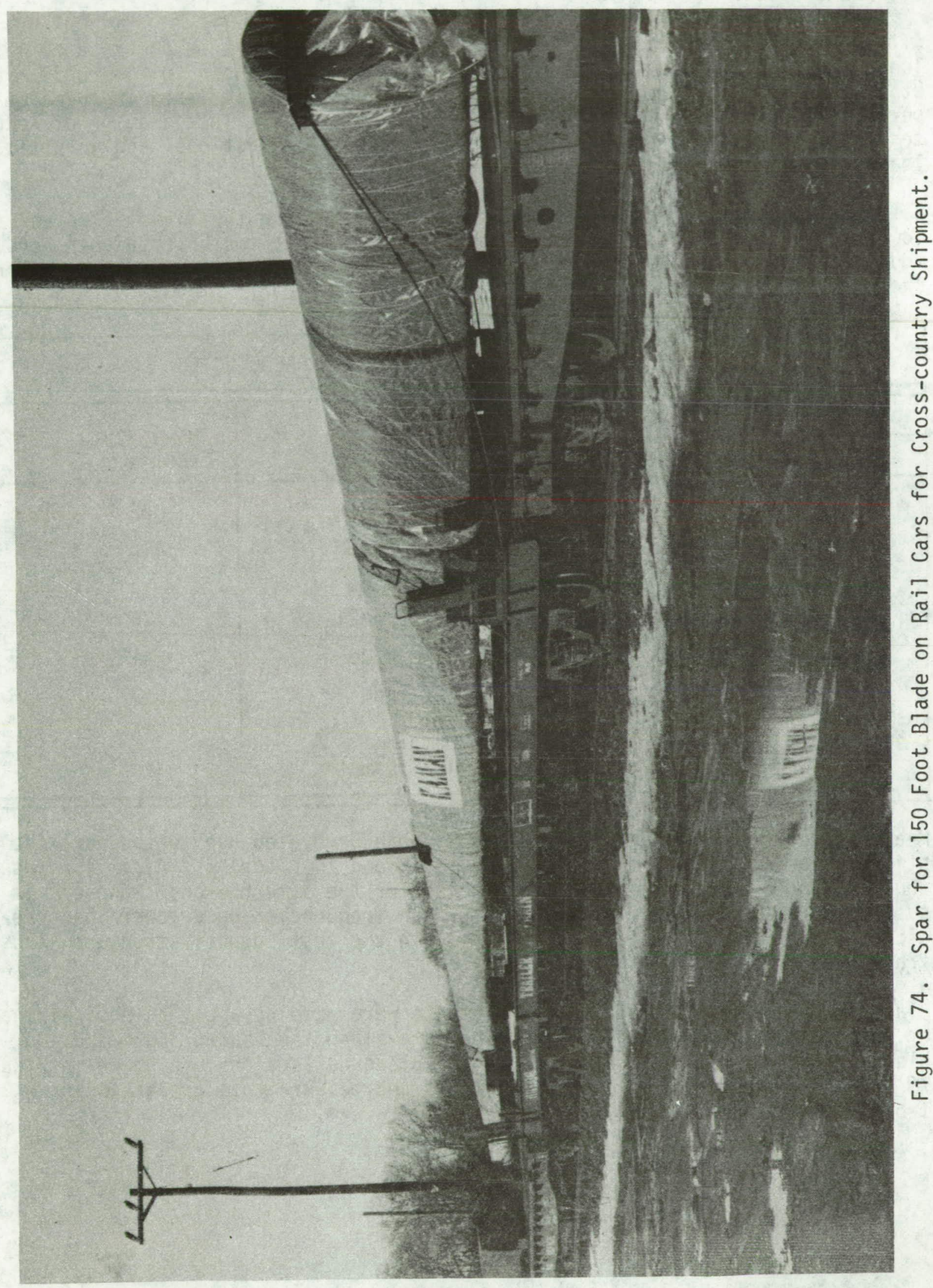




\subsection{BLADE TESTS}

After completion of blade fabrication, the hub adapter was welded to a 30-ft long load reaction beam and mounted on a test fixture, shown in Figure 75 , for static tests and natural frequency determinations. Static tests included measurement of blade edgewise and flatwise stiffness and deflections, proof-load tests to design limit load in edgewise and flatwise directions, and an ultimate load test to failure in the flatwise direction.

Natural frequencies were determined by manually shaking the blade to reveal the low frequency fundamental bending modes, and by impact tests for higher bending modes and torsion. Measured vs predicted non-rotating natural frequencies are shown in Table 9.

TABLE 9. NON-ROTATING BLADE NATURAL FREQUENCIES

\begin{tabular}{|c|c|c|c|}
\hline \multicolumn{2}{|c|}{ FREQUENCY, $\mathrm{Hz}$} & \multirow[b]{2}{*}{ MODE } & \multirow{2}{*}{$\begin{array}{l}\text { DAMPING } \\
\text { FACTOR }\end{array}$} \\
\hline PREDICTED & MEASURED & & \\
\hline .57 & .54 & Flatwise, 1st Mode & .027 \\
\hline 1.23 & 1.43 & Edgewise, ist Mode & .042 \\
\hline \multirow[t]{2}{*}{1.66} & 1.60 & Flatwise, 2nd Mode & --- \\
\hline & 3.19 & Coupled Edgewise/Flatwise & --- \\
\hline 3.46 & 4.35 & Edgewise, 2nd Mode & $-\cdots$ \\
\hline \multirow[t]{2}{*}{14.80} & 8.90 & Torsion, lst Mode & .009 \\
\hline & \multicolumn{2}{|c|}{ Damping Factor: $\frac{\text { Damping }}{\text { Critical Damping }}$} & \\
\hline
\end{tabular}

Measured edgewise frequencies were higher than predicted due to the edgewise stiffness being greater than predicted, as shown in Figure 6 . A similar result would be expected for flatwise frequencies for the same reason. However, it is suspected that measured flatwise and torsion frequencies were lower than predicted as a result of lateral flexibility in the test support structure illustrated in Figure 75.

Blade stiffness and deflection measurements were made by applying nominal loads at the blade tip, recording strain gage data along the blade, and measuring blade deflections from a reference line. Blade deflections are shown in Figures 76 and 77 , and blade stiffness predictions and measurements are given in Table 10. 


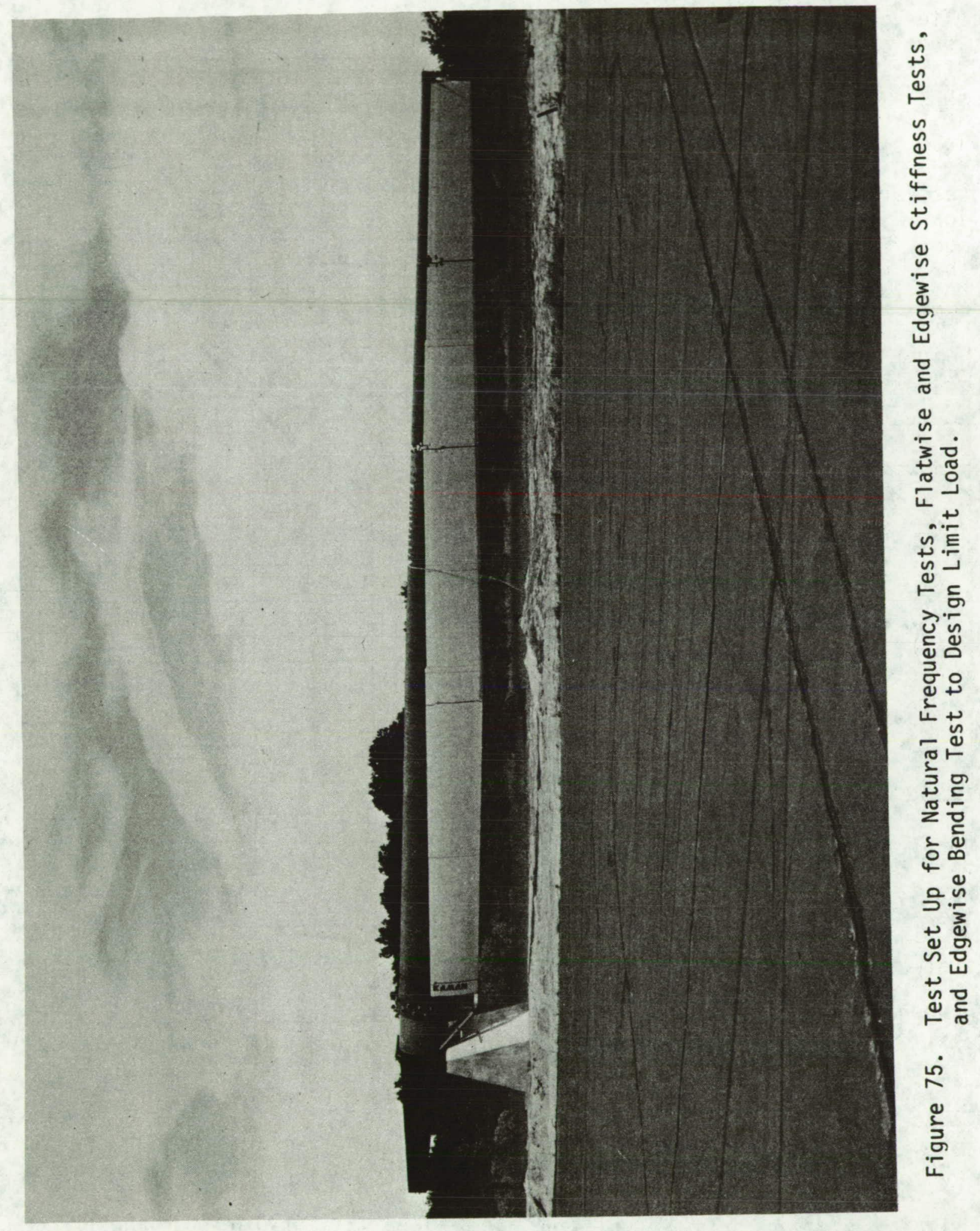




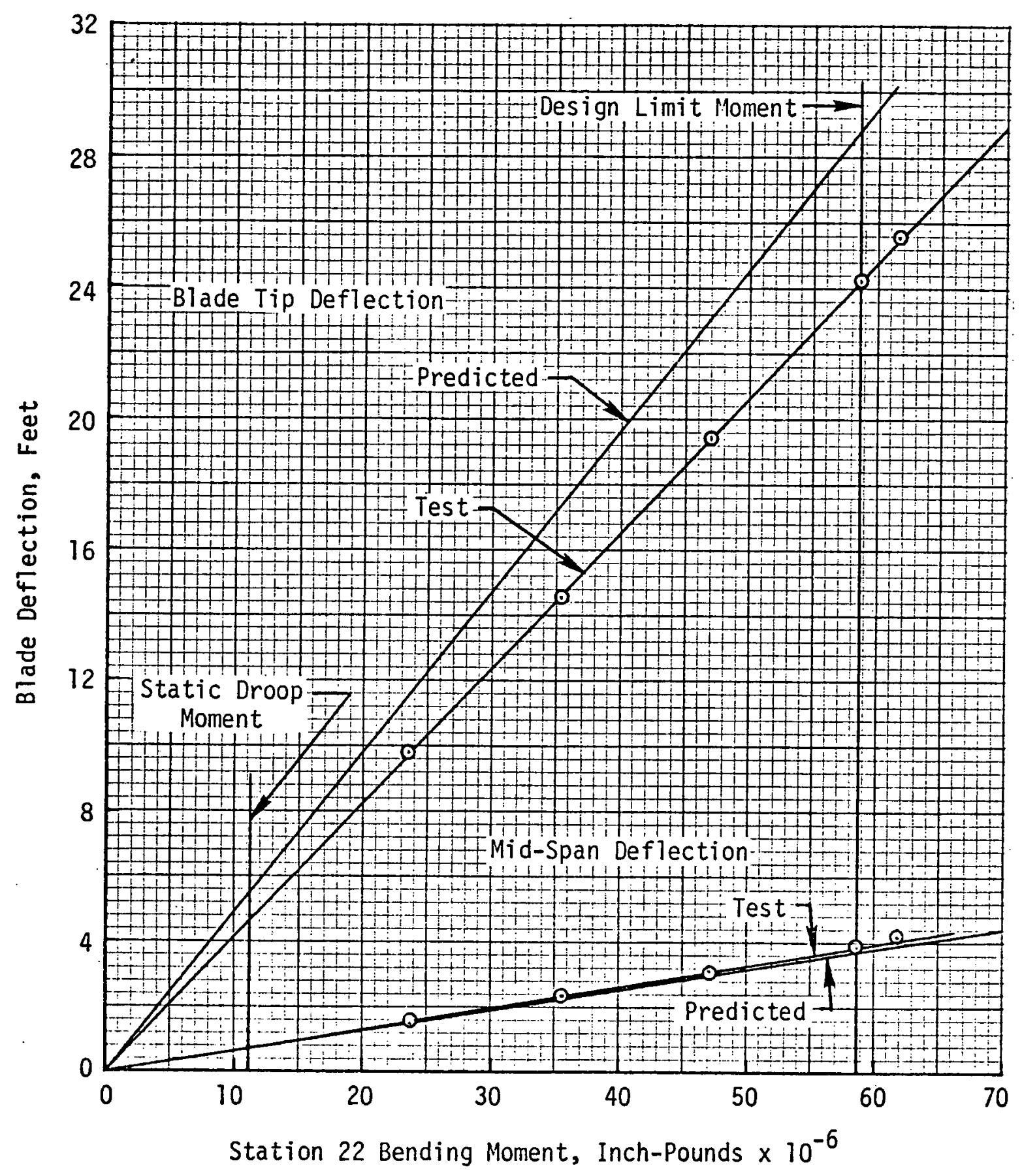

Figure 76. Flatwise Bending Deflections at Blade Mid-span and Tip. 




Figure 77. Edgewise Deflection at the Blade Tip. 


\begin{tabular}{|c|c|c|c|c|}
\hline \multicolumn{5}{|c|}{$\begin{array}{l}\text { TABLE 10. BENDING STIFFNESS DISTRIBUTIONS } \\
\text { (Predicted and Experimentally Determined) }\end{array}$} \\
\hline \multirow{2}{*}{$\begin{array}{l}\text { STATION } \\
\text { (Ft.) }\end{array}$} & \multicolumn{2}{|c|}{ EI FLATWISE $\left(\right.$ Lb-In. $\left.{ }^{2} \times 10^{-10}\right)$} & \multicolumn{2}{|c|}{ EI EDGEWISE $\left(\right.$ Lb-In. $\left.{ }^{2} \times 10^{-10}\right)$} \\
\hline & Predicted & Exper. Determ. & Predicted & Exper. Determ. \\
\hline 22 & 39.46 & 50.72 & 116.70 & 179.10 \\
\hline 70 & 5.92 & 7.97 & 23.77 & 61.84 \\
\hline 106.83 & 0.87 & 1.25 & 6.52 & 10.52 \\
\hline 130 & 0.40 & 0.54 & 2.88 & 5.12 \\
\hline
\end{tabular}

The predicted EIs were computed for each blade station using the Kaman SHELLD code which combines modulus and structural inertia properties of the various plies of spar laminate, the afterbody, and the trailing edge spline to arrive at an effective stiffness of each blade section.

The discrepancy between predicted stiffness and measured stiffness displayed above is attributed to conservatism in the prediction techniques used in this project. This conservatism was used because no direct prior experience was available, this being the first full size article of its kind ever attempted. Specimens cut from the full size article yielded an $E_{c}$ of $4.25 \times 10^{6} \mathrm{psi}$. If this value were used with an "I" based upon actual (not nominal) walls, very close correlation can be achieved between experimental and predicted EIs and deflections.

The limit load test in the edgewise direction, Figure 78, was based upon the design loads of Case 6 , the yaw condition, which is critical for the structure along the blade trailing edge. The limit load and ultimate failing load tests in the flatwise direction were based on Case 5 , the hurricane wind condition (164 mph wind at hub height), which is critical for spar buckling.

After completion of the natural frequency and stiffness determinations, and the edgewise test to design limit load, the blade was repositioned as shown in Figure 79 for the flatwise tests. The blade was tested to design limit load in the flatwise direction, Figure 80, and then taken to failure which occurred at 9 percent above design limit load, Figure 81 . Failure occurred at blade station 45, Figures 82 and 83 , as local crippling at a flaw in the spar laminate. Although the flaw was detected in the surface of the spar during the NDI process, its effect on crippling strength was not recognized. Subsequent investigation revealed that the flaw was a local bulge in 60 percent of the spar wall thickness, resulting from the four step winding process and the associated soft tooling. Future blades will be made in a single step with improved tooling to eliminate such flaws. 




Figure 78. Blade Edgewise Bending Moment vs Radial Blade Station. 


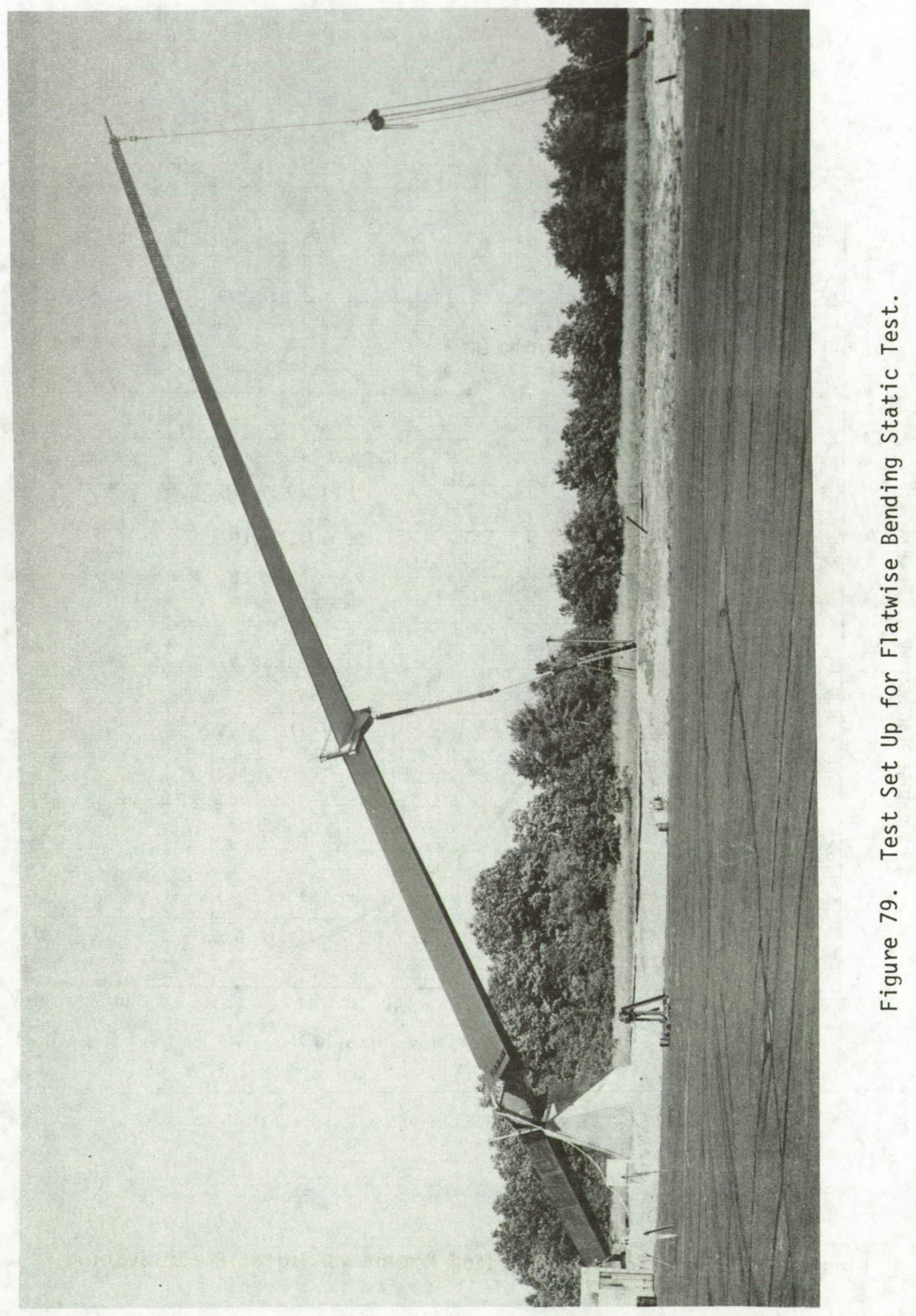




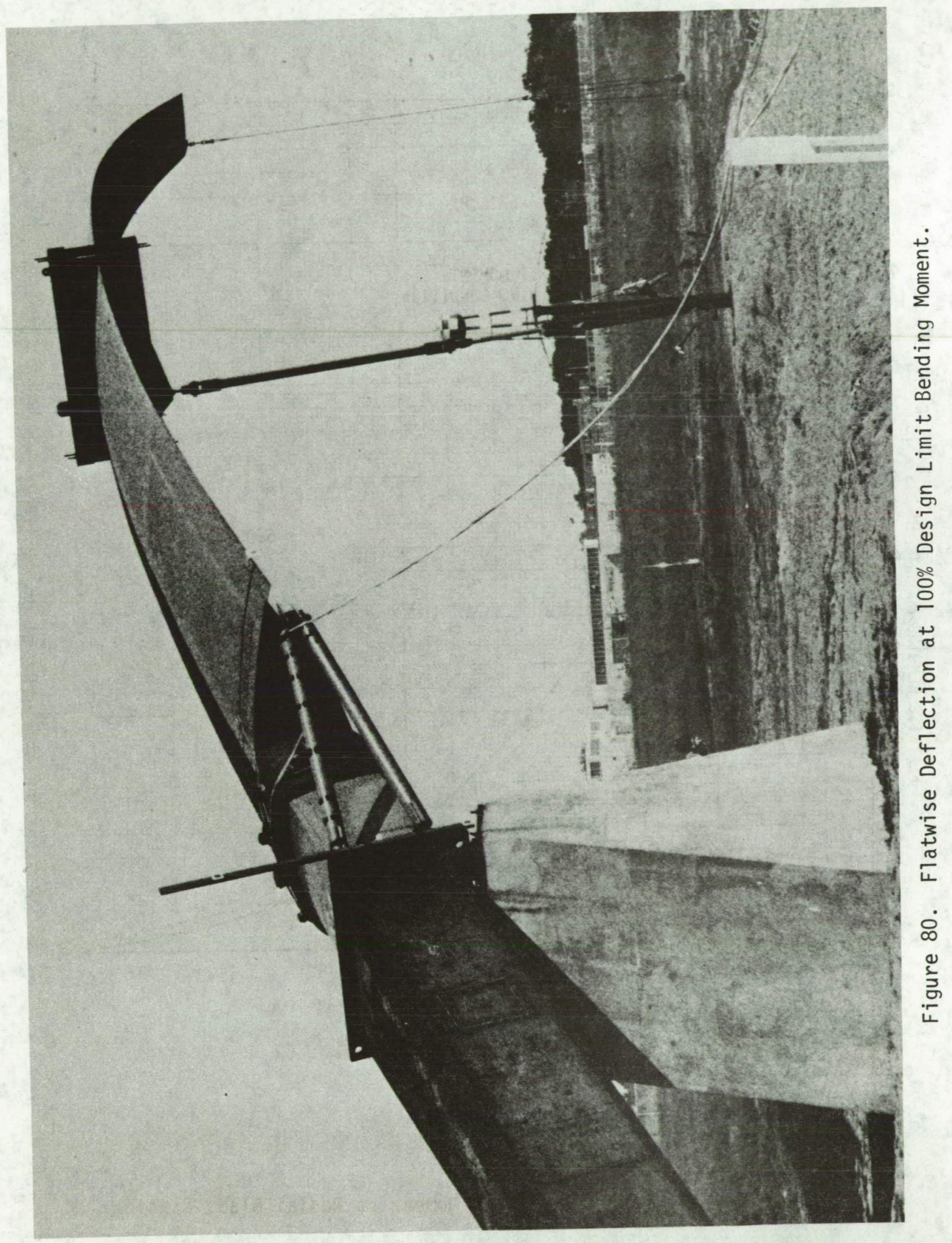




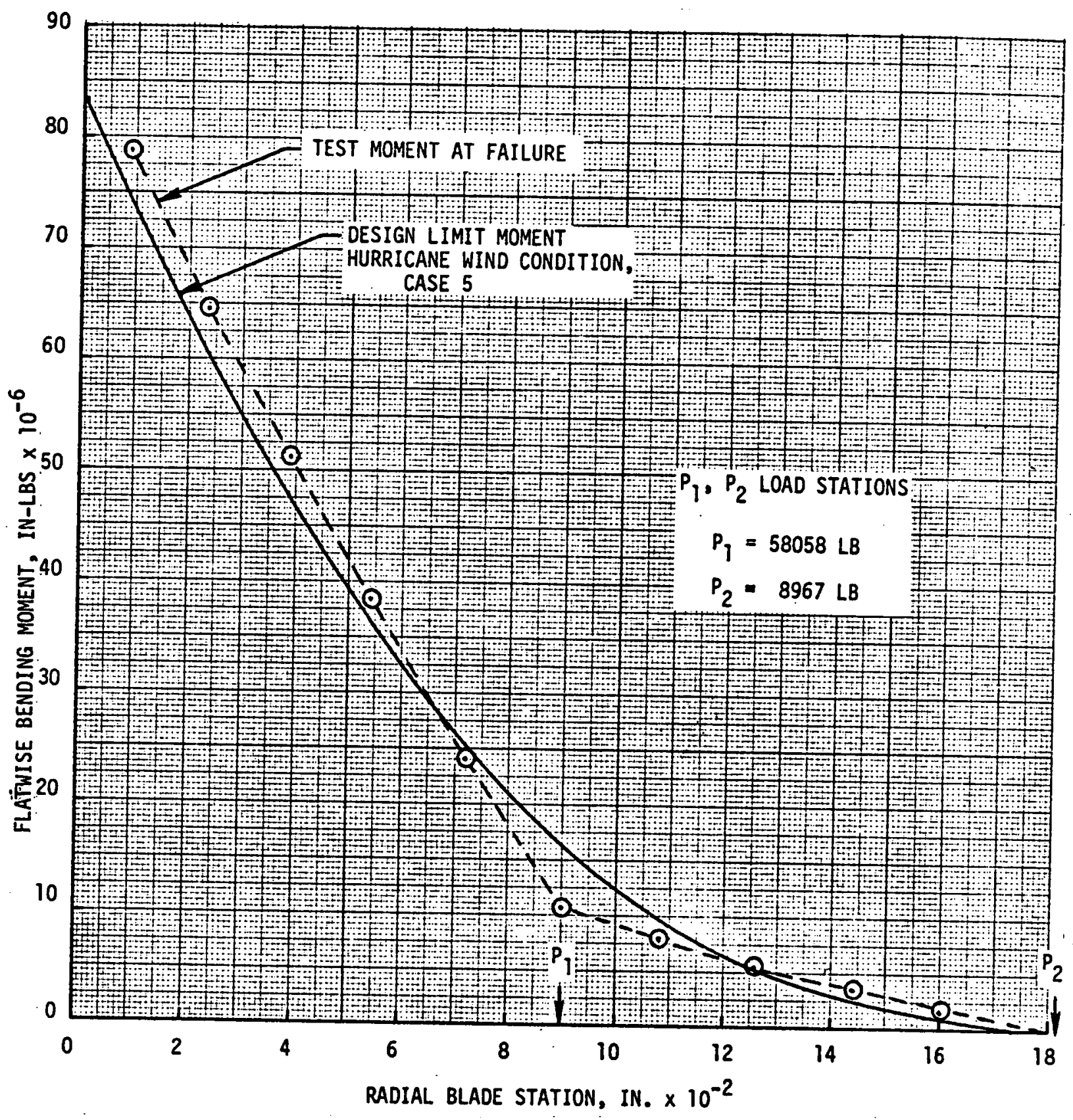

Figure 81. Blade Flatwise Bending Moment vs Radial Blade Station. 


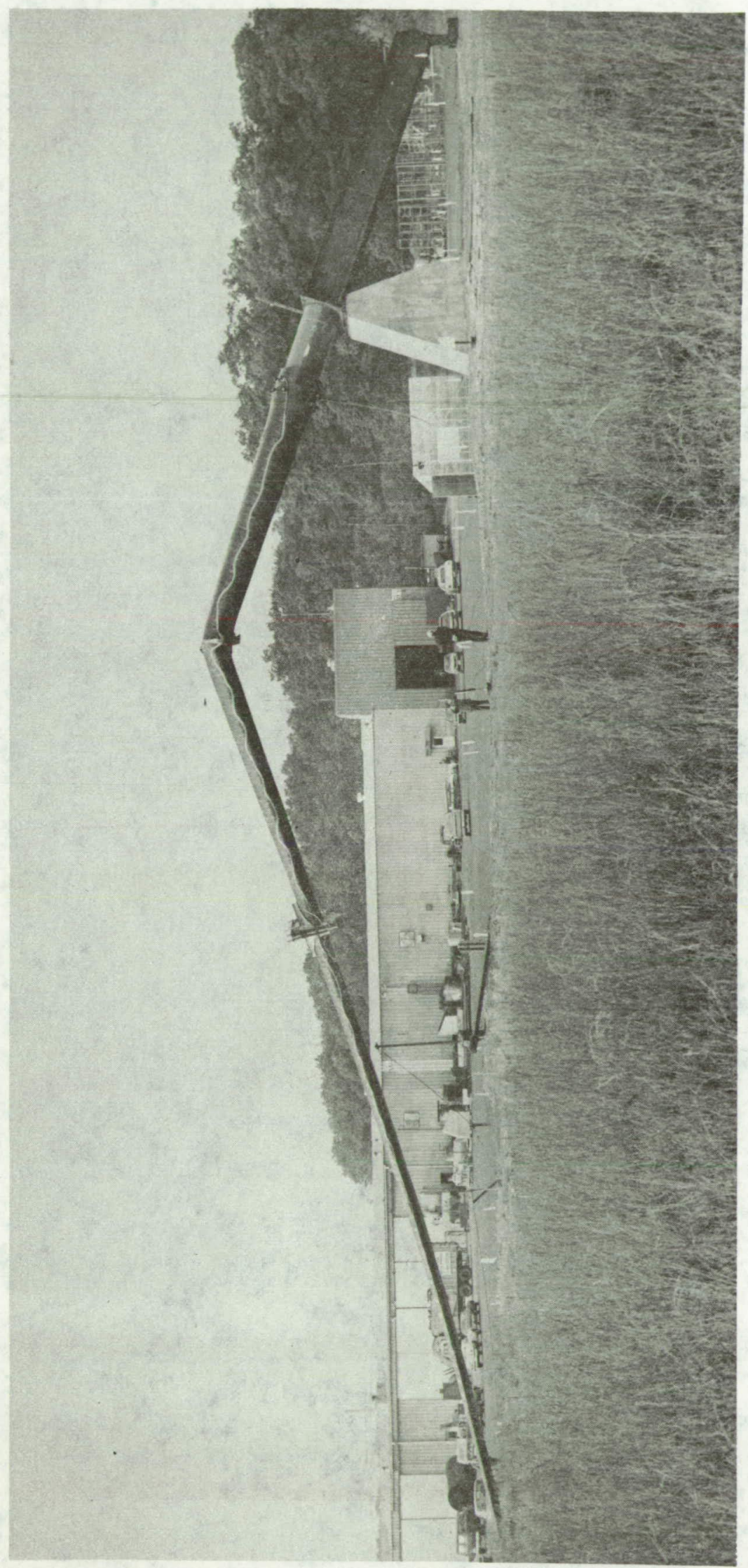

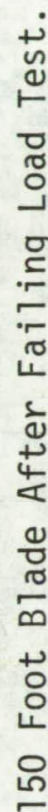

๓

它 


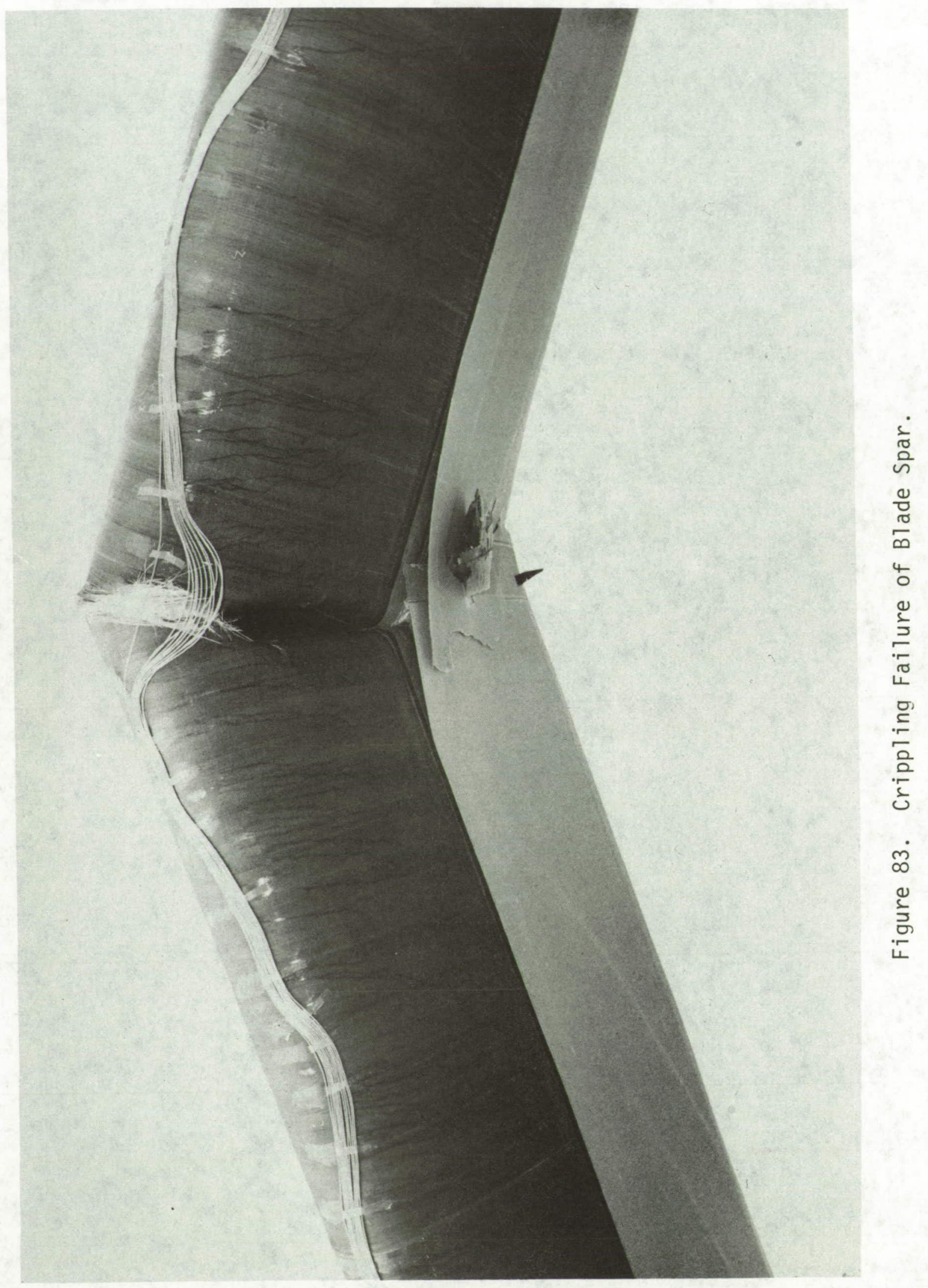


Subsequent to the ultimate load test of the complete blade, the outboard $100 \mathrm{ft}$ of blade was still structurally intact, so it was set up and tested in flatwise bending as a simply-supported overhanging beam, Figure 84 . The test section from station 90 to 150 had none of the local flaws observed in the inboard region of the spar where the previous test had resulted in failure.

The outboard test section successfully sustained bending moments in excess of the ultimate design condition (defined as 1.5 times design limit) from blade station 106 to the tip. At blade station 130, the applied moment was 2.8 times design 1imit, Figure 85, well above the predicted buckling strength of the spar wa 11.

This test demonstrated that large knockdown factors from theoretical crippling strength predictions are not necessary for pure monocoque glass/epoxy structures of this type, provided no serious material defects (such as the local bulges present at the station 45 failure location) are present. 


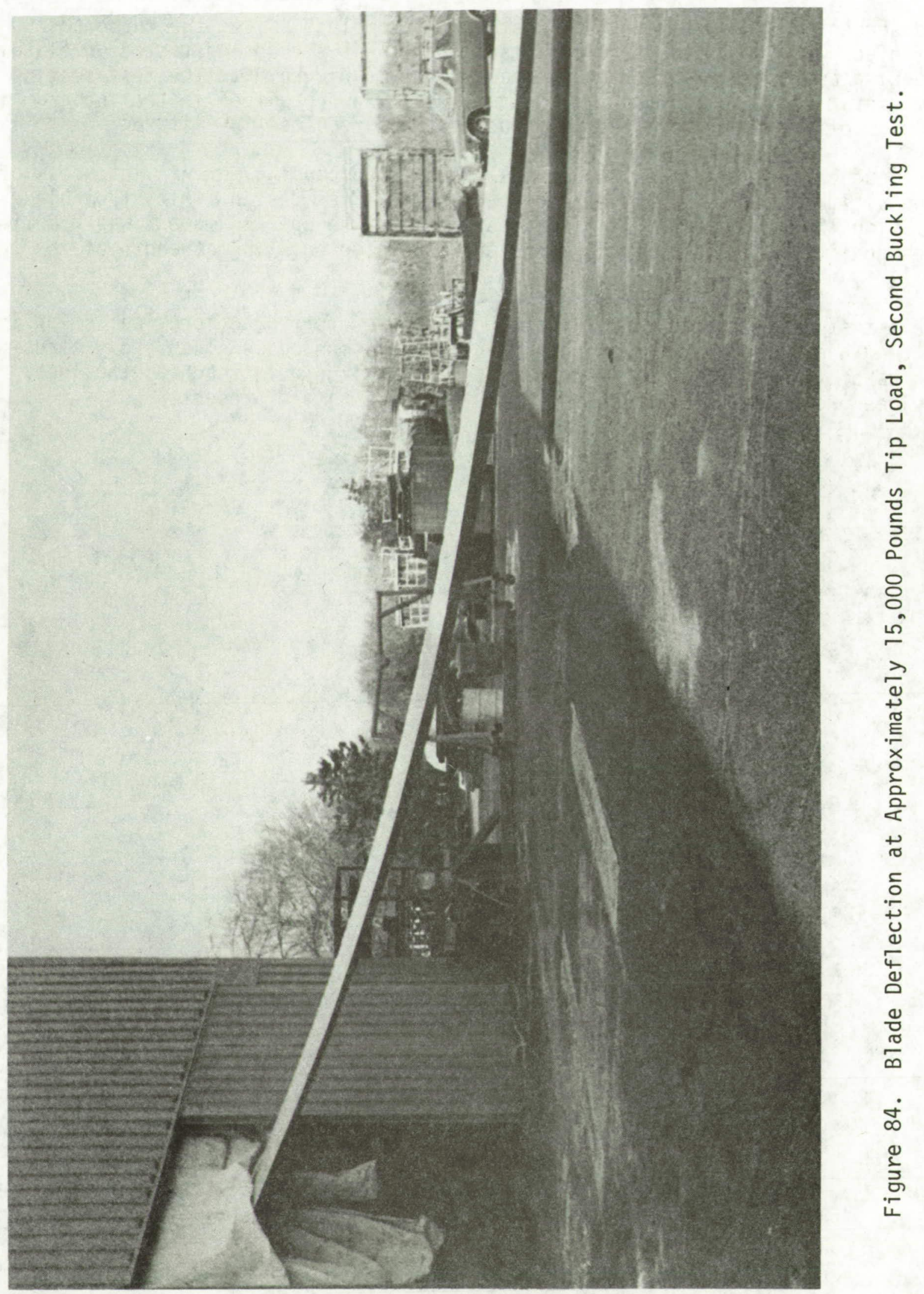




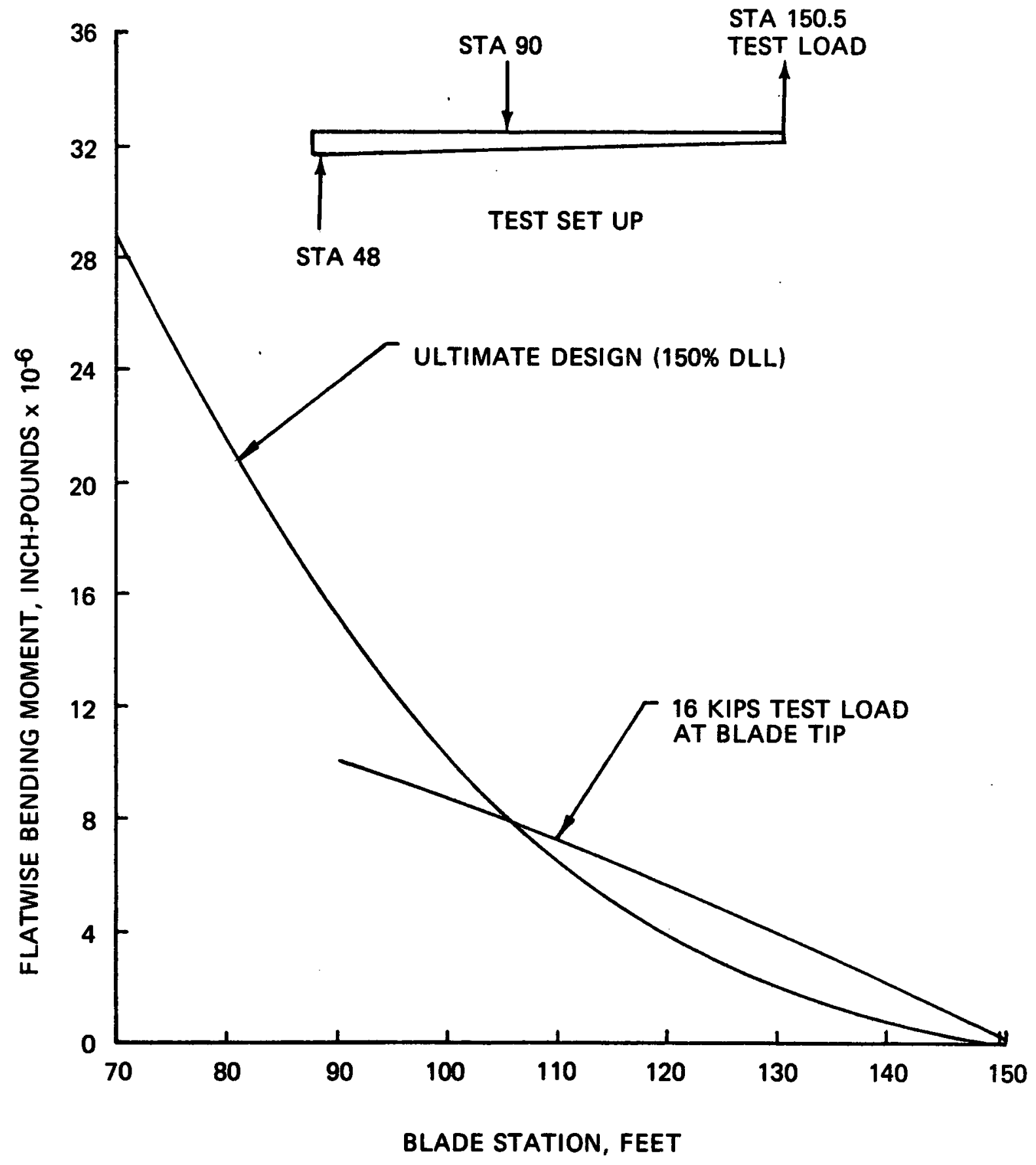

Figure 85 . Bending Moments for Simple Cantilever Buckling Test of 150 Foot Blade Section. 


\subsection{BLADE COST AND PRODUCTION COST PROJECTIONS}

The actual cost of fabricating the first prototype $150 \mathrm{ft}$ blade was just over $\$ 10 / 1 \mathrm{~b}$, exclusive of tooling and other non-recurring costs. The blade was made on one of a kind soft tooling, plywood forms for blade final assembly, and juryrigged support fixtures for drilling the root end adapter holes. The $60 \mathrm{ft}$ trailing edge spline was carved by hand. The blade spar was wound in four steps by SCI on a low cost steel mandrel which had a steadyrest at mid-span to minimize bending deflections and fatigue stresses. Actual costs of the prototype blade are given in Table 11.

TABLE 11. ACTUAL COSTS OF THE PROTOTYPE $150 \mathrm{FT}$ BLADE

\begin{tabular}{|c|c|c|c|c|}
\hline \multirow[b]{2}{*}{ COMPONENT } & \multirow[b]{2}{*}{ WEIGHT } & \multicolumn{3}{|c|}{ THOUSANDS } \\
\hline & & LABOR COST & MATERIAL COST & TOTAL \\
\hline Spar & 19,079 & $\$ 121$ & $\$ 55$ & $\$ 176$ \\
\hline $\begin{array}{l}\text { Afterbody Panels } \\
\text { Splices, Adhesive }\end{array}$ & 3,272 & 34 & 24 & 58 \\
\hline Trailing Edge Spline & 627 & 10 & 6 & 16 \\
\hline $\begin{array}{l}\text { Root End Truss and } \\
\text { Hardware }\end{array}$ & 2,882 & 9 & 14 & 23 \\
\hline Hub Adapter & 10,306 & 17 & 4 & 21 \\
\hline Assembly & --- & 77 & --- & 77 \\
\hline TOTAL & 36,166 & $\$ 268$ & $\$ 103$ & $\$ 371$ \\
\hline
\end{tabular}

The cost of fabricating second and third blades using the same tooling and fabrication processes as on the prototype blade would be reduced by experience and efficiency improvements for components that are basically unchanged from the first blade. The cost of an operational, flanged hub adapter would be greater than the test adapter for the first blade, and the cost of paint, lightning protection, erosion protection, and tip and root fairings would also be additional.

Learning curves for the various elements of the blade were selected based on Kaman manufacturing experience and published data. A 90 percent learning curve and additional process efficiencies have been projected for fabrication of the spar, an $82 \%$ learning curve for afterbody panels and spline, and $80 \%$ for the assembly process. The adapter cost reflects vendor quotations based on preliminary design of an operational adapter. Estimates of adapter, root end truss and attachment hardware are based on an 83 percent learning curve. Cost components on the 2nd and 3rd blades are given in Table 12. 
TABLE 12. ESTIMATED COST OF 2nd AND 3rd $150 \mathrm{FT}$ BLADES

\begin{tabular}{|c|c|c|c|c|}
\hline \multirow[b]{3}{*}{ COMPONENT } & \multirow{3}{*}{$\begin{array}{l}\text { WE IGHT } \\
\text { (POUNDS) }\end{array}$} & \multicolumn{3}{|c|}{ THOUSANDS } \\
\hline & & \multicolumn{2}{|c|}{ LABOR COST } & \multirow{2}{*}{$\begin{array}{c}\text { MATERIALS } \\
(\text { EACH })\end{array}$} \\
\hline & & (2nd) & $(3 r d)$ & \\
\hline Spar & 19,100 & $\$ 109$ & $\$ 90$ & $\$ 39$ \\
\hline $\begin{array}{l}\text { Afterbody Panels, } \\
\text { Adhesives, Paint, } \\
\text { Erosion Guard, } \\
\text { Lightning Protection }\end{array}$ & 3,400 & 38 & 27 & 26 \\
\hline Trailing Edge Spline & 600 & 8 & 6 & 6 \\
\hline Truss and Hardware & 2,900 & 8 & 6 & 14 \\
\hline Hub Adapter & 15,000 & 42 & 37 & 11 \\
\hline Assembly & $\ldots$ & 62 & 39 & --- \\
\hline TOTALS & 41,000 & $\$ 267$ & $\$ 205$ & $\$ 96$ \\
\hline \multicolumn{2}{|c|}{$\begin{array}{l}\text { Total cost of } 2 \text { nd Blade } \\
\text { Total cost of } 3 \text { rd Blade } \\
1978 \text { dollars and rates } \\
\text { No transportation costs } \\
\text { Cost to Customer (includes fee) }\end{array}$} & $\begin{array}{l}63,000 \\
01,000\end{array}$ & & \\
\hline
\end{tabular}

Production improvement of obvious limitations to efficiency in the prototype soft tooling includes a stiffer, smoother mandrel which would allow spar fabrication in one step instead of four, use of a fixture capable of machining all root end holes without repositioning the fixture support structure or the spar, fabrication of the trailing edge spline as a molded detail to eliminate hand carving, and use of a final assembly fixture that positions subassembly details with less hand-fitting. Implementation of these improvements is projected to result in production learning curve slopes listed below: 


\section{PRODUCTION LEARNING CURVES}

COMPONENT

Materials

Labor:

Spar

Afterbody Panels

Trailing Edge Spline

Assembly

Drag Brace

Hub Adapter

\section{1 to 200 BLADES}

$97 \%$ *

$92 \%$

$85 \%$

$85 \%$

$80 \%$

$90 \%$

$90 \%$
$100 \%$

201 to 2000 BLADES

$95 \%$
$88 \%$
$88 \%$
$82 \%$
$93 \%$
$93 \%$

$95 \%$

$88 \%$

$82 \%$

$93 \%$

$93 \%$

*Includes design refinements, material resourcing and value engineering effects

Using these values, the estimated costs of the 100th and 1000th blades are given on Table 13 .

TABLE 13. ESTIMATED COSTS OF 100th AND 1000th 150 FT BLADES






\subsection{REFERENCES}

1. Kaman Aerospace Corporation, "Design Study of Wind Turbines, $50 \mathrm{kWl}$ to $3000 \mathrm{~kW}$ for Electrical Utility Applications, Analys is and Design," NASA CR134937, February 1976.

2. General Electric Company, "Design Study of Wind Turbines, $50 \mathrm{~kW}$ to $3000 \mathrm{~kW}$ for Electric Utility Applications, Volume II, Analys is and Design," NASA CR134935, December 1976.

3. Ham, N. D., "Some Recent Research on Airfoil Dynamic Stall With Application to Airfoil Design," ASRL TR-165-1, Massachusetts Institute of Technology, Cambridge, Massachusetts.

4. Miller, R. H., and Ellis, C. W., "Helicopter Blade Vibration and Flutter," Journal of the American Helicopter Society, Volume 1, No. 3, July 1956.

5. Hall, W. E., Jr., "Application of Floquet Theory to the Analys is of Rotary Wing VTOL Stability," Stanford University, Stanford, Cal ifornia, February, 1970.

6. MIL-HDBK-17A, "Plastics for Aerospace Vehicles, Part 1, Reinforced Plastics," January 1971.

7. Ashton, Chalpin, Petit, "Primer on Composite Materials: Analysis," Technomic Publishing Company, Inc., Stamford, Connecticut, 1969. 
APPENDIX A

DESIGN REQUIREMENTS, CONTRACT NAS 3-20600

\section{SPECIFICATIONS}

1. General

1.1 Summary of Technical Requirements/Design Characteristics

The blade shall be designed for a wind turbine having the following characteristics:

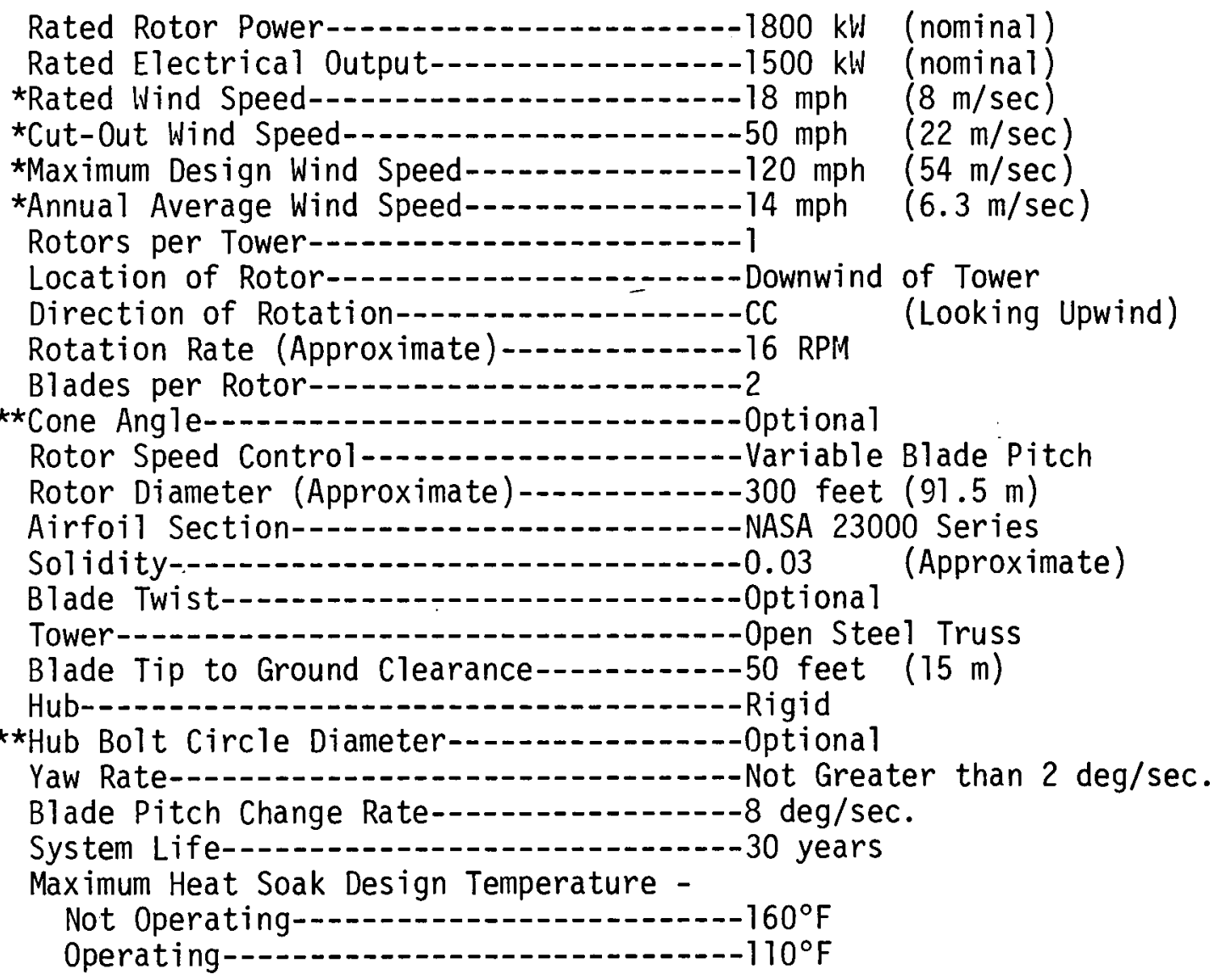

NOTE: English dimensions are exact and the metric equivalents are approximate.

\footnotetext{
${ }^{\star} \mathrm{A} 7 \mathrm{~T}$ Wind Velocities at 30 feet ( 9 meters) Elevation.

**To be determined by the Contractor, in order to minimize blade root bending moments.

***To be determined by the Contractor, in order to provide a structurally efficient blade-to-hub transition.
} 


\subsection{Wind Shear}

A reasonable representation of the steady-state wind profile for engineering applications is given by:

$$
u(z)=u(R) *(\ln (z / h) / \ln (R / h))
$$

where $u(z)$ is the mean wind at height $z$ above natural grade, $u(R)$ is the mean wind at a reference level $z=R$, and $h$ is the surface roughness length. The surface roughness length recommended for engineering applications is $h=.05 \mathrm{~m}$ (.16 feet).

\subsection{General Design Requirements}

1.3.1 Design Life - The blade shall be designed for a service life of 30 years and may include periodic maintenance and/or replacement if cost effective.

\subsubsection{Materials, Parts and Components - The technology used shall} have a base of proven experience.

\subsubsection{Assembly - The designs shall provide for a maximum of shop} assembly and a minimum of field assembly prior to erection.

1.3.4 Transportability and Erection - The design shall give consideration to transport via existing surface vehicles and ease of field assembly and erection.

1.3.5 Environmental - The blade design shall consider and identify the requirements for operation in snow, rain, lightning, hail, icing conditions, salt water vapors, wind-blown sand and dust, solar radiation, and in temperature extreemes of -35 degrees $C(-31$ degrees $F)$ to 49 degrees $C$ ( 120 degrees $F$ ). (The blade to be fabricated under this contract need not necessarily have provisions for these conditions.)

\section{SPECIFIC}

\subsection{Blades}

\subsubsection{Overal1 Requirements}

2.1.1.1 The blade design shall make provisions for proper balancing.

2.1.1.2 The blade shall be designed to allow installation of strain gage instrumentation and wiring. 


\section{DESIGN REQUIREMENTS (continued)}

\subsubsection{Design Conditions}

The blades shall be designed to withstand aerodynamic, aeroelastic, inertial and gravity loads. The design loading conditions are as follows:

2.1.2.1 Case 1 - A wind velocity of $18 \mathrm{mph}(8 \mathrm{~m} / \mathrm{sec})$ occurs 30 feet (9 meters) above ground level. The rotor produces rated power at design rotation speed. An average tower shadow of 30 per cent (velocity retardation) occurs behind the tower.

2.1.2.2 Case 2 - With the rotor operating initially as in Case 1, the wind velocity increases to $60 \mathrm{mph}(27 \mathrm{~m} / \mathrm{sec})$ in 0.25 second. No change in blade pitch angle occurs. The rotor speed increase to 25 percent overspeed.

2.1.2.3 Case 3 - With the rotor operating initially as in Case 1, the blade pitch angle is changed to the feather position in 11 seconds.

2.1.2.4 Case 4 - With the rotor operating initially as in Case 1, the wind velocity decreases from $18 \mathrm{mph}(8 \mathrm{~m} / \mathrm{sec})$ to $0 \mathrm{mph}(0 \mathrm{~m} / \mathrm{sec})$ in 0.25 second.

2.1.2.5 Case 5 - With the blades set and locked in a horizontal feathered position, a maximum wind velocity of $120 \mathrm{mph}$ (54 m/sec) occurs at 30 feet (9 meters) above ground level. The wind at $120 \mathrm{mph}(54 \mathrm{~m} / \mathrm{sec})$ may occur in any direction while the yaw angle remains fixed.

2.1.2.6 Case 6 - With the rotor yawed to the wind 20 degrees, operating at design rpm rotor speed and producing rated power at a wind velocity of $50 \mathrm{mph}(22 \mathrm{~m} / \mathrm{sec})$, the nacelle is yawed at its maximum rate.

2.1.2.7 The frequency of occurence of loads for these cases are:

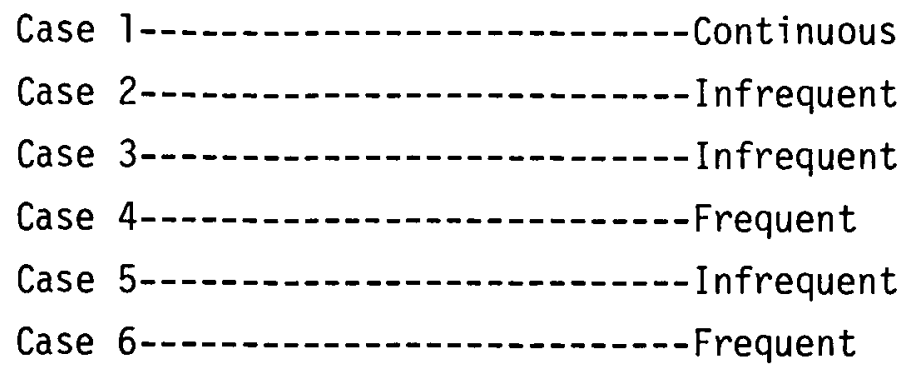




\section{DESIGN REQUIREMENTS (continued)}

2.1.2.8 The definition of loading frequency and corresponding material strength is:

\section{Frequency of 0ccurrence}

a. Infrequent

b. Frequent $(100,000$ Cycles $)$

c. Continuous $(100,000,000$ Cycles $)$
Material Strength Proportional Limit

Fatigue Strength

Endurance Limit

\subsubsection{Blade Tuning Requirements}

2.1.3.1 The first flapwise frequency shall be at least 2.15 times the normal operating frequency.

2.1.3.2 The first chordwise frequency shall be at least 4.15 times the normal operating frequency.

2.1.3.3 First chordwise, flapwise and torsional blade frequencies shall not fall on the operating frequency of the machine or on the integer multiples of the operating frequency.

2.1.3.4 The blade shall be without dynamic instability, including, but not limited to, static divergence and flap-lag flutter instabilities. 


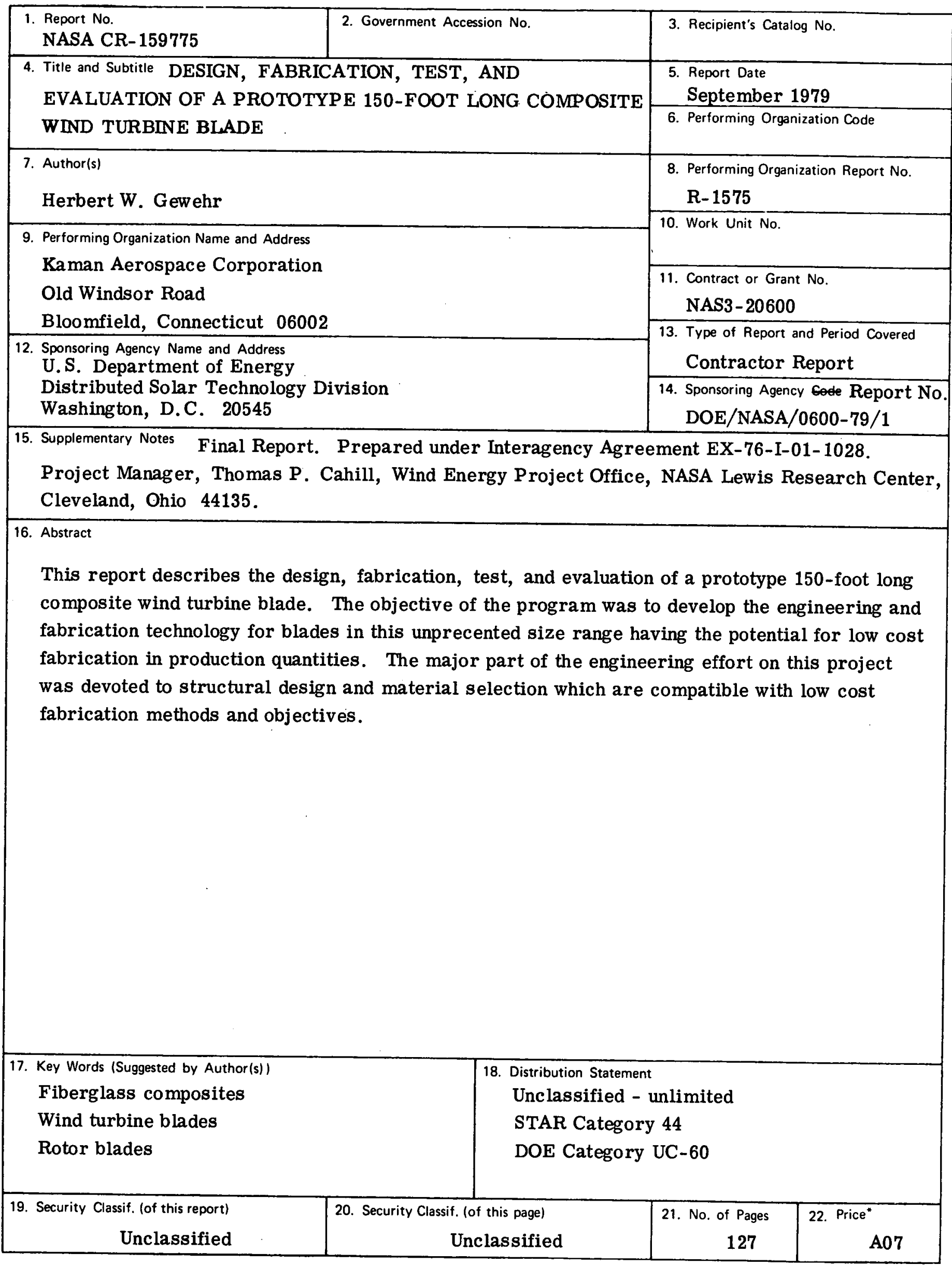

${ }^{*}$ For sale by the National Technical Information Service, Springfield, Virginia 22161 





